\title{
Children with cryptogenic localization related epilepsy: neuropsychological outcome
}

Citation for published version (APA):

van Mil, S. G. M. (2008). Children with cryptogenic localization related epilepsy: neuropsychological outcome. [Doctoral Thesis, Maastricht University]. Datawyse / Universitaire Pers Maastricht. https://doi.org/10.26481/dis.20081113sm

Document status and date:

Published: 01/01/2008

DOI:

10.26481/dis.20081113sm

Document Version:

Publisher's PDF, also known as Version of record

\section{Please check the document version of this publication:}

- A submitted manuscript is the version of the article upon submission and before peer-review. There can be important differences between the submitted version and the official published version of record.

People interested in the research are advised to contact the author for the final version of the publication, or visit the DOI to the publisher's website.

- The final author version and the galley proof are versions of the publication after peer review.

- The final published version features the final layout of the paper including the volume, issue and page numbers.

Link to publication

\footnotetext{
General rights rights.

- You may freely distribute the URL identifying the publication in the public portal. please follow below link for the End User Agreement:

www.umlib.nl/taverne-license

Take down policy

If you believe that this document breaches copyright please contact us at:

repository@maastrichtuniversity.nl

providing details and we will investigate your claim.
}

Copyright and moral rights for the publications made accessible in the public portal are retained by the authors and/or other copyright owners and it is a condition of accessing publications that users recognise and abide by the legal requirements associated with these

- Users may download and print one copy of any publication from the public portal for the purpose of private study or research.

- You may not further distribute the material or use it for any profit-making activity or commercial gain

If the publication is distributed under the terms of Article $25 \mathrm{fa}$ of the Dutch Copyright Act, indicated by the "Taverne" license above, 


\section{Children with cryptogenic localization related epilepsy: Neuropsychological outcome}


() copyright 2008 , Saskia van Mil

ISBN 9789052787718

Het schilderij op de kaft van dit proefschrift is gemaakt door Gerrie Volckerick, kunstenaar bij Atelier Galerie Kempro 


\title{
Children with cryptogenic localization related epilepsy: Neuropsychological outcome
}

\author{
PROEFSCHRIFT \\ ter verkrijging van de graad van doctor aan de Universiteit Maastricht, \\ op gezag van de Rector Magnificus, Prof. mr. G.P.M.F. Mols \\ volgens het besluit van het College van Decanen, \\ in het openbaar te verdedigen \\ op donderdag 13 november 2008 om 15.30 uur
}

door

Saskia Geertje Mijntje van Mil

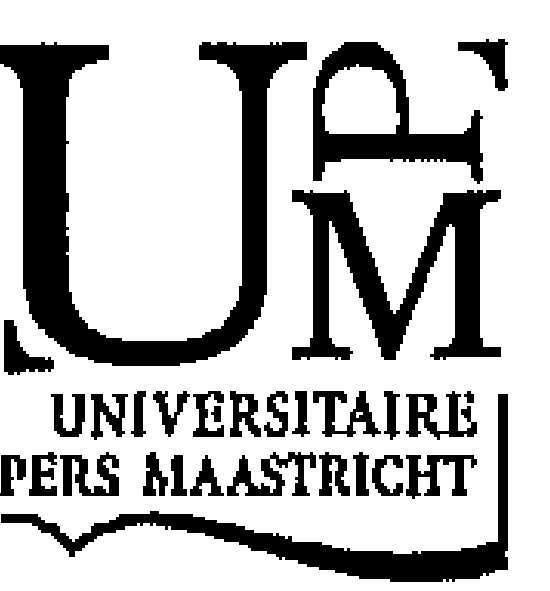




\section{Promotores}

Prof. dr. A.P. Aldenkamp

Prof. dr. W.O. Renier (Radboud Universiteit Nijmegen)

\section{Copromotor}

Dr. M.H.J.A. Debeij-Van Hall (Epilepsiecentrum Kempenhaeghe)

\section{Beoordelingscommissie}

Prof. dr. H. Vles (voorzitter)

Prof. dr. G. Baker (University of Liverpool, United Kingdom)

Prof. dr. J. Jolles

Dr. M. de Krom (afdeling Neurologie, academisch ziekenhuis Maastricht)

Prof. dr. M. Sillanpaa (University of Turku, Finland) 
"If something exists, it exists in some amount.

If it exists in some amount, then it is capable of being measured."

(Rene Descartes, Principles of Philosophy, 1644) 


\section{Contents}

1. General introduction 9

1. Introduction: background and outline of the thesis 11

2. Cryptogenic localization-related epilepsy with childhood onset: The 17 problem of definition and prognosis.

II. Cohort studies

3. Neuropsychological profile of children with Cryptogenic Localization $\quad 37$ Related Epilepsy.

4. The effect of duration of epilepsy on IQ in children with CLRE; a 53 comparison to SLRE and IGE.

5. Behavioral status of children with cryptogenic localization related 65 epilepsy.

6. Psychomotor and motor functioning in children with cryptogenic $\quad 75$ localization related epilepsy.

III. Follow-up studies

7. Neuropsychological functioning in children with cryptogenic 87 localization related epilepsy; a follow-up study.

8. Behavior in children with cryptogenic localization related epilepsy; 103 a follow up study.

IV. General discussion

9. General conclusions and discussion

Summary

Samenvatting

Dankwoord

Curriculum Vitae

List of publications 
I

General introduction 


\section{Chapter 1}

Introduction: background and outline of the thesis 
Epilepsy is the most common neurological disorder in childhood. It is characterized by recurrent unprovoked seizures. A seizure is the clinical manifestation of an abnormal and excessive electrical discharge of cerebral neurons.

In the field of clinical research, the most widely used classification is the International Classification of Epilepsies and Epileptic Syndromes proposed by the International League Against Epilepsy (ILAE) [1]. According to this classification, epilepsies are subdivided into two major categories: generalized and localisation related epilepsies. The first are epilepsies with seizures in which the first clinical changes indicate initial involvement of both hemispheres, the second are epilepsies in which seizure semiology or findings at investigation disclose a focal (localized) origin of the seizures.

The two major classes of generalized and localization related epilepsies are each subdivided based on aetiology. There are three aetiological categories: idiopathic, symptomatic and cryptogenic. In idiopathic epilepsy there is no underlying cause other than a possible hereditary predisposition. It is defined by age-related onset, clinical and electroencephalographic characteristics, and a presumed genetic aetiology. Symptomatic epilepsy is considered the consequence of an essentially known disorder of the central nervous system. The term cryptogenic refers to a disorder whose cause is occult. The cryptogenic epilepsies are presumed to be symptomatic, but the aetiology is not known. Cryptogenic epilepsy is also age-related, but often does not have clear neurophysiological or clinical characteristics [1].

The prevalence rate in the Netherlands is not precisely known. Like in other industrialized countries, it is estimated between 0.5 and $0.8 \%$ [2], which means that roughly 100,000 to 120,000 people in the Netherlands are suffering from epilepsy. The number of children with epilepsy in the Netherlands is estimated around 40,000 [3].

About one third of the paediatric epilepsy population consists of children with cryptogenic localization related epilepsy (CLRE) $[4,5,6,7]$. CLRE is a large non-specific category within the ILAE classification. No unequivocal prognosis exists for these children [8].

Until now, limited information exists about the course of CLRE [8]. Both high remission rates $[9,10]$ and frequent relapses $[6,10]$ are reported. Furthermore, studies have found that children with CLRE experience academic difficulties. Delays up to two school years in reading and arithmetic have been reported [11]. Children with CLRE also appeared to have more behavioural problems than children with idiopathic epilepsy and controls [12].

Currently, the clinical prognosis of CLRE is assumed to be somewhere between the benign course of many idiopathic epilepsies and the more malignant course of most symptomatic epilepsies. This is in line with Camfield and Camfield [13], who described a benign clinical course for about half of the children with CLRE, whereas in the other half, the prognosis was uncertain. This is confirmed by Dunn, Buelow, Austin, Shinnar, \& Perkins [14] who studied the severity of paediatric epilepsy syndromes. Each syndrome was rated on a 10-point scale, with 1 being least severe and 
10 being most severe. On this scale, CLRE scored 7, symptomatic localization related epilepsies scored between 5 and 9 and idiopathic generalized epilepsies scored between 2 and 6 .

Comorbid disorders are frequently described in epilepsy. The most common comorbidities are cognitive impairment and educational underachievement [15]. Children with epilepsy are also known to have an increased risk for behavioural problems [16]. And even problems in motor functioning are frequently described in children with epilepsy [17]. As yet it is unclear whether there is a specific risk to develop these kinds of comorbidities for children with CLRE.

Several epilepsy-related factors, possibly influencing these comorbidities in children, have been identified. Age at onset, duration of epilepsy, seizure type, seizure frequency and number of anti-epileptic drugs (AED) are examples of these factors. Although the results of the studies exploring the impact of these factors are quite contradictory, the fact that they do influence comorbidities in epilepsy is beyond dispute.

Both an early and a late age at onset are described to be predictors of a poor cognitive or behavioural outcome $[18,19,20,21,22]$. However, there are also studies describing no relationship to age at onset [23]. For duration of epilepsy, it is mostly described that a longer duration has a negative impact on cognition and behaviour $[24,25,26,27,28]$. Although there are some studies who did not found any relationship [19]. When for seizure type a relationship is found, it is usually described that the more severe the seizure type, the more serious the impact on cognition and behaviour $[19,29,30,31,32]$. Furthermore, also seizure frequency is described as predictor of cognitive decline and behavioural problems $[22,24,25,28,33]$. There are, however, also studies describing no such relationships $[19,23]$. And lastly, the use of antiepileptic drugs (AED) is mentioned in relation to cognition and behavioural difficulties $[21,34,35,36,37]$; patients on polytherapy appeared to have more problems than children on monotherapy. The effects of such factors have generally been studied independent of the type of epilepsy. Therefore the impact of each of these factors and the factors combined in CLRE is unknown.

In this thesis, we tried to get more insight into the course of cryptogenic localization related epilepsy. This course is approached from a neuropsychological point of view; how is the neuropsychological prognosis of children with CLRE?

Chapter 2 is a review describing the current knowledge on cryptogenic localization related epilepsy. Twenty-five articles describing aspects of CLRE were included in this review. Since a lack of a clear diagnosis makes it impossible to formulate a clear prognosis, the diagnostic reliability of CLRE within the current classification system is discussed first. In addition, an overview of the knowledge on two aspects of prognosis is given; seizure control and cognitive and psychosocial prognosis.

The next four chapters are cohort studies describing different aspects of CLRE. 
Chapter 3 focus on the question whether a group of children with CLRE differ from age-related normative values on several neuropsychological tests. Furthermore, this study aims to determine whether a characteristic neuropsychological profile of CLRE exists and which epilepsy-factors might influence this profile.

Chapter 4 presents a study on IQ in a group of children with CLRE. The influence of duration of epilepsy on IQ is studied. Besides, the impact of CLRE on IQ in comparison to symptomatic localization related epilepsy (SLRE) and idiopathic generalized epilepsy (IGE) is investigated.

In chapter 5 the behavioural status of children with CLRE is described. This study aims to answer the question what kind of behavioural problems exists in children with CLRE and which epilepsy-factors are related to these problems.

Chapter 6 describes psychomotor and motor functioning in children with cryptogenic localization related epilepsy. Furthermore, a possible relationship between these two functions is explored.

In the next two chapters follow-up studies on the course of CLRE are described. Children are followed for one to four years and the results of this follow-up are presented.

Chapter 7 aims to answer the question how the epilepsy interferes with the cognitive development on the long term in children with CLRE. It is also studied whether possible changes in performance are due to changes in epilepsy factors.

Chapter 8 is a description of the course of behaviour in children with cryptogenic localization related epilepsy. The question whether there are indications for stabilization or improvement over time is attempted to be answered.

Finally, the findings provided in the preceding chapters are combined and discussed in chapter 9. 


\section{References}

1. Commission on Classification and Terminology of the International League Against Epilepsy. Proposal for revised classification of epilepsies and epileptic syndromes. (1989). Epilepsia, 30(4): 389-399.

2. Sanders, E.A.C.M., Volwassenenepilepsie handboek; een beknopte leidraad voor de praktijk. Utrecht: Academic Pharmaceutical Productions bv, 2005.

3. Nationaal Epilepsie Fonds, Schoolkinderen met epilepsie. Utrecht: PlantijnCasparie, 2004.

4. Eriksson, KJ, \& Koivikko, MJ (1997). Prevalence, classification, and severity of epilepsy and epileptic syndromes in children. Epilepsia. 38(12): 1275-1282.

5. Waaler, PE, Blom, BH, Skeidsvoll, H, \& Mykletun, A (2000). Prevalence, classification, and severity of epilepsy in children in western Norway. Epilepsia. 41(7): 802-810.

6. Berg, AT, Lin, J, Ebrahimi, N, Testa, FM, Levy, SR, \& Shinnar, S (2004). Modeling remission and relapse in pediatric epilepsy: application of a Markov process. Epilepsy Res, 60(1): 31-40.

7. Durá-Travé T, Yoldi-Petri ME, \& Gallinas-Victoriano F. (2007). Epilepsy in children in Navarre, Spain: epileptic seizure types and epileptic syndromes. J Child Neurol: 22(7): 823-828.

8. Reijs, RP, van Mil, SG, van Hall, MH, Arends, J8, Weber, JW, Renier, WO, \& Aldenkamp, AP (2006). Cryptogenic localization-related epilepsy with childhood onset: The problem of definition and prognosis. Epilepsy Behav. 8(4): 693-702.

9. Shinnar, S., O'Dell, C., Berg, A.T., 1999. Distribution of epilepsy syndromes in a cohort of children prospectively monitored from the time of their first unprovoked seizure. Epilepsia 40 (10), 1378-1383.

10. Berg, A.T., Shinnar, S., Levy, S.R., Testa, F.M., Smith-Rapaport, S., Beckerman, B., Ebrahimi, N., 2001. Two-year remission and subsequent relapse in children with newly diagnosed epilepsy. Epilepsia 42 (12), 1553-1562.

11. Aldenkamp, AP, \& Arends, J (2004). The relative influence of epileptic EEG discharges, short nonconvulsive seizures, and type of epilepsy on cognitive function. Epilepsia. 45(1): 54-63.

12. Oostrom, KJ, Schouten, A, Kruitwagen, CL, Peters, AC, \& Jennekens-Schinkel, A (2003). Behavioral problems in children with newly diagnosed idiopathic or cryptogenic epilepsy attending normal schools are in majority not persistent. Epilepsia. 44(1): 97-106.

13. Camfield, P, \& Camfield, C (2002). Epileptic syndromes in childhood: clinical features, outcomes, and treatment. Epilepsia. 43(Suppl 3): 27-32.

14. Dunn, DW, Buelow, JM, Austin, JK, Shinnar, S, Perkins, SM, 2004. Development of syndrome severity scores for peadiatric epilepsy. Epilepsia. 45(6): 661-666.

15. Aldenkamp, AP, Weber, B, Overweg-Plandsoen, WC, Reijs, R, \& van Mil, $S$ (2005). Educational under* achievement in children with epilepsy: a model to predict the effects of epilepsy on educational achievement. J Child Neurol. 20(3): 175-180.

16. Rodenburg RMA, Stams GJ, Meijer AM, Aldenkamp AP, \& Dekovic M. (2005). Psychopathology in children with epilepsy: a meta-anaiysis. Journal of Pediatric Psychology, 30(6), 453-468.

17. van Empelen R, Jennekens-Schinkel A, Gorter JW, Volman MJ, van Nieuwenhuizen $O$, Helders PJ; Dutch Collaborative Epilepsy Surgery Programme. Epilepsy surgery does not harm motor performance of children and adolescents. Brain. $2005 \mathrm{Jul} ; 128(\mathrm{Pt} 7): 1536-45$.

18. Fastenau, P. S., Shen, J., Dunn, D. W., Perkins, S. M., Hermann, B. P., \& Austin, J. K. (2004). Neuropsychological predictors of academic underachievement in pediatric epilepsy: moderating roles of demographic, seizure, and psychosocial variables. Epilepsia, 45(10), 1261-1272.

19. Schoenfeld J, Seidenberg M, Woodard A, Hecox K, Inglese C, Mack K, et al. (1999). Neuropsychological and behavioral status of children with complex partial seizures. Developmental Medicine and Child Neurology, 41 (11), 724-731.

20. Vasconcellos, E., Wyllie, E., Sullivan, S., Stamford, L., Bulacio, J., Kotagal, P., \& Bingaman, W. (2001) Mental retardation in pediatric candidates for epilepsy surgery: the role of early seizure onset. Epilepsia, 42(2), 268-274.

21. Freilinger $M$, Reisel $B$, Reiter $E$, Zelenko $M$, Hauser $E$, \& Seidl R. (2006). Behavioral and emotional probiems in children with epilepsy. Journal of Child Neurology, 21(11), 939-45.

22. Aldenkamp AP, \& Bodde N. (2005). Behavior, cognition and epilepsy. Acta Neurologica Scandinavica, 112 (suppl 182), 19-25.

23. Bailet LL, \& Turk WR. (2000). The impact of childhood epilepsy on neurocognitive and behavioral performance: a prospective longitudinal study. Epilepsia, 41 (4), 426-431. 
24. Elger, C. E., Helmstaedter, C., \& Kurthen, M. (2004). Chronic epilepsy and cognition. Lancet Neurol, 3(11), 663-672.

25. Bjornes, H., Stabell, K., Henriksen, O., \& Loyning, Y. (2001). The effects of refractory epilepsy on intellectual functioning in children and adults. A longitudinal study. Seizure, 10(4), 250-259.

26. Farwell, J., Dodrill, C., \& Batzel, L. . (1985). Neuropsychological abilities of children with epilepsy. Epilepsia 26(5), 395-400.

27. Singhi, P., Bansal, U., Singhi, S., \& Pershad, D. (1992). Determinants of IQ profile in children with idiopathic generalized epllepsy. Epilepsia, 33(6), 1106-1114.

28. Datta SS, Premkumar TS, Chandy S, Kumar S, Kirubakaran C, Gnanamuthu C, et al. (2005). Behavior problems in children and adolescents with seizure disorder: association and risk factors. Seizure, 14 190-197.

29. Hoie, B., Mykletun, A., Sommerfelt, K., Bjornaes, H., Skeidsvoll, H., \& Waaler, P.E. (2005). Seizurerelated factors and non-verbal intelligence in children with epilepsy. A population-based study from Western Norway. Seizure, 14(4), 223-231.

30. Aldenkamp, A. P., \& Alpherts, W. C. J. (1999). Psychological assessment. In H. Meinardi (Ed.), Handbook of Clinical Neurology (part 1 ed., Vol. 72 (28), pp. 387-406). Amsterdam: Elsevier Science B.V.

31. Williams J. (2003). Learning and behavior in children with epilepsy. Epilepsy \& Behavior, 4, 107-111.

32. McDermott S, Mani S, \& Krishnaswami S. (1995). A population-based analysis of specific behavior problems associated with childhood seizures. Journal of Epilepsy, 8, 110-118.

33. Dunn DW. Neuropsychiatric aspects of epilepsy in children. Epilepsy Behav 2003; 4: 101-106.

34. Bulteau, C., Jambaque, I., Viguier, D., Kieffer, V., Dellatolas, G, \& Dulac, O. (2000). Eplleptic syndromes, cognitive assessment and school placement: a study of 251 children. Dev. Med. Child Neurol. 42(5), 319 327.

35. Aldenkamp, A.P., \& Vermeulen, J. (2001). Cognitive side-effects of antiepileptic drugs. In: J.M. Pellock, W.E. Dodson, B.F.D. Bourgeois. Pediatric Epilepsy; diagnosis and therapy (2nd edition, pp. 629-636)

36. Lagae, L. (2006). Cognitive side effects of anti-epileptic drugs. The relevance in childhood epilepsy. Seizure, 15(4), 235-241.

37. Cornaggia CM, Beghi M, Provenzi M, \& Beghi E. (2006). Correlation between cognition and behavior in epilepsy. Epilepsia, 47 (Suppl 2), 34-9. 


\section{Chapter 2}

\section{Cryptogenic localization related epilepsy with childhood onset:}

The problem of definition and prognosis

Published as:

Reijs, RP*, van Mil, SGM*, van Hall, MHJA, Arends, JBAM, Weber, JW, Renier, WO, \& Aldenkamp, AP (2006).

Cryptogenic localization-related epilepsy with childhood onset: The problem of definition and prognosis.

Epilepsy \& Behavior, 8(4): 693-702.

" both authors accepted as first author. 


\section{Abstract}

Up to one third of the children with epilepsy are diagnosed with cryptogenic localization related epilepsy (CLRE). CLRE is a large non-specific category within the ILAE classification. For this population no unequivocal prognosis exists.

Methods: Twenty-five articles describing aspects of CLRE were included in this review.

Results: As a result of the progress in epilepsy research, as well as more advanced investigation in individual cases, the population of CLRE constantly changes. Also, disagreement on interpretation of the classification has resulted in striking differences between the populations described. High remission rates are reported, but relapse occurs frequently, leaving the long-term prognosis unforeseeable. This is reflected in academic and psychosocial prognosis, which is described to be problematic in CLRE specifically. Possible prognostic factors of CLRE in children have been identified: age at onset, seizure semiology, seizure frequency, intractability, interictal epileptiform activity on EEG and premorbid IQ. These factors are explored to define subgroups within the CLRE population.

Discussion: Prospective studies on well-defined CLRE cohorts are needed to identify factors that distinguish various prognostic subgroups. Specific attention should be focused on course of the epilepsy, scholastic achievement and psychosocial outcome. 


\section{Introduction}

Epilepsy is a symptom of an underlying neurological deficit or dysfunction [1]. However, the exact mechanisms underlying epilepsy remain unknown. Through classification of the epilepsies, results of research can be universally compared. In the field of clinical research, the most widely used classification is the International Classification of Epilepsies and Epileptic Syndromes proposed by the International League Against Epilepsy (ILAE) [2]. According to this classification the cryptogenic epilepsies are presumed to be symptomatic, but their etiology is unknown.

With respect to severity, epilepsies can be subdivided into more benign (idiopathic generalized epilepsies (IGEs) and idiopathic localization-related epilepsies (ILREs)) and more malignant (symptomatic localization-related epilepsies (SLREs), followed by symptomatic "catastrophic" generalized epilepsies (SGEs)). Cryptogenic localization-related epilepsy (CLRE) can be positioned between the idiopathic and the symptomatic epilepsies. Indeed, when scoring the severity of pediatric epilepsy syndromes in the development of the Epileptic Syndrome Severity Scores-Child (ESSS-C), Dunn et al. consulted experts who rated the severity of CLRE as 7 on a 10-point scale [3]. Benign epilepsy with centrotemporal spikes was rated 2, and LandauKleffner syndrome 8 , on this scale.

Although the ILAE classification [2] has been said to be very applicable, also in the range of childhood epilepsies [4-6], it has also been strongly criticized. Only a small proportion, 4 to $21 \%$ [6], of the patients in a tertiary epilepsy center are diagnosed with specific epilepsy syndromes; most patients end up in rather unspecific categories. One of these relatively nonspecific categories is CLRE. Up to one-third of children with epilepsy are classified as having CLRE [7-9].

In daily practice, accurate classification should lead to information on prognosis as well as preferred treatment and pedagogical and academic support. Prognosis should concentrate not only on seizure outcome, but also on cognitive development and educational achievement. As epilepsy is known to have a large impact on these developmental aspects [10], a detailed classification is of major importance for children with epilepsy. As far as CLRE is concerned, no unequivocal prognosis is known [11-13].

In this article, we review the available literature on the prognosis of CLRE with childhood onset. The first issue, which is discussed thoroughly, is the diagnostic reliability of CLRE. Lack of a clear diagnosis makes it impossible to formulate the right prognosis. For this reason, we critically look at the current classification system. As we focus on childhood epilepsies, we approach mainly two aspects of prognosis: seizure control and psychosocial outcome. The psychosocial outcome is the result of cognitive development and academic opportunities. In the neuropsychological literature, this is described in terms of cognitive variables, educational achievements, and behavior. 


\title{
Methods
}

\author{
Study selection
}

We searched for articles with WebSPIRS 5.03 for Medline and Pub-Med, using the query: (cryptogenic OR localisation related OR partial) AND epilep* AND child* AND (prognos* OR outcome OR neuropsychol* OR cognit*). An asterisk indicates that the search was extended to find all terms that begin with a given text string. The limits were set for English language, research in humans, and a publication date up to November 2005. One hundred and twelve articles were found.

On the basis of the titles of the publications, we studied the abstracts that seemed to describe the neurological and neuropsychological prognosis of children with CLRE. Many studies did not specify their results as for children with CLRE, but described combinations of either "cryptogenic and/or symptomatic" or "cryptogenic and/or idiopathic" epilepsy. Because we were interested in the prognosis of CLRE, these articles appeared to be inappropriate.

After selecting the relevant articles, we used the PubMed-function related articles. We also checked the references of the selected articles for other relevant literature. Case reports were not considered. In total, 25 articles were included.

\section{Subjects}

The patients described in the included studies have been diagnosed with CLRE. Patients with the diagnosis of localization-related epilepsy with cryptogenic etiology, but related to a specific syndrome, were not considered to have CLRE.

Age at onset of epilepsy ranged between 0 and 18. Age at follow-up varied (Table 1). In 15 studies, the patients described were still children at the end of follow-up [1428]. One study describes very long term outcome; hence the followed up patients are all adults [29]. In the other studies, patients were followed into adolescence and adulthood $[4,5,7,30-35]$. Therefore, it is fair to say the reviewed studies focused on school-aged children and their prognosis.

Patients described in the studies selected for this review were included because of their epilepsy. In some studies, however, epilepsy patients were selected using more specific criteria, such as seizure freedom [14,20,27], a normalized EEG [14,20], language disorders and the refractory nature of their epilepsy [26], and fluctuations in cognitive performance [21] (Table 2). It is important that these criteria be taken into account when reviewing these articles, because they may influence the prognosis we attempt to construct. For this purpose, an overview is given in Table 2. 
Table 1 Cohorts described in reviewed articles

\begin{tabular}{|c|c|c|c|c|}
\hline Author, year & Outcome variable & $n$ & Age at follow-up & Duration of follow-up \\
\hline $\begin{array}{l}\text { Aldenkamp and Arends, } \\
2004[21]\end{array}$ & $\begin{array}{l}\text { Educational } \\
\text { achievement }\end{array}$ & $\begin{array}{l}\text { CLRE : } 68 \\
\text { SLRE: } 28 \\
\text { IGE: } 19 \\
\text { Controls: } 31\end{array}$ & $7-12$ years & Not applicable \\
\hline Arts et al., 1999 [25] & Remission & $\begin{array}{l}\text { CLRE: } 86 \\
\text { SLRE: } 69 \\
\text { ILRE: } 28\end{array}$ & Median 5.5 years & 2 years \\
\hline Arts et al., 2004 [19] & Remission & $\begin{array}{l}\text { CLRE : } 86 \\
\text { SLRE : } 67 \\
\text { ILRE : } 28\end{array}$ & Median 5.5 years & 5 years \\
\hline Berg et al., 1999 [4] & Interrater agreement & $\begin{array}{l}\text { CLRE: } 103 \\
\text { Total patients: } \\
613\end{array}$ & 1 month -15.6 years & Not applicable \\
\hline Berg et al., 2000 [5] & Reassessment & $\begin{array}{l}\text { CLRE: } 103 \\
\text { Total patients: } \\
613\end{array}$ & 1 month -15.6 years & Median 5.3 years \\
\hline Berg et al., 2001 [31] & $\begin{array}{l}\text { Remission, relapse } \\
\text { (reassessment) }\end{array}$ & $\begin{array}{l}\text { CLRE: } 99 \\
\text { SLRE: } 189 \\
\text { ILRE: } 57\end{array}$ & 1 month -15.6 years & Median 5.3 years \\
\hline Berg et al., 2004 [7] & $\begin{array}{l}\text { Remission, relapse, } \\
\text { Markov process }\end{array}$ & $\begin{array}{l}\text { CLRE: } 216 \\
\text { SLRE: } 79 \\
\text { ILRE: } 56\end{array}$ & $7-12$ years & Median 7 years \\
\hline $\begin{array}{l}\text { Camfield and Camfield, } \\
1993 \text { [32] }\end{array}$ & Remission & $\begin{array}{l}\text { CLRE: } 132 \\
\text { Total patients: } \\
504\end{array}$ & 1 month-16 years & Average 85 months \\
\hline Genton et al., 1997 [33] & $\begin{array}{l}\text { Remission, psycho- } \\
\text { social outcome }\end{array}$ & $\begin{array}{l}\text { CLRE: } 38 \\
\text { SLRE: } 68\end{array}$ & $5-46$ years & 5 to 41 years \\
\hline $\begin{array}{l}\text { Geelhoed et al., } 2005 \\
\text { [30] }\end{array}$ & Remission & $\begin{array}{l}\text { CLRE: } 299 \\
\text { SLRE: } 183 \\
\text { ILRE: } 58\end{array}$ & 1 month-16 years & 6 months- 26 years \\
\hline Grosso et al., 2005 [17] & $\begin{array}{l}\text { Response to topi- } \\
\text { ramate }\end{array}$ & $\begin{array}{l}\text { CLRE : } 7 \\
\text { SLRE : } 12 \\
\text { ILRE : } 2\end{array}$ & $0-24$ months & Median 11 months \\
\hline Hauser et al, 1996 [34] & Remission & $\begin{array}{l}\text { CLRE: } 19 \\
\text { SLRE: } 43 \\
\text { ILRE: } 26\end{array}$ & $\begin{array}{l}\text { Mean } 9.6 \text { years plus } \\
\text { mean follow-up } 5.3 \\
\text { years }\end{array}$ & Up to 14 years \\
\hline Hoie et al., 2004 [15] & $\begin{array}{l}\text { Nonverbal intelli- } \\
\text { gence }\end{array}$ & $\begin{array}{l}\text { CLRE: } 25 \\
\text { SLRE: } 42 \\
\text { ILRE: } 30 \\
\text { Total: } 198 \\
\text { Controls: } 126\end{array}$ & $6-12$ years & Not applicable \\
\hline Miura, 2004 [16] & $\begin{array}{l}\text { Response to zoni- } \\
\text { samide }\end{array}$ & CLRE: 72 & $\begin{array}{l}8.3 \text { years }(3 \text { months } \\
14.11 \text { years) }\end{array}$ & $\begin{array}{l}-27.2 \text { months } \\
\text { (6-43 months) }\end{array}$ \\
\hline $\begin{array}{l}\text { Murakami et al., } 1995 \\
{[27]}\end{array}$ & $\begin{array}{l}\text { Withdrawal, age, } \\
\text { EEG }\end{array}$ & $\begin{array}{l}\text { CLRE: } 58 \\
\text { SLRE: } 60 \\
\text { ILRE: } 72\end{array}$ & $4-18.2$ years & At least 5 years \\
\hline Ohta et al., 2004 [28] & $\begin{array}{l}\text { Withdrawal, risk } \\
\text { factors for relapse }\end{array}$ & CLRE: 82 & Average 12.4 years & Average 4.7 years \\
\hline
\end{tabular}




\begin{tabular}{|c|c|c|c|c|}
\hline Author, year & Outcome variable & $n$ & Age at follow-up & Duration of follow-up \\
\hline $\begin{array}{l}\text { Oostrom et al., } 2001 \\
\text { [24] }\end{array}$ & $\begin{array}{l}\text { Parents' perceptions } \\
\text { at onset }\end{array}$ & $\begin{array}{l}\text { CLRE: } 33 \\
\text { IGE: } 33\end{array}$ & $5-16$ years & Not applicable \\
\hline $\begin{array}{l}\text { Oostrom et al., } 2002 \\
\text { [23] }\end{array}$ & Altention & $\begin{array}{l}\text { CLRE: } 23 \\
\text { IGE: } 28 \\
\text { Controls: } 48\end{array}$ & $5-16$ years & 1 year \\
\hline $\begin{array}{l}\text { Oostrom et al. } 2003 \\
{[22]}\end{array}$ & Behavioral problems & $\begin{array}{l}\text { CLRE: } 33 \\
\text { IGE: } 33 \\
\text { Controls: } 66\end{array}$ & $5-16$ years & 1 year \\
\hline $\begin{array}{l}\text { Oostrom et al., } 2005 \\
\text { [18] }\end{array}$ & $\begin{array}{l}\text { Cognition and } \\
\text { behavior }\end{array}$ & $\begin{array}{l}\text { CLRE: } 19 \\
\text { ILRE: } 11 \\
\text { IGE: } 12 \\
\text { Controls: } 30\end{array}$ & $7-16$ years & $3-4$ years \\
\hline Parkinson, 2002 [26] & Language disorders & $\begin{array}{l}\text { CLRE: } 16 \\
\text { SLRE: } 37 \\
\text { CGE: } 33 \\
\text { SGE: } 13\end{array}$ & $\begin{array}{l}11.4 \text { years }(5-18.9 \\
\text { years) }\end{array}$ & Not applicable \\
\hline Shinnar et al., 1999 [35] & $\begin{array}{l}\text { Reclassification, } \\
\text { remission }\end{array}$ & $\begin{array}{l}\text { CLRE: } 34 \\
\text { Total patients: } \\
182\end{array}$ & $\begin{array}{l}1 \text { month-19 years, } \\
\text { plus follow up }>5 \\
\text { years }\end{array}$ & $\begin{array}{l}\text { Mean } 8.2 \text { years, } \\
\text { minimum } 2 \text { years }\end{array}$ \\
\hline $\begin{array}{l}\text { Slllanpää et al, } 1999 \\
\text { [37] }\end{array}$ & Remission & $\begin{array}{l}\text { CLRE : } 40 \\
\text { SLRE : } 120 \\
\text { ILRE : } 23\end{array}$ & $\begin{array}{l}\text { Mean } 35.6 \text { years at } \\
\text { last visit }\end{array}$ & 30 years \\
\hline Verrotti et al., $2000[14]$ & $\begin{array}{l}\text { Discontinuation of } \\
\text { AED }\end{array}$ & CLRE: 89 & $\begin{array}{l}\text { Mean } 11.2 \text { years } \\
\text { (SD } 3.4)\end{array}$ & $5.1-6.7$ years \\
\hline Verrotti et al., 2000 [20] & $\begin{array}{l}\text { Withdrawal, predic- } \\
\text { tive EEG }\end{array}$ & CLRE: 84 & $\begin{array}{l}\text { Mean } 10.6 \text { years } \\
(S D 3.0)\end{array}$ & $\begin{array}{l}4-7 \text { years } \\
\text { mean } 5.5 y\end{array}$ \\
\hline
\end{tabular}

a CLRE, cryptogenic localization-related epilepsy; SLRE, symptomatic localization-related epilepsy; IGE, idiopathic generalized epilepsy; CGE, cryptogenic generalized epilepsy; SGE, symptomatic generalized epilepsy; AED, antiepileptic drugs

\section{Studies}

Only three articles focused purely on children with CLRE $[14,20,28]$. In the other studies, the authors provided specific results for or made remarks on the patients with CLRE within their pediatric epilepsy cohort.

Most studies follow the 1989 ILAE proposal for classification of epileptic seizures and epilepsy syndromes [2]. However, this classification leaves room for interpretation. The Commission on Classification and Terminology defines symptomatic epilepsies and syndromes as the consequence of a known or suspected disorder of the central nervous system. The cryptogenic category is derived from this definition: cryptogenic epilepsies are presumed to be symptomatic but the etiology is unknown. Subsequently, the classification is not decisive on a matter such as mental retardation. To some authors, the presence of mental retardation is considered grounds for a diagnosis of (remote) SLRE $[19,25,28,29,32,34]$ or for exclusion from a study of patients with CLRE $[14,20]$ (Table 2). However, the majority of authors do not mention this 
issue $[4,5,7,15-18,21-24,26,27,30,31,33,35]$. Importantly, intelligence has been shown to be a prognostic factor with respect to both seizure outcome and neuropsychological outcome. Therefore, studies in which developmental problems (i.e., clinically diagnosed mental retardation or $I Q<70$ ) were described within the cohort designated as having CLRE were excluded. However, studies in which such problems were not mentioned, and in which there was no reason to suspect mental delay of large impact in the described cohort, were not excluded.

In our opinion, CLRE can be diagnosed only after neuroimaging. Indeed, in nine studies normal neuroimaging was confirmed $[14,17,18,20,22-24,32,34]$. One study did perform neuroimaging in the majority of the patients with CLRE [15], but another did so in less than half of the patients [33]. In 10 of the studies included, it was not clear whether all patients diagnosed as having CLRE had undergone neuroimaging (Table 2) $[4,5,7,19,25,26,28,29,31,35]$. Four studies did not mention neuroimaging at all $[16,21,27,30]$. All but three studies $[27,30,33]$ were carried out in a prospective design. There are also methodological and general remarks to be considered regarding the included studies (Table 2). These issues are commented on under Results.

Table 2 Characteristics of reviewed articles

\begin{tabular}{|c|c|c|c|c|c|}
\hline Author, year & $\begin{array}{l}\text { Definition of } \\
\text { CLRE }^{a}\end{array}$ & Neuroimaging & $\mathrm{IQ}<70^{\mathrm{b}}$ & $\begin{array}{l}\text { Prospective/ } \\
\text { retrospective }\end{array}$ & Complicating factors ${ }^{c}$ \\
\hline $\begin{array}{l}\text { Aldenkamp } \\
\text { and Arends, } \\
2004[21]\end{array}$ & - & Not mentioned & - & Prospective & $\begin{array}{l}\text { Fluctuations in cogni- } \\
\text { tive performance; } \\
\text { clinical question on } \\
\text { cognitive impact of } \\
\text { discharges }\end{array}$ \\
\hline $\begin{array}{l}\text { Arts et al., } \\
1999[25], \\
2004 \text { [19] }\end{array}$ & ILAE [1] & $\begin{array}{l}\text { Not in absence } \\
\text { epilepsy; not when } \\
\text { treating physician did } \\
\text { not find it necessary. }\end{array}$ & SLRE & Prospective & \\
\hline $\begin{array}{l}\text { Berg et al., } \\
1999[4], \\
2000[5], \\
2001[31]\end{array}$ & $\begin{array}{l}\text { No identifiable } \\
\text { underlying etiology, } \\
\text { no idiopathic syn- } \\
\text { drome; focus on } \\
\text { EEG: SLRE }\end{array}$ & $\begin{array}{l}\text { Neuroimaging was } \\
\text { done in } 79.6 \% \text { of } \\
\text { children }\end{array}$ & - & Prospective & $\begin{array}{l}\text { Symptomatic epilepsy } \\
\text { diagnosed on basis of } \\
\text { localization, with } \\
\text { cryptogenic etiology }\end{array}$ \\
\hline $\begin{array}{l}\text { Berg et al., } \\
2004 \text { [7] }\end{array}$ & $\begin{array}{l}\text { Symptomatic vs } \\
\text { cryptogenic based } \\
\text { on aetiology }\end{array}$ & See Berg, 1999 & - & Prospective & \\
\hline $\begin{array}{l}\text { Camfield and } \\
\text { Camfield, } \\
1993[32]\end{array}$ & - & $\begin{array}{l}\text { All CLRE patients } \\
\text { had normal CT }\end{array}$ & $\begin{array}{l}\text { CLRE defined } \\
\text { as 'otherwise } \\
\text { normal } \\
\text { children' }\end{array}$ & Prospective & \\
\hline $\begin{array}{l}\text { Genton et al., } \\
1997[33]\end{array}$ & $\begin{array}{l}\text { Without evidence of } \\
\text { a brain lesion, no } \\
\text { idiopathic focal } \\
\text { epilepsy }\end{array}$ & $\begin{array}{l}\text { f Neuroimaging was } \\
\text { done in } 15 \text { out of } 38 \\
\text { patients with CLRE }\end{array}$ & - & Retrospective & \\
\hline $\begin{array}{l}\text { Geelhoed et } \\
\text { al., } 2005 \text { [30] }\end{array}$ & ILAE [1] & - & - & Retrospectlve & \\
\hline
\end{tabular}




\begin{tabular}{|c|c|c|c|c|c|}
\hline Author, year & $\begin{array}{l}\text { Definition of } \\
\text { CLRE }^{\mathrm{a}}\end{array}$ & Neurolmaging & $\mathrm{IQ}<70^{\mathrm{b}}$ & $\begin{array}{l}\text { Prospective/ } \\
\text { retrospective }\end{array}$ & Complicating factors $^{c}$ \\
\hline $\begin{array}{l}\text { Grosso, } 2005 \\
{[17]}\end{array}$ & $\overline{-}$ & $\begin{array}{l}\text { MRI was done in all - } \\
\text { patients }\end{array}$ & - & Prospective & \\
\hline $\begin{array}{l}\text { Hauser et al., } \\
1996[34]\end{array}$ & $\begin{array}{l}\text { Symptomatic and of } \\
\text { unknown etiology }\end{array}$ & $\begin{array}{l}\text { f Neuroimaging was } \\
\text { done in all patients } \\
\text { with CLRE }\end{array}$ & $\begin{array}{l}\text { Symptomatic } \\
\text { aetiology }\end{array}$ & Prospective & \\
\hline $\begin{array}{l}\text { Hoie et al., } \\
2004 \text { [15] }\end{array}$ & ILAE [1] & $\begin{array}{l}\text { Neuroimaging was } \\
\text { done in } 192 \text { of } 198 \\
\text { patients }\end{array}$ & - & Prospective & $\begin{array}{l}\text { Unexplained } \\
\text { adaptation of the } \\
\text { ILAE guidelines }\end{array}$ \\
\hline $\begin{array}{l}\text { Miura, } 2004 \\
{[16]}\end{array}$ & - & Not mentioned & - & Prospective & \\
\hline $\begin{array}{l}\text { Murakami et } \\
\text { al., } 1995 \text { [27] }\end{array}$ & ILAE [1] & Not mentioned & - & Retrospective & \\
\hline $\begin{array}{l}\text { Ohta et al., } \\
2004 \text { [28] }\end{array}$ & $\begin{array}{l}\text { Not idiopathic or } \\
\text { symptomatic; no } \\
\text { underlying dis- } \\
\text { eases, no } \\
\text { signs/symptoms of } \\
\text { brain injuries }\end{array}$ & $\begin{array}{l}\text { Definition of CLRE } \\
\text { suggests that all } \\
\text { included patients did } \\
\text { have (normal) MRI }\end{array}$ & SLRE & Prospective & $\begin{array}{l}3 \text { years of seizure } \\
\text { freedom, no epileptic } \\
\text { discharges on EEG }\end{array}$ \\
\hline $\begin{array}{l}\text { Oostrom et al., } \\
2001 \text { [24], } \\
2002 \text { [23], } \\
2003 \text { [22], } \\
2005 \text { [18] }\end{array}$ & $\begin{array}{l}\text { Probably of symp- } \\
\text { tomatic origin but no } \\
\text { etiology has been } \\
\text { found. }\end{array}$ & $\begin{array}{l}\text { Neuroimaging was } \\
\text { onormal in all patients } \\
\text { with CLRE }\end{array}$ & - & prospective & \\
\hline $\begin{array}{l}\text { Parkinson, } \\
2002[26]\end{array}$ & - & $\begin{array}{l}\text { In collaboration with } \\
\text { the referring consult- } \\
\text { ant }\end{array}$ & - & Prospective & $\begin{array}{l}\text { Refractory epilepsy; } \\
\text { more than two-thirds } \\
\text { attend special educa- } \\
\text { tion; language im- } \\
\text { pairments }\end{array}$ \\
\hline $\begin{array}{l}\text { Shinnar et al., } \\
1999 \text { [35] }\end{array}$ & $\operatorname{ILAE}[1]$ & $\begin{array}{l}\text { CT or MRI was per- } \\
\text { formed when clinically } \\
\text { indicated }\end{array}$ & 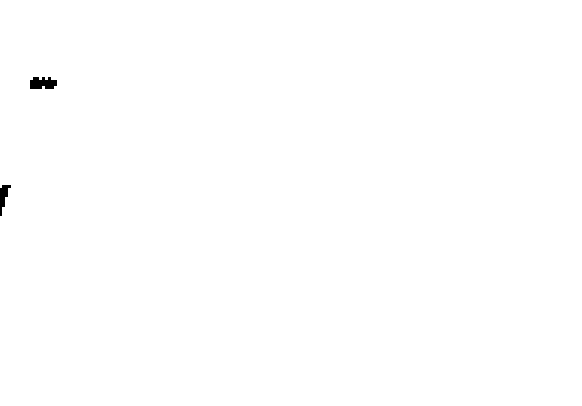 & Prospective & $\begin{array}{l}\text { Symptomatic epilepsy } \\
\text { diagnosed on basis of } \\
\text { localization }\end{array}$ \\
\hline $\begin{array}{l}\text { Sillanpää et } \\
\text { al., } 1999 \text { [37] }\end{array}$ & $\begin{array}{l}\text { Otherwise normal } \\
\text { individuals with no } \\
\text { clear etiology }\end{array}$ & $\begin{array}{l}\text { Unclear, reclassifica- } \\
\text { tion was based on } \\
\text { imaging }\end{array}$ & $\begin{array}{l}\text { Remote } \\
\text { symptomatic }\end{array}$ & Prospective & $\begin{array}{l}\text { symptomatic epilepsy } \\
\text { diagnosed on basis of } \\
\text { localization }\end{array}$ \\
\hline $\begin{array}{l}\text { Verrotti, } 2000 \\
{[14]}\end{array}$ & $\begin{array}{l}\text { To be concluded } \\
\text { from exclusion } \\
\text { criteria }\end{array}$ & $\begin{array}{l}\text { Cerebral CT and MRI } \\
\text { findings normal in all } \\
\text { children }\end{array}$ & $\begin{array}{l}\text { Not consid- } \\
\text { ered }\end{array}$ & Prospective & $\begin{array}{l}\text { Seizure-free patients } \\
\text { with normal EEG }\end{array}$ \\
\hline $\begin{array}{l}\text { Verrotti, } 2000 \\
\text { [20] }\end{array}$ & $\begin{array}{l}\text { To be concluded } \\
\text { from exclusion } \\
\text { criteria }\end{array}$ & $\begin{array}{l}\text { CT scan and MRI } \\
\text { were normal in all } \\
\text { children }\end{array}$ & $\begin{array}{l}\text { Not included } \\
\text { in this study }\end{array}$ & Prospective & $\begin{array}{l}\text { Seizure-free patients } \\
\text { with normal EEG }\end{array}$ \\
\hline
\end{tabular}

Definition of CLRE as applied by these authors; ${ }^{b}$ How authors dealt with an $\mathrm{Q} Q<70 ;{ }^{\circ}$ Other factors complicating the assessment of an article. 


\section{Results}

\section{Diagnosis of CLRE}

The diagnosis epilepsy is by definition a clinical diagnosis and, thus, is subject to interrater (dis) agreement. Berg et al. [4] studied this phenomenon in a large cohort of newly diagnosed children. Three child neurologists compared their diagnoses of 613 children with epilepsy. In the 103 cases of CLRE, there was full interrater agreement in 83 cases. The agreement parameter $j$ was in the very good to excellent range for all types of epilepsy, ranging from 0.82 to 0.89 . The authors explained this excessively high score as the result of the large amount of information that can be used to diagnose a syndrome. CLRE was part of two of the three most commonly occurring disagreements: between CLRE and undetermined whether focal or generalized and without unequivocal focal or generalized features, classification depended on the interpretation of the seizures where EEG was not helpful; between CLRE and symptomatic localization-related epilepsy, the disagreement involved the degree of localization on the EEG.

According to these and other authors, detecting an epileptic focus on EEG $[4,5,29,31,35]$ would lead to the diagnosis SLRE (with the etiology marked as cryptogenic). In a later study, these authors departed from this method of classification [7], and the shift between the CLRE and SLRE groups that can be seen comparing these studies is dramatic [7]. The same cohort of patients with epilepsy then contained more than twice as many patients with CLRE. It is not possible to estimate the impact this finding has had on the outcomes for the CLRE group in the previous studies $[4,5,31]$, which are therefore less reliable sources for the concept of CLRE.

The group of patients with CLRE, by definition, will constantly be reassessed. With improvement in technology and diagnostic clinical insights, etiology is clarified and patients from this group are reclassified [5,25,35]. Within a 2-year period, 14 of 103 patients with CLRE were rediagnosed as having SLRE. This was done on the basis of localization through EEG or etiologic clues [5]. As mentioned earlier, this artificial method of classification, and hence of reclassification, decreases the reliability of this study for our review.

\section{Prognosis of seizure control}

The ILAE guidelines for epidemiologic studies propose 5 years of seizure freedom as a definition of remission [36]. Such a long follow-up is not often feasible, so most studies apply their own definition of remission. Yet a lack of consensus makes it difficult to compare studies discussing remission.

Berg et al. defined remission as 2 years of seizure freedom [31]. Among 99 patients with CLRE with a median follow-up of 5.3 years, $83 \%$ achieved remission at some time. Relapse occurred in $24 \%$. Many children regained remission. For ILRE, these figures were 93 and 7\% respectively, and for SLRE, 72\% (achieving 2-year remission) and $30 \%$ (relapse). 
Shinnar et al. [35] followed 182 children with all kinds of epilepsies for at least 2 years after diagnosis. Their definition of (terminal) remission was also 2 years of seizure freedom; they did not allow for relapse. Thirty-four children were classified as having CLRE. After a mean follow-up of 8.3 years, $82 \%$ were found to be in remission.

Camfield and Camfield studied a cohort of childhood epilepsies prospectively for more than 7 years [12,32]. For the 132 children with CLRE, follow-up lasted $88 \pm 31$ months. Two-thirds of these children entered remission without medication. In $45 \%$ of the CLRE group, the epilepsy was considered to be truly benign, with instant seizure remission on initial treatment. However, in the other half of the cohort, the epilepsy was rather persistent.

Reporting on a 30-year prospective follow-up of childhood epilepsy, Sillanpää et al. initially included 40 CLRE patients, 8 of whom were lost to follow up ( 3 of these 8 died) [37]. Of the other 32 patients with CLRE, 20 were in remission. The classification of these patients dates back before the ILAE classification of 1989 [2], and before the widespread use of neuroimaging. Together with the aforementioned classification issues, this indicates the decreased reliability of this article for our review. Twenty of one hundred twenty patients with SLRE died. Forty-seven patients with SLRE were seizure-free. For the ILRE cohort, these figures describe a more benign course, with 18 of 23 patients being seizure-free. Still, 2 died during follow-up.

Hauser et al. [34] used 1 year of remission as an outcome variable. Within their CLRE group of 19 patients, $17(89 \%)$ reached 1 year of remission at some time. Some patients who had a 1-year remission relapsed, and some of them regained remission, but no specific figures are given. For comparison, all 26 patients with benign idiopathic focal epilepsy reached 1 year of remission, and 36 of 43 patients $(83.7 \%)$ with SLRE did so.

Genton et al. [33] regarded low seizure frequency as a "good outcome." Only $63 \%$ of their patients met this criterion. However, in 8 of their 38 patients with CLRE, onset of epilepsy occurred in the first year of life, and therefore, they had a worse prognosis. Also, only 15 underwent brain imaging, which made the cryptogenic etiology less certain, and a symptomatic etiology possible, with worse prognosis. Therefore, this cohort and the results do not seem very reliable for the purpose of this review.

Arts et al. [25] investigated the short-term outcome of childhood epilepsy. They defined as poor outcome less than 6 months of terminal remission at an evaluation point 2 years after initial diagnosis. Of their children with CLRE, $37 \%$; of their children with SLRE, $46 \%$; and of their children with ILRE, $21 \%$ had a poor short-term outcome.

In a later study, the authors compared outcome and predicting variables at 2 and 5 years after diagnosis [19]. For children with CLRE, $34 \%$ had a terminal remission of less than 1 year at 5 years after diagnosis compared with $48 \%$ at 2 years. The odds ratio $(\mathrm{OR})$ of not having reached a longer than 1-year terminal remission at 5 years after diagnosis for the CLRE type of epilepsy ( 6 months after first diagnosis) is 2.76 $(P<0.001)$. For SLRE, the OR is $3.45(P<0.001)$. By 5 years after diagnosis, all patients diagnosed with ILRE at 6 months had been seizure-free for at least 1 year. 
Arts et al. analyzed the determinants of CLRE and SLRE predicting $>1$-year terminal remission 5 years after diagnosis, as they argue these children cannot depend on a defined syndrome to predict their prognosis. The occurrence of postictal signs is the only significant determinant, still amounting to $33 \%$ of mispredictions. As for specific variables within the CLRE cohort, age at onset between 3 and 9 is noted to predict a worse prognosis; this finding is significant.

Collaborating with Camfield and colleagues, these authors tried to build a prediction model based on models developed by both research groups [30]. The outcome measure was "off medication at the end of follow-up." For CLRE, percentages did not differ among the two cohorts (Camfield et al., Nova Scotia cohort: $62 \%$; Geelhoed et al., Dutch cohort: $56 \%$ ). In contrast to the Dutch model, the Nova Scotia model as well as the combined model attributed a good outcome to CLRE.

In a clinical trial, 72 previously untreated children with CLRE were treated with zonisamide monotherapy [16]. When zonisamide did not suffice, carbamazepine was added. Seizure control was attained by 57 patients $(79.2 \%)$. Five patients experienced cognitive side effects (short attention span and drowsiness).

In a topiramate trial, 5 of 7 children with CLRE who were treated with topiramate addon therapy were regarded as responders [17]. For SLRE, 7 of 12 responded, and for ILRE, 1 of 2 children responded.

In the case of persisting seizure freedom, drug withdrawal is considered. Within a CLRE cohort of seizure-free children with a normal EEG, Verrotti et al. determined the rate of relapse to be $27 \%$ [14]. There was no difference with respect to the outcome of withdrawal between 1 and 2 years of seizure freedom. It is generally believed that a normal EEG decreases the risk for relapse, so a more benign part of the CLRE population may be reflected in this study.

Ohta et al. retrospectively diagnosed children with CLRE to study their long-term outcome [28]. They found two independent risk factors for relapse after withdrawal of antiepileptic drugs (AEDs): first, 5 years or more from start of AED therapy until seizure remission, and second, age at onset of epilepsy of 6 or older. The low relapse rate $(9.8 \%)$ reflects their criteria before withdrawal ( 3 or more years of seizure freedom and no abnormalities on EEG tracings).

According to Murakami et al., remaining EEG abnormalities despite drug therapy and seizure freedom did not predict the occurrence of a relapse after AED withdrawal [27]. Moreover, the relapse rate of the CLRE group was significantly lower (8.6\%) than the relapse rate of the total cohort consisting of childhood epilepsy patients $(13.5 \%)$ with 3 years of seizure freedom. Also, the comparison with the SLRE cohort, which has a relapse rate of $20.0 \%$, is striking; however the ILRE cohort had a relapse rate similar to that of the CLRE cohort $(8.3 \%)$.

Verrotti et al. evaluated the predictive value of interictal EEG findings during drug withdrawal [20]. Their patients did not exhibit any EEG abnormalities on three different occasions before drug withdrawal. Relapse occurred in $24 \%$. EEG abnormalities were exhibited by $67 \%$ of children who relapsed versus $10 \%$ of children who did not relapse. They concluded that reappearance of EEG abnormalities after drug withdrawal is a risk factor for relapse. 
Recently, Berg et al. applied a Markov process to model the course of several epilepsy groups [7].This method characterizes remissions and relapses in a more quantitative way. It examines the probability of being in a given state, can follow the individual as he or she changes state, and allows for calculation of the net effects. First, they defined three possible states of epilepsy: not yet being in remission, being in a remission of 1 year, and having relapsed after at least 1 year of remission. Their results for CLRE were similar to the results for IGE: neither a very benign nor a very malignant course. Throughout the whole study CLRE could be found right between ILRE, with the more benign course, and SLRE, with the markedly worse outcome. In a second phase, they analyzed the course of the epilepsy in more detail, implementing a second and third state of remission and accompanying relapses. Now the difference between IGE and CLRE became clear: Patients with IGE almost never relapsed; however, patients with CLRE exhibited a pattern of remission and relapse. This wavelike pattern could have an important effect on the personal development of patients. However, this pattern could also be merely a consequence of the method applied. This will have to be confirmed in further studies on the course of seizure control.

\section{Cognitive and psychosocial prognosis}

A precondition for attention is a normal state of responsiveness. Attention plays a key role in learning processes. Oostrom et al. stated that attention seemed to be the outstanding function reflecting the behavioral or cognitive effects of epilepsy. They did not find any significant difference in attention and reaction time between the cryptogenic group and the idiopathic group or the controls [23].

Parkinson studied the relationship between presence of language disorders and type of epileptic seizures in children. Within the subgroup of children with language disorders, significantly more children had partial than generalized seizure types. A larger percentage of these children had SLRE than CLRE. Because these patients belong to a group noted for the refractory nature of their epilepsy, and more than two-thirds of these children attend special education classes [26], these results are not applicable for generating a prognosis for patients with CLRE.

In a population-based study, Hoie et al. studied the prevalence of severe nonverbal problems (SNVPs) with the Raven Matrices in children with epilepsy and in healthy controls. The Raven Matrices is a robust nonverbal reasoning ability test based on figural test stimuli in the visual modality. SNVPs were considered to exist if the Raven score was at or below the 10th percentile [15]. Children with epilepsy were highly overrepresented in the lowest Raven percentile group, whereas controls were highly overrepresented in the higher percentile groups. Five of the twenty-five children with CLRE (20\%) had SNVPs; for ILRE this was $7 \%$, and for SLRE $62 \%$. Only $3 \%$ of the healthy controls scored below the 10th percentile.

Oostrom et al. found that groups of children with idiopathic or cryptogenic epilepsy and controls could not be distinguished by their IQs or attitudes toward school [23]. Not significantly more children with epilepsy than controls repeated a year at school. 
However, significantly more children with epilepsy, including the subgroup of children with CLRE, required special education assistance at school [23].

Oostrom et al. stated that at 3 to 4 years of follow-up [18], both parents and teachers reported more behavioral problems for the group of children with epilepsy only than for healthy controls. Also, the epilepsy-only group was reported as performing worse on measures of learning, memory span for words, and attention. After they controlled for school delay, only proactive interference remained a significant finding. None of these findings distinguishes the children with CLRE from the children with ILRE [18].

Aldenkamp and Arends studied two scholastic variables, reading and arithmetic, in a cohort of children with nonconvulsive seizures and learning problems [21]. The control group in this study consisted of 31 children in whom the diagnosis epilepsy was rejected. All of these children had a normal IQ and no other neurological disorders. The results indicated no delay in reading for the control group, whereas the children with CLRE had a delay of 19.2 months. The idiopathic and symptomatic groups had delays of respectively 2.3 and 12.2 months. For arithmetic, the same pattern was observed, although the difference was somewhat smaller. The control group had a delay of 3.9 months, the CLRE group had a delay of 17.0 months, and the idiopathic and symptomatic groups had delays of respectively 4.5 and 13.2 months. Because in these tests, a 10-month delay equals a full school year, the delay in both reading and arithmetic was almost 2 school years for the children with CLRE [21].

In general, schoolchildren with epilepsy have more behavioral problems than their healthy classmates. Oostrom et al. [22] studied the occurrence of behavioral problems in children with cryptogenic and idiopathic epilepsy. The only specific result was that children with cryptogenic epilepsy were rated as having significantly more behavioral problems than children with idiopathic epilepsy and children from the control group on the Child Behavior Checklist (CBCL). Oostrom et al. gave two possible explanations. First, cerebral dysfunction may contribute to the behavioral problems [22]. Second, because many parents of children with cryptogenic epilepsy perceived themselves as having been thrown off balance at the onset of the epilepsy, this stress in the parent(s) could be related to behavioral problems in children with epilepsy [24].

Genton et al. studied the psychosocial outcome of nonidiopathic focal childhood epilepsies [33]. Outcome was categorized as either "normal" or "abnormal." A normal outcome was defined as "lack of evident neuropsychological deficit and normal schooling and/or unrestricted choice of profession and lifestyle, as well as absence of any behavioral problems." The psychosocial outcome in this study was poor, because at the end of the follow-up period, only $50 \%$ of the cryptogenic patients and only $13 \%$ of the symptomatic cases were reported as "normal." It must be taken into account that

$55 \%$ of the total cohort was already categorized as "abnormal" at the start of the study. Even though the patients with cryptogenic epilepsy seemed to have a somewhat better evolution than the patients with symptomatic epilepsy [33], a score of only $50 \%$ with "normal outcome" can hardly be regarded "better." 


\section{Discussion}

On review of the literature on CLRE with childhood onset, six articles provide information that is considered of value in describing prognosis. The short-term prognosis is generally good [25] (2 years after diagnosis, almost two-thirds of patients have been seizure-free for 6 months), and in the long term, the chance of achieving seizure freedom also is good [34] (89\% of patients reach a 1-year remission). However, relapse occurs frequently [7]. Also, children with CLRE experience academic and behavioral difficulties $[22,23]$. The prognosis seems to be unpredictable, as both benign and malignant courses are described [12].

\section{Diagnosis of CLRE}

In the 2001 proposal for a diagnostic scheme as an expansion of the classification, cryptogenic is replaced by probably symptomatic [38]. This scheme is divided into axes; on the third axis a syndromic diagnosis is given, whenever possible. On this axis, the former category CLRE is incorporated into "symptomatic (or probably symptomatic) focal epilepsies," more specifically "Other Types Defined by Location and Etiology." The nonspecificity remains.

Even before this proposal, CLRE was often assigned to the same research cohort as SLRE. This explains the limited amount of information we were able to retrieve from the literature. Even though many of these patients with CLRE will eventually be recognized as having SLRE, this requires focused research on a clearly defined cohort.

\section{Prognosis for seizure control}

Unfortunately, impressive studies $[4,5,29,31,35]$ were substantially flawed with respect to the CLRE cohort. Camfield and Camfield [32] report widely differing seizure outcomes: up to half of their cohort had a truly benign course, whereas in the other half, prognosis was uncertain.

In an innovative approach, Berg et al. applied a Markov process to describe the course of epilepsy. They suggest that there may exist a wavelike pattern of relapse and remission [7], which might be distinct for CLRE. This finding has not yet been reproduced. The overall question is whether there is a relationship between the clinical appearance of CLRE with respect to seizure control and the worrisome neuropsychological outcome.

\section{Cognitive and psychosocial prognosis}

Even though it is known that children with epilepsy are at risk for cognitive delay $[10,21,39]$, little can be confirmed concerning CLRE specifically. For some children with CLRE, the consequences have proven to be serious. Delays up to two school years in reading and arithmetic have been reported [21]. Even though the children in this study were included because of fluctuations in cognitive performance, 
It is noteworthy that the children with CLRE had dramatically worse delays than the children with symptomatic or idiopathic epilepsy. Also, according to another study, patients with CLRE had more behavioral problems in comparison with their healthy peers, but also in comparison with children with idiopathic epilepsy [22].

\section{Heterogeneity within CLRE}

It seems reasonable to assume that the CLRE group, like the SLRE group, comprises several subgroups. Major risk factors such as etiology and syndrome diagnosis are irrelevant in predicting the prognosis of CLRE. Therefore, other, apparently superficial factors may be more important when studying CLRE subgroups. Of course, these are the factors that define epilepsy syndromes in general.

For CLRE as an undefined group, these factors take on a wide variety of values, and the challenge is to recognize combinations of these to predict prognosis.

From this review, several factors can be suggested as important in prognosis. First, age at onset between 5 and 9 was found to predict attainment of remission, regardless of syndrome [31]. On the other hand, age at onset after 6 was found to be an independent risk factor for seizure relapse after AED withdrawal in children with CLRE [28]. Ohta et al. partly explain their outcomes as the result of the diversity of their population [28]. A portion of the children in their cohort may turn out to have benign partial epilepsy, which seems idiopathic because of the high rate of family history, age at onset below 6 , and benign course.

Second, a direct way to break down the large and cluttered CLRE-population is by semiology of the seizures. With a highly developed classification such as Luders' [40], semiology can be correlated with other outcome measures. It has previously been described how seizure semiology can predict clinical outcome. It is also known that for epilepsy in general, patients with more than one seizure type are at greater risk with respect to both seizure outcome and cognitive outcome, especially if the epilepsy is associated with neurological deficit or psychiatric or behavioral disturbances [11]. In particular, a possible correlation between a pattern of recurrent remission and relapse and the disruption of cognitive development in children with CLRE should be explored.

Third, seizure frequency may be a factor. Children with low seizure frequency can fit into the so-called benign subgroups of CLRE, whereas patients with frequent seizures may constitute more malignant subgroups. Those children with CLRE who experience subtle seizures may pose a dilemma with respect to prognosis [41]. The failure to notice the many seizures they experience may explain the malignant outcome in the presence of an apparently low seizure frequency [21].

Fourth, (in)tractability of the epilepsy seems to be a very important factor. The number of seizures experienced before medication is also described as a risk factor [32]. Ohta et al. reported that the time between the start of an AED and seizure control is a prognostic factor in the patient's chance of relapse [28]. The current number of AEDs, the number of AEDs tried in the past, and also the kinds of AEDs are essential. Together, these factors can also distinguish benign from malignant subgroups. Arts et 
al. [25] wonder: Does the refractory epilepsy make the patient insensitive to treatment, or are the ongoing seizures worsening the course of the epilepsy and determining the prognosis of their cohort, consisting predominantly of CLRE and SLRE patients? Regardless of diagnosis, one-third of epilepsy patients appear to be resistant to drug therapy. Bearing in mind the hypothesis of "seizures beget seizures," research on patient drug matches is very important. Pharmacogenetic research has led to the assumption of subgroups within diseases, which, although indistinguishable on clinical grounds, are different on a molecular level. These would lead to specific approaches regarding treatment.

Fifth, a high percentage of epileptiform activity on EEGs can be a risk factor for cognitive skills [21]. Two possible explanatory EEG features are nocturnal epileptiform activity and interictal epileptiform activity irrespective of time of day. It is known that nocturnal epileptiform activity strongly affects cognitive skills [42]. Landau-Kleffner and ESES can be considered extreme syndromes in such a spectrum. A less often described but powerful relationship exists between daytime interictal epileptiform activity and cognitive impairment. Even a little daytime interictal epileptiform activity, only $1 \%$ of the time, has an important noticeable effect on cognition, compared with the high percentages of interictal epileptiform activity in children with ESES, in whom discharges are generally observed more than $85 \%$ of the time [21]. Further quantification of these

EEG features may contribute to the identification of different subgroups within CLRE. Lastly, according to Camfield and Camfield [32], $Q$ Q predicts long-term outcome better than neurological deficit does. Epilepsy patients were divided into those with normal $I Q$ and those with abnormal IQ. Some clinicians diagnose localization-related epilepsy in the presence of mental retardation as symptomatic, and others do not, or do so on the matter of diagnosis, but not when discussing etiology. Thus, it seems a matter of opinion whether this could be a prognostic factor in CLRE. When the diagnostic scheme proposed by Engel [38] is used, etiology (axis 4) is in fact appointed independent of impairment (axis 5). We suggest that differences within the normal range of $I Q$ could also have meaning for subgroups. Therefore, premorbid IQ could be a distinguishing characteristic within the CLRE cohort.

These subgroups may explain the wide variety of outcomes of previous studies and the unpredictable outcome of CLRE in individual cases. In every study published so far, one subgroup might have unintentionally been overrepresented, which strongly influenced the outcome for the entire CLRE cohort.

In conclusion, CLRE remains a diagnosis that is difficult to grasp. In clinical research it has had a subordinate position, which is not in proportion either to the prevalence of CLRE in the pediatric epilepsy population or to the not so benign prognosis that can be expected for at least part of this group. Prospective studies on well-defined CLRE cohorts are needed to identify factors that distinguish various prognostic subgroups. Specific attention should be focused on course of the epilepsy, scholastic achievement, and psychosocial outcome. 


\section{References}

1. Duncan J, Shorvon S, Fish D. Clinical epilepsy. New York: Churchill Livingstone; 1995.

2. Commission on Classification and Terminology of the International League Against Epilepsy Proposal for revised classification ofepilepsies and epileptic syndromes. Epilepsia 1989;30:389-399.

3. Dunn DW, Buelow JM, Austin JK, et al. Development of syndrome severity scores for pediatric epilepsy. Epilepsia 2004;45:661-6.

4. Berg AT, Levy SR, Testa FM, et al. Classification of childhood epilepsy syndromes in newly diagnosed epilepsy: interrater agreement and reasons for disagreement. Epilepsia 1999;40:439-44.

5. Berg AT, Shinnar S, Levy SR, et al. How well can epilepsy syndromes be identified at diagnosis? A reassessment 2 years after initial diagnosis. Epilepsia 2000;41:1269-75.

6. Kellinghaus $\mathrm{C}$, Loddenkemper $\mathrm{T}, \mathrm{Najm} \mathrm{IM}$, et al. Specific epileptic syndromes are rare even in tertiary epilepsy centers: a patient-oriented approach to epilepsy classification. Epilepsia 2004;45:268-75.

7. Berg AT, Lin J, Ebrahimi $\mathrm{N}$, et al. Modeling remission and relapse in pediatric epilepsy: application of a Markov process. Epilepsy Res 2004;60:31-40.

8. Waaler PE, Blom BH, Skeidsvoll $H$, et al. Prevalence, classification, and severity of epilepsy in children in western Norway. Epilepsia 2000;41:802-10.

9. Eriksson KJ, Koivikko MJ. Prevalence, classification, and severity of epilepsy and epileptic syndromes in children. Epilepsia 1997;38:1275-82.

10. Cascino G, Hopkins A, Shorvon SD, editors. Epilepsy. 2nd ed. London/New York: Chapman \& Hall; 1995. p. 503. [chapter xvii].

11. Sander JW. Some aspects of prognosis in the epilepsies: a review. Epilepsia 1993;34:1007-16.

12. Camfield $P$, Camfield $C$. Epileptic syndromes in childhood: clinical features, outcomes, and treatment. Epilepsia 2002;43(Suppl. 3):27-32.

13. Camfield P, Camfield C. Childhood epilepsy: what is the evidence for what we think and what we do? J Child Neurol 2003;18:272-87.

14. Verrotti $A$, Morresi $S$, Basciani $F$, et al. Discontinuation of anticonvulsant therapy in children with partial epilepsy. Neurology 2000;55:1393-5.

15. Hoie $B$, Mykletun $A$, Sommerfelt $K$, et al. Seizure-related factors and non-verbal intelligence in children with epilepsy: a populationbased study from western Norway. Seizure 2005;14:223-31.

16. Miura H. Zonisamide monotherapy with once-daily dosing in children with cryplogenic localization-related epilepsies: clinical effects and pharmacokinetic studies. Seizure 2004;13 (Suppl. 1):S17-23. discussion S24-5.

17. Grosso S, Galimberti D, Farnetani MA, et al. Efficacy and safety of topiramate in infants according to epilepsy syndromes. Seizure 2005;14:183-9.

18. Oostrom KJ, van Teeseling $H$, Smeets-Schouten $A$, et al. Three to four years after diagnosis: cognition and behaviour in children with 'epilepsy only'. A prospective, controlled study. Brain 2005;128 ( $\mathrm{Pt}$. 7): $1546-55$.

19. Arts WF, Brouwer OF, Peters AC, et al. Course and prognosis of childhood epilepsy: 5-year follow-up of the Dutch study of epilepsy in childhood. Brain 2004;127(Pt. 8):1774-84.

20. Verrotti A, Morresi $S$, Cutarella $R$, et al. Predictive value of EEG monitoring during drug withdrawal in children with cryptogenic partial epilepsy. Neurophysiol Clin 2000;30:240-5.

21. Aldenkamp $A$, Arends $J$. The relative influence of epileptic EEG discharges, short nonconvulsive seizures, and type of epilepsy on cognitive function. Epilepsia 2004;45:54-63.

22. Oostrom KJ, Schouten $\mathrm{A}$, Kruitwagen $\mathrm{CL}$, et al. Behavioral problems in children with newly diagnosed idiopathic or cryptogenic epilepsy attending normal schools are in majority not persistent. Epilepsia 2003;44:97-106.

23. Oostrom KJ, Schouten A, Kruitwagen $\mathrm{CL}$, et al. Attention deficits are not characteristic of schoolchildren with newly diagnosed idiopathic or cryptogenic epilepsy. Epilepsia 2002;43:301-10.

24. Oostrom KJ, Schouten A, Kruitwagen CL, et al. Parents' perceptions of adversity introduced by upheaval and uncertainty at the onset of childhood epilepsy. Epilepsia 2001;42:1452-60.

25. Arts WF, Geerts AT, Brouwer OF, et al. The early prognosis of epilepsy in childhood: the prediction of a poor outcome. The Dutch study of epilepsy in childhood. Epilepsia 1999;40:726-34.

26. Parkinson GM. High incidence of language disorder in children with focal epilepsies. Dev Med Child Neurol 2002;44:533-7. 
27. Murakami $M$, Konishi $T$, Naganuma $Y$, et al. Withdrawal of antiepileptic drug treatment in childhood epilepsy: factors related to age. J Neurol Neurosurg Psychiatry 1995;59:477-81.

28. Ohta $H$, Ohtsuka $Y, T$ suda $T$, et al. Prognosis after withdrawal of antiepileptic drugs in childhood-onset cryptogenic localization-related epilepsies. Brain Dev 2004;26:19-25.

29. Sillanpaa $M$, Jalava $M$, Kaleva $O$, et al. Long-term prognosis of seizures with onset in childhood. $N$ Engl $J$ Med 1998;338:1715-22

30. Geelhoed $M$, Boerrigter $A O$, Camfield $P$, et al. The accuracy of outcome prediction models for childhoodonset epilepsy. Epilepsia 2005;46:1526-32.

31. Berg AT, Shinnar S, Levy SR, et al. Two-year remission and subsequent relapse in children with newly diagnosed epilepsy. Epilepsia 2001;42:1553-62.

32. Camfield $\mathrm{C}$, Camfield $\mathrm{P}$. Predicting the outcome of childhood epilepsy: a population-based study yielding a simple scoring system. J Pediatr 1993;122:861-8.

33. Genton P, Battaglia D, Pinto $P$, et al. Long-term outcome of nonidiopathic focal childhood epilepsies: a retrospective study of 106 cases including 33 cases with extensive evaluation and follow-up. In: Tuxhorn $J$, Holthausen $H$, Boenigk $H$, editors. Paediatric epilepsy syndromes and their surgical treatment. London: John Libbey; 1997. p. 47-54.

34. Hauser $E$, Freilinger $M$, Seidl $R$, et al. Prognosis of childhood epilepsy in newly referred patients. J Child Neurol 1996;11:201-4.

35. Shinnar S, O'Dell C, Berg AT. Distribution of epilepsy syndromes in a cohort of children prospectively monitored from the time of their first unprovoked seizure. Epilepsia 1999;40:1378-83.

36. Commission on Epidemiology and Prognosis, International League Against Epilepsy. Guidelines for epidemiologic studies on epilepsy. Epilepsia 1993;34:592-6.

37. Sillanpaa $M$, Jalava $M$, Shinnar $S$. Epilepsy syndromes in patients with childhood-onset seizures in Finland. Pediatr Neurol 1999;21:533-7.

38. Engel Jr J. A proposed diagnostic scheme for people with epileptic seizures and with epilepsy: report of the ILAE Task Force on Classification and Terminology. Epilepsia 2001;42:796-803.

39. Seidenberg $M_{1}$ Beck $N_{1}$ Geisser $M_{1}$ et al. Academic achievement of children with epilepsy. Epilepsia 1986;27:753-9.

40. Luders $H$, Acharya J, Baumgartner $C$, et al. Semiological seizure classification. Epilepsia 1998;39:1006 13.

41. Aldenkamp AP, Overweg-Plandsoen WC, Arends J. An open, nonrandomized clinical comparative study evaluating the effect of epilepsy on learning. J Child Neurol 1999;14:795-800.

42. Baglietto $M G$, Battaglia $F M$, Nobili $L$, et al. Neuropsychological disorders related to interictal epileptic discharges during sleep in benign epilepsy of childhood with centrotemporal or Rolandic spikes. Dev Med Child Neurol 2001;43:407-12. 
II

Cohort studies 


\section{Chapter 3}

\section{Neuropsychological profile of children with Cryptogenic Localization Related Epilepsy}

Published as:

van Mil, SGM, Reijs, RP, van Hall, MHJA, Aldenkamp, AP (2008).

Neuropsychological profile of children with Cryptogenic Localization Related Epilepsy Child Neuropsychology, 14(4): 291-302. 


\begin{abstract}
Up to one third of the epilepsy population consists of children with cryptogenic localization related epilepsy (CLRE). Unfortunately, the effect of CLRE on the development is still unclear. Behavioural and academic problems have been reported, but no conclusive study concerning the impact of CLRE on neuropsychological functioning is yet published.
\end{abstract}

This study was a systematic cross-sectional open clinical and non-randomized investigation, which included 68 children with CLRE. Several neuropsychological tests were analysed and age-related normative values were used as reference. Differences between CLRE and reference values were tested with Paired-Samples T-tests. Z-scores were computed to compare the different neuropsychological tests and to inspect whether a characteristic neuropsychological profile exists for CLRE. The Independent-Samples T-test was used to explore which epilepsy-factors (seizure type, seizure frequency, age at onset, duration of epilepsy and drug load) were influencing the cognitive profile of CLRE.

There seems to be a characteristic cognitive profile for children with CLRE; children with CLRE experience cognitive difficulties on a wide range of areas - in particular alertness, mental speed and memory. Seizure type, seizure frequency, duration of epilepsy and drug load do not influence this neuropsychological profile. Age at onset was an important risk factor; the earlier the age at onset, the worse the cognitive performance. In spite of the influence of age at onset, the revealed profile can be seen as a stable, independent of temporary factors, neuropsychological profile for children with CLRE. 


\section{Introduction}

Epilepsy is the most common neurological disorder in childhood. Cognitive impairment and educational underachievement are frequently described as comorbid disorders [1].

About one third of the epilepsy population consists of children with cryptogenic localization related epilepsy (CLRE) $[2,3,4]$. The term cryptogenic refers to a disorder whose cause is occult. It is presumed to be symptomatic, but the aetiology is not known. Localization related means that the seizure semiology or EEG findings at investigation disclose a localized origin of the seizures [5].

The knowledge about the prognosis of CLRE is poor [6]. Currently, it is assumed that the prognosis of CLRE is positioned somewhere between the more benign idiopathic and the more malignant symptomatic epilepsies. Camfield and Camfield [7] confirmed this by finding that about half of the children with CLRE have a very benign course, whereas in the other half, the prognosis was uncertain. Also in line with this finding is the fact that both high remission rates $[8,9]$ and frequent relapses $[2,8]$ are described. This leaves the long-term prognosis unforeseeable.

As epilepsy is known to have a large impact on cognitive development and educational achievement [1], prognosis should not concentrate only on seizure outcome. But also the academic and psychosocial outcome is still unclear for children with CLRE. It is described that children with CLRE have more behavioural problems than children with idiopathic epilepsy and controls [10]. Children with CLRE also seem to experience academic difficulties. Delays up to two school years in reading and arithmetic have been reported [11]. No conclusive data are available yet. Therefore, the question arises how the epilepsy interferes with cognitive development in children with CLRE.

Several epilepsy-factors, possibly influencing cognitive development in children, have been identified. Seizure type is frequently seen as an important risk factor for cognitive impairment [12]. Especially tonic-clonic and complex partial seizures (CPS) have serious effects on cognitive functioning [13]. CPS are associated with memory difficulties [14] and with cognitive, academic, behavioural, and psychosocial difficulties [15]. However, other studies do not describe any influence of seizure type on cognition; Williams et al. [16] found no differences in memory performance based on seizure type and Williams, Griebel and Dykman [17] and Bailet and Turk [18] found no influence of seizure type on cognitive and behavioural tests.

Seizure frequency seems to be a strong predictor for cognitive decline; poor seizure control is linked to poor cognitive outcome $[19,20,21,22,23]$. However, other studies have shown conflicting results. Schoenfeld et al. [15] described that seizure frequency was not significantly related to cognitive functioning. Also age at onset seems to be an important risk factor for cognition; an early age at onset is associated with a poor cognitive outcome $[15,19,22,24,25]$. Duration of epilepsy is often linked to cognitive development. Long duration of active epilepsy has a significant impact on intel- 
lectual functioning $[19,20,21,26]$. Finally, the use of antiepileptic drugs (AED) is mentioned in relation to cognition. Patients on polytherapy showed a pattern of poorer performance than patients on monotherapy $[15,22,27]$. A major concern of AED is their negative effect on information processing speed, memory and attention processes $[28,29]$.

In clinical practice, but also in epileptology in general, there is an increasing tendency to couple 'epilepsy types' with characteristic cognitive and behavioural profiles. See for example the work on Rolandic epilepsy [30]. Therefore, the objective of this study is to investigate whether a group of children with CLRE, referred to our tertiary outpatient clinic, differ from age-related normative values on neuropsychological tests. Furthermore, this study aims to determine whether a characteristic neuropsychological profile of CLRE exists and which epilepsy-factors might influence this profile.

\section{Patients and methods}

\section{Design}

A systematic cross-sectional open clinical and non-randomized design was used.

\section{Subject selection}

A total of 68 children and adolescents were included consecutively in this study. All these patients were referred to a specialized expert team in our epilepsy centre between January 1999 and December 2004 for assessment in a program for school going children with epilepsy. In this program, relationships between epilepsy and learning difficulties are studied.

The inclusion criteria were age between 6 and 16 years and a diagnosis of CLRE, which was made or confirmed by one of our (child) neurologists following the 1989 revised International League Against Epilepsy (ILAE) classification [5], including normal neuroimaging. The exclusion criteria were $I Q<70$, absence of neuroimaging, a neurological disease other than epilepsy.

Age-related normative values derived from standardization samples were used as reference values to evaluate the results in the investigated children.

\section{Statistical analysis}

Data were collected on record forms and entered into a database. To analyse these data, the Statistical Package for Social Sciences (SPSS), version 14.0 for Windows, was used. Differences in neuropsychological test results between the CLRE group and the reference values were tested with Paired-Samples T-tests. The significance level (two-tailed testing) was set at $5 \%$. 
To compare the neuropsychological test results amongst each other, Z-scores were computed. Subdivisions on seizure type, seizure frequency, age at onset, duration of epilepsy and drug load were made to explore which epilepsy-factors influenced the neuropsychological profile. The Independent-Samples T-Test with a two-tailed significance level of $5 \%$ was used.

In case of multiple comparisons, a bonferroni-correction was done. For every hypothesis that was studied, 17 neuropsychological (sub)tests were compared. Therefore, alpha was divided by 17 resulting in a corrected alpha of .003 .

\section{Assessment procedures}

During a three day admission at our epilepsy centre, a standardized assessment battery was used containing neurological consultation, psychomotor screening, EEG recording, observation by specialized nurses, neuropsychological testing, and collecting information on school achievement.

The children were assessed using the following neuropsychological tests:

Psychomotor speed and fluency:

Finger tapping task: measuring motor speed and fluency in five consecutive trials for the index finger of the dominant and the non-dominant hand separately.

\section{Psychomotor speed / alertness:}

Simple reaction time measurement: the patient has to react as quickly as possible on either auditory $(800 \mathrm{~Hz}$ tones) or visual (white square on the screen) stimuli that were presented at random intervals by the computer. Activation and alertness are measured by these tests and a strong motor component is involved.

\section{Central information processing speed:}

Binary choice reaction-time measurement: a reaction time test with a decision component. The patient has to react differentially to a red square on the left side of the screen and to a green square at the right side of the screen. The reaction time does not only reflect motor speed, but also the decision making process.

Computerized visual searching task (CVST): an adaptation of Goldstein's Visual Searching Task. A centred grid pattern has to be compared with 24 surrounding patterns. Only one of them is identical to the target pattern. The test consists of 24 trials and gives an indication of the information processing speed and perceptual mental strategies. In this study only reaction times are used, therefore only data on information processing speed are available.

\section{Short term memory:}

Recognition of words and figures: the stimuli (six words or four figures) are presented simultaneously during a learning phase with a presentation time of 1 second per item. After a delay of two seconds the screen shows one of these words/figures between distractors. The target item has to be recognized. 
The 15 word test (15 woordentest Kalverboer): a list of 15 words is orally presented five times. After every presentation, immediate recall is requested.

\section{Long term memory:}

The 15 word test (15 woordentest Kalverboer): after five consecutive trials with direct recall, a delayed recall is requested after a 20 minutes interval.

Complex figure test (Rey-Osterrieth figure): twenty minutes after copying a complex figure, the same figure has to be drawn from memory.

\section{Selective attention:}

The Stroop colour word test: a classic measure of selective attention, consisting of three cards: colour naming (the patient has to name colour blocks), word reading (the patient has to read words printed in black ink) and interference (the patient has to name the colour of a word printed in an incongruent colour; e.g., the word red written in blue ink). By comparing the speed of the last card with the speed of the second card, interference of cognitive functioning can be measured. Increased interference can be interpreted as a disturbance in the concentration process.

\section{Visual-spatial functions:}

Complex figure test (Rey-Osterrieth figure): the patient has to copy a complex figure.

Verbal functions:

WISC (Wechsler Intelligence Scale for Children) subtest similarities: the patient has to explain the similarity between two words.

WISC subtest vocabulary: the patient has to explain the meaning of several words.

\section{Results}

Table 1 summarizes the demographic and clinical characteristics of the children in this study.

The cohort consisted of 40 males and 28 females with a mean age of 10 years and 3 months. About half of the patients were suffering from complex partial seizures $(57 \%) .32 \%$ were suffering from (secondary) generalized seizures. The other children were suffering from simple partial seizures. Half of the patients had a low seizure frequency (seizure free up to one seizure a month), the other half of the patients experienced seizures more than once a month (high seizure frequency). The mean age at onset was 6 years and 2 months. The mean duration of epilepsy was 4 years and 1 month. Age at onset was unclear in 4 patients. Consequently duration of epjlepsy was unknown for these patients. About $65 \%$ of the patients were on monotherapy, $22 \%$ were on polytherapy and $13 \%$ were not using antiepileptic drugs. Drug load was computed as defined by the World Health Organization by dividing the prescribed daily dose by the defined daily dose. When a child was using two or more AEDs, the drug loads were added up. 45 children had a low $(<1)$ drug load, while the 
other 23 had a high $(>1)$ drug load. All children had normal neuroimaging; in 62 children an MRI was done, in the other six a CT-scan was performed.

The mean full scale IQ was 87.7 (70-127). Fifty-six children were attending mainstream education, while the other 12 children attended special education. A school achievement test, comparable to the Wide-Range Achievement Test (WRAT) in English-speaking countries [31], showed delays between 7 and 10 months (10 months equals one school year).

Table 1 Demographic and clinical characteristics

\begin{tabular}{|c|c|}
\hline Characteristic & $\mathrm{n} /$ mean \\
\hline $\mathbf{N}$ & 68 \\
\hline Age (years; months) & $10 ; 3($ sd $2 ; 5)$ \\
\hline Sex & $40: 28(m: f)$ \\
\hline \multicolumn{2}{|l|}{ Seizure type } \\
\hline Simple partial seizures & 7 \\
\hline Complex partial seizures & 39 \\
\hline (Secondary) generalized seizures & 22 \\
\hline \multicolumn{2}{|l|}{ Seizure frequency } \\
\hline Low seizure frequency* & 34 \\
\hline High seizure frequency* & 34 \\
\hline Age at onset (years; months) & $6 ; 2$ (sd $3 ; 9)$ \\
\hline Duration of epilepsy (years; months) & $4 ; 1(\mathrm{sd} 3 ; 0)$ \\
\hline \multicolumn{2}{|l|}{ AED treatment } \\
\hline No AED & 9 \\
\hline Monotherapy & 44 \\
\hline Polytherapy & 15 \\
\hline Low drug load $(<1)$ & 45 \\
\hline High drug load $(>1)$ & 23 \\
\hline \multicolumn{2}{|l|}{ Education type } \\
\hline Mainstream education & 56 \\
\hline Special education & 12 \\
\hline \multicolumn{2}{|l|}{ IQ } \\
\hline Total & $87.7(70-127 ;$ sd 12.0$)$ \\
\hline Verbal & $89.8(60-124 ;$ sd 11.5) \\
\hline Performance & $88.3(63-125 ;$ sd 14.5$)$ \\
\hline \multicolumn{2}{|l|}{ School achievement } \\
\hline Reading words & 8.4 months delay (sd 13.8) \\
\hline Reading sentences & 10.0 months delay (sd 14.8) \\
\hline Arithmetic & 6.9 months delay (sd 15.4) \\
\hline
\end{tabular}

*Low seizure frequency: ranging from seizure free up to one seizure a month; *High seizure frequency: ranging from more than one seizure a month to daily seizures. 
Table 2 presents the statistical details of the neuropsychological tests, compared to the reference values, corrected for age.

Table 2 Neuropsychological test results

\begin{tabular}{|c|c|c|c|c|c|c|}
\hline & CLRE & & Referen & ce values & twalue & p-value \\
\hline \multicolumn{7}{|l|}{ Psychomotor speed / fluency } \\
\hline \multicolumn{7}{|l|}{ Finger tapping } \\
\hline Tapping rate dominant hand & 44.7 (sd & $8.5)$ & 43.2 & (sd 6.8) & $t=1.443$ & $p=.154$ \\
\hline Tapping rate non-dominant hand & 39.7 (sd & $8.2)$ & 36.5 & $(\mathrm{sd} 5.5)$ & $t=3.064$ & $p=003$ \\
\hline \multicolumn{7}{|l|}{ Psychomotor speed / alertness } \\
\hline \multicolumn{7}{|l|}{ Simple reaction time } \\
\hline Auditory dominant hand reaction time & $328.9(\mathrm{sd} 1$ & (14.5) & 287.5 & (sd 57.6) & $t=2.946$ & $p=004$ \\
\hline Auditory non-dominant hand reaction time & 325.1 (sd 1 & 102.1) & 276.3 & $(\mathrm{sd} 45.9)$ & $t=3.966$ & $p=000$ \\
\hline Visual dominant hand reaction time & 376.7 (sd & $99.8)$ & 296.9 & (sd 48.7) & $t=6.591$ & $p=000$ \\
\hline Visual non-dominant hand reaction time & 409.9 (sd 1 & 119.0) & 312.9 & (sd 54.7) & $t=6.716$ & $p=000$ \\
\hline \multicolumn{7}{|l|}{ Central information processing speed } \\
\hline \multicolumn{7}{|l|}{ Binary Choice reaction time } \\
\hline Reaction time & $460.0 \quad(\mathrm{sd} 1$ & 139.1) & 461.3 & (sd 96.7) & $\mathrm{t}=-.056$ & $p=.956$ \\
\hline \multicolumn{7}{|l|}{ CVST } \\
\hline Reaction time & 25.31 sd & 10.4) & 17.1 & (sd 7.1) & $\mathrm{t}=5.402$ & $p=000$ \\
\hline \multicolumn{7}{|l|}{ Short term memory } \\
\hline \multicolumn{7}{|l|}{ Recognition } \\
\hline Words simultaneous (number correct) & $15.8<\mathrm{sd}$ & 3.6) & 16.9 & $(s d 3,9)$ & $t=-1.828$ & $p=.076$ \\
\hline Figures simultaneous (number correct) & $9.9 \mathrm{sd}$ & 2.9) & 11.8 & $(\mathrm{sd} 3.2)$ & $\mathrm{t}=-4.089$ & $\mathrm{p}=000$ \\
\hline \multicolumn{7}{|l|}{15 words test } \\
\hline Total direct reproduction & 40.7 (sd & $12.0)$ & 41 & $(\mathrm{sd} 10)$ & $t=-.237$ & $p=.813$ \\
\hline \multicolumn{7}{|l|}{ Long term memory } \\
\hline \multicolumn{7}{|l|}{15 words test } \\
\hline Recall & $8.0 \quad(s d$ & 3.3) & 9 & (sd 2.5) & $t=-2.483$ & $p=016$ \\
\hline \multicolumn{7}{|l|}{ Figure of Rey } \\
\hline Recall & $10.6(\mathrm{sd}$ & $6.7)$ & 19.73 & (sd 6.71) & $t=-10.633$ & $p=000$ \\
\hline \multicolumn{7}{|l|}{ Selective attention } \\
\hline \multicolumn{7}{|l|}{ Stroop colour word test } \\
\hline Time card 3-2 & 73.96 (sd & $43.2)$ & $54 \mathrm{sec}$ & $(s d 21)$ & $t=3.203$ & $\mathrm{p}=002$ \\
\hline \multicolumn{7}{|l|}{ Visual-spatial functions } \\
\hline \multicolumn{7}{|l|}{ Figure of Rey } \\
\hline Copy & $23.8(\mathrm{sd}$ & 11.5) & 27.20 & (sd 7.58) & $t=-2.256$ & $p=028$ \\
\hline \multicolumn{7}{|l|}{ Verbal functions } \\
\hline \multicolumn{7}{|l|}{ WISC subtests } \\
\hline Similarities & 9.38 (sd & $3.0)$ & 10 & $(\mathrm{sd} \mathrm{3})$ & $t=1.652$ & $p=.103$ \\
\hline Vocabulary & $8.52(\mathrm{sd}$ & 2.6) & 10 & (sd 3) & $t=4.603$ & $p=000$ \\
\hline
\end{tabular}


On the finger tapping task, children with CLRE showed a significantly higher motor fluency rate on the nondominant hand compared to reference values (see table 2 for the statistical details). The simple reaction time measurements showed significantly slowing for the CLRE children relative to the reference values on both the auditory and the visual tasks. No significant differences relative to the reference values were found on the binary choice reaction-time task. On the CVST, children with CLRE performed significantly slower. On the recognition task, no differences on 'words' were found, however, children with CLRE performed significantly worse on 'figures'. On the direct reproduction of the 15 words test, no differences were found. The tasks measuring long term memory, selective attention and visual-spatial functions, showed weaker performance for CLRE compared to the reference values. On the two WISC (Wechsler Intelligence Scale for Children) subtests that measure verbal functions, no differences were found on 'similarities'. Nevertheless, on 'vocabulary' children with CLRE showed a worse performance relative to the reference values.

After the Bonferroni-correction, the results of the auditory reaction time test (dominant hand), the 15 words test recall and the complex figure (copy) were no longer significant.

Hence there is a broad set of neuropsychological tests that show weaker function level in children with CLRE relative to reference values. Figure 1 shows the neuropsychological profile for the total cohort. Children with CLRE perform worse (below $1 \mathrm{SD}$ ) on tasks measuring psychomotor speed / alertness, central information processing speed (only the self-structured task, the CVST) and on visual oriented long term memory.

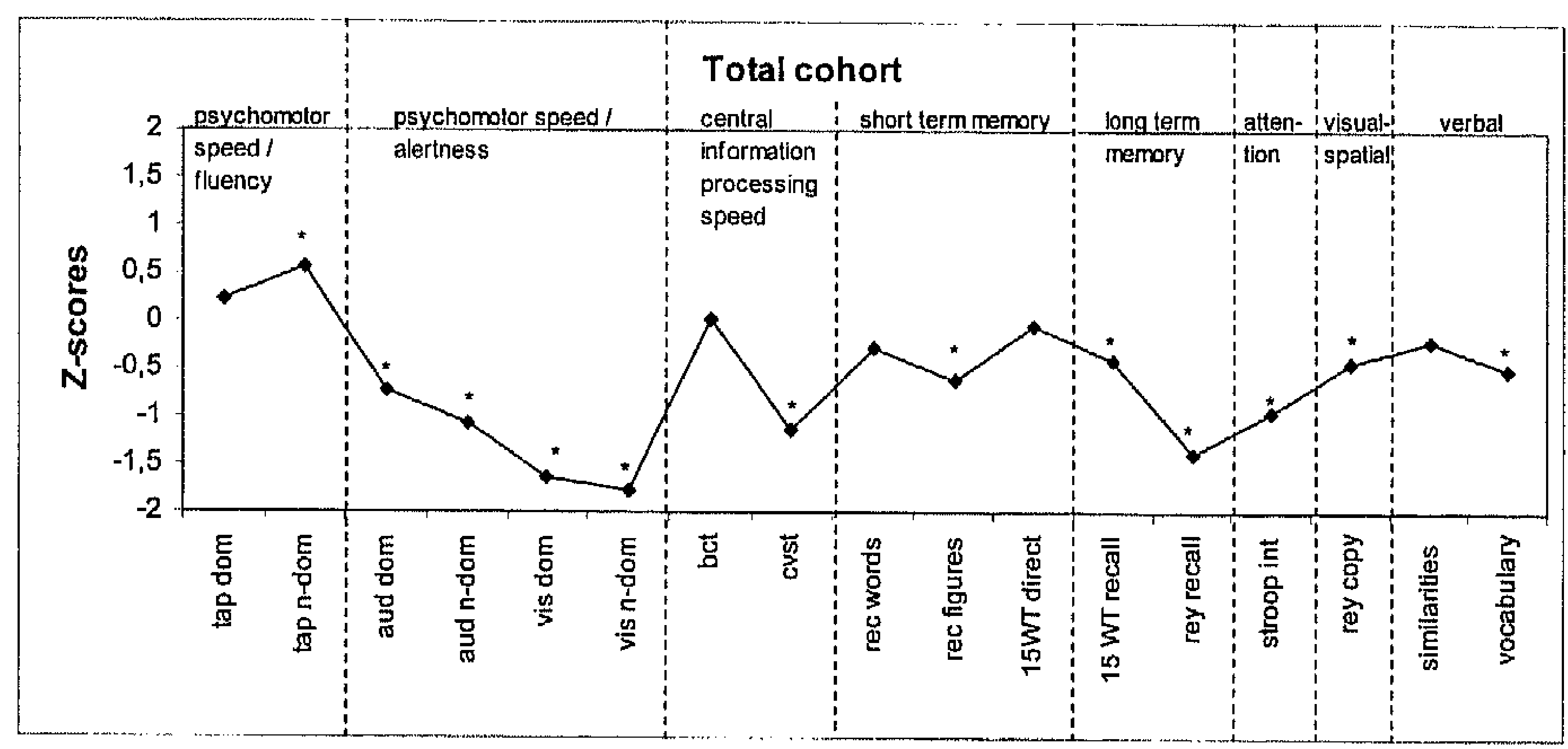

Figure 1 Total cohort tap dom: tapping dominant hand; tap n-dom: tapping non-dominant hand; aud dom: auditory dominant hand reaction time; aud $n$-dom: auditory non-dominant hand reaction time; vis dom: visual dominant hand reaction time; vis n-dom: visual non-dominant hand reaction time; bct: binary choice reaction time; cvst: computerized visual searching task; rec words: recognition words; rec figures: recognition figures; 15WT direct: 15 words test direct reproduction; 15 WT recall: 15 word test recall; rey recall: complex figure recall; stroop int: stroop colour word test interference; rey copy: complex figure copy; similarities: WISC subtest similarities; vocabulary: WISC subtest vocabulary.

${ }^{*} p<.05$ 
Next it was tested whether this is a 'characteristic neuropsychological profile' for CLRE, or whether it is affected by the following factors: seizure type, seizure frequency, age at onset, duration of epilepsy and drug load. To analyse this, the cohort was subdivided according to their score on each of the factors (see table 3).

\begin{tabular}{lc} 
Table 3 Subdivision of the CLRE patients & n \\
\hline Factor & 7 \\
\hline Seizure type & 39 \\
Simple partial seizures & 22 \\
Complex partial seizures & \\
(Secondary) generalized seizures & 34 \\
Seizure frequency & 34 \\
Low seizure frequency & \\
High seizure frequency & 30 \\
Age at onset & 23 \\
Early onset: 0-6 years & 11 \\
Middle onset: $6-9$ years & 4 \\
Late onset: $9-14$ years & \\
Missing* & 23 \\
Duration of epilepsy & 35 \\
Short duration: $0-3$ years & 4 \\
Long duration: $3-12$ years & \\
Missing* & 45 \\
Drug load & \\
Low drug load (< 1 ) & \\
High drug load (> 1) & \\
\hline
\end{tabular}

* No clear age at onset, therefore no clear duration of epilepsy.

A subdivision on seizure type into simple partial seizures, complex partial seizures and (secondary) generalized seizures, showed no differences.

A subdivision on seizure frequency showed that children with a low (less than one seizure a month) seizure frequency had a significantly higher motor fluency rate for the nondominant hand than patients with a high (more than one seizure a month) seizure frequency $(t=2.610, p=.011)$. After the Bonferroni-correction, this was no longer significant.

As can be seen in figure 2 many differences for age at onset were found. Overall, the group with the earliest age (0-6 years) at onset performed worst, while the latest category (9-14 years) performed best. The middle onset group (6-9 years) performed in between. 
Significant differences were found between early and late onset (tapping dominant hand: $t=-4.360, p=.000$, tapping non-dominant hand: $t=-3.894, p=.000$, auditory dominant hand: $t=-2.117, p=.041,15$ word test direct reproduction: $t=-2.108, p=.042$, complex figures test recall: $t=-3.085, p=.004$ ) and between middle and late onset (tapping dominant hand: $t=-4.008, p=.000$, tapping non-dominant hand: $t=-2.371$, $p=.024$, auditory dominant hand: $t=-2.210, p=.034$, complex figures test recall: $t=-$ 2.134, $p=.041$ ).

After the Bonferroni-correction, only differences on the tapping task were still significant.

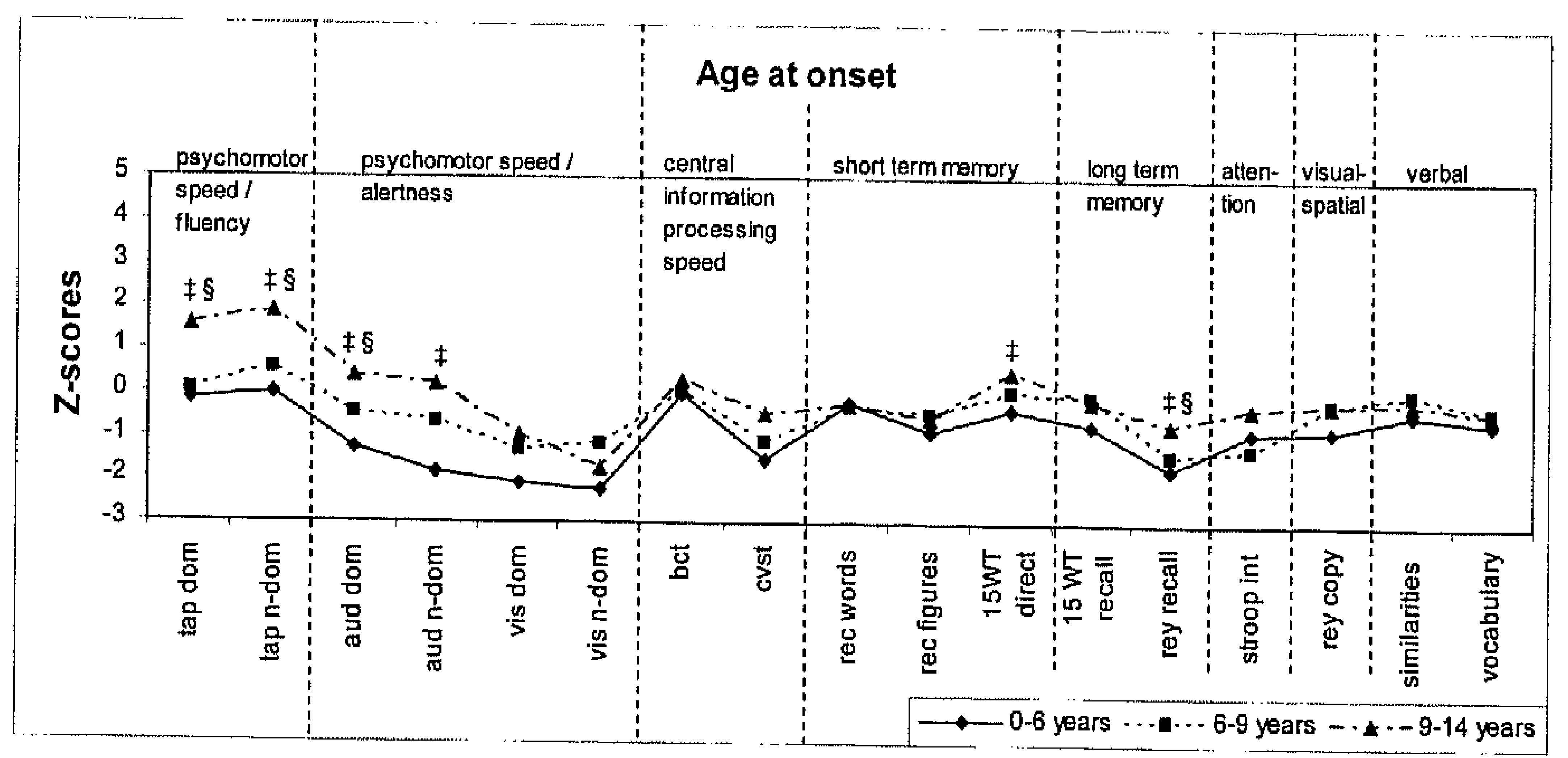

Figure 2 Age at onset

$\ddagger 0-6$ years versus $9-14$ years, $p<.05 ; \S 6-9$ years versus $9-14$ years, $p<.05$

Looking at the duration of the epilepsy, no differences between short duration (0-3 years) and long duration (3-12 years) were found.

A subdivision based on drug load, low $(<1)$ versus high $(>1)$, showed no differences between high and low drug load.

\section{Discussion}

There seems to be a characteristic cognitive profile for children with CLRE; children with CLRE experience cognitive difficulties on a wide range of areas - in particular alertness, mental speed and memory. In the course of CLRE these functions must be carefully followed.

Within this profile of neuropsychological capacities, several subdivisions were made to study which epilepsy-factors were probably influencing this profile.

Cognitive decline is frequently associated with complex partial seizures and tonicclonic seizures $[13,14,15]$. However, it is also frequently described that no relation- 
ship exists between seizure type and cognition $[16,17,18]$. Corresponding to this, no differences were found between children with simple partial seizures (SPS), complex partial seizures (CPS) and (secondary) generalized seizures in this study. Besides seizure type, localization of seizure onset would probably have been interesting. However, as a result of the retrospective and clinical nature of this study, neurophysiological parameters were reduced to a single variable: the presence of interictal activity on EEG. This was studied in a previous article, and no relationship between interictal activity and neuropsychological outcome was found [32].

Also seizure frequency had no influence on cognitive functioning in CLRE. This is in line with Schoenfeld et al. [15] who found that frequency of seizures was not significantly related to cognitive functioning. However, more frequently described is the association between seizure frequency and cognitive decline; there seems to be a link between poor seizure control and poor cognitive outcome $[19,20,21,22,23]$.

In contrast to literature, no influence of duration of epilepsy was found in this study. Longer duration of epilepsy is in literature associated with poorer intellectual abilities $[19,20,21,26]$. Impairments in attention and psychomotor speed in relation to longer epilepsy duration were found in an adult temporal lobe epilepsy population [33]. Even though children cannot completely be compared to adults, the CLRE children in this study showed large problems on these capacities. Therefore, differences based on duration of epilepsy would not have been unexpected. Nevertheless, this was not the case.

In general, major concerns exist about potential side effects of antiepileptic drugs (AED). In this study children were included who were on high dosage monotherapy, while there were also children included on low dosages polytherapy. The level of active substance could be much higher in children on monotherapy than in children on polytherapy. Therefore, drug load is used in stead of a comparison of monotherapy with polytherapy. Drug-induced impairments of memory, attention and mental speed are described as cognitive side effects of AED in literature $[28,29]$. Since these are exactly the problems found in CLRE, effects of drug load were suspected. However, no effects of drug load were found.

The last factor in this study that might influence the neuropsychological profile of CLRE is age at onset. For other types of epilepsy, it is described that an early age at onset is associated with worse cognitive functioning and lower intellectual status $[15,19,22,24,25]$. In line with this, we found that age at onset is also of great influence for children with CLRE. Children with an early age at onset (0-6 years) performed, overall, worse than children with a middle (6-9 years) or a late (9-14 years) age at onset. Furthermore, children with a middle age at onset performed, overall, worse than children with a late age at onset. Most of these findings were no longer significant after a Bonferroni correction. Only the tapping task still shows significant differences.

Some explanations for the effect of age at onset have been suggested. Firstly, an early age at onset can interfere with brain development for example by affecting myelination and reducing cell numbers and cell size. Disruption of these neuronal processes during certain critical phases of neurodevelopment may lead to long term 
impairments in cognitive functioning [13,33,34,35]. Secondly, an early age at onset might also be of risk since the brain was not yet able to develop a reserve capacity to deal with subsequent loss [36]. And lastly, an early age at onset may be equivalent to a greater number of seizures during lifetime, which is suggested to be a risk factor for cognitive deterioration [13].

The question arises whether this profile is characteristic for children with CRLE or whether this profile might be characteristic for children with epilepsy in general. No conclusive answer can be given to this question yet.

In case of symptomatic localization related epilepsies (SLRE), the cognitive deficits will be a reflection of the underlying pathology. Both the localization and the size of the lesion will be of influence. It is possible that some children with SLRE appear to have the same cognitive profile as children with CLRE, while many other children might have a complete different profile. Because of the involvement of both hemispheres in idiopathic generalized epilepsies, a profile of relatively diffuse and generalized cognitive dysfunction might be expected. In most idiopathic epilepsies, cognition is only mildly deteriorated or even within the normal range [19].

Hence, this profile seems characteristic for children with CLRE. Though, to find more conclusive answers to this question, further research should be done on neuropsychological profiles in different epilepsy types and syndromes.

In conclusion: children with CLRE seem to have a characteristic neuropsychological profile that is not affected by temporary factors, such as seizure type, seizure frequency, duration of epilepsy or drug load. Therefore, it represents a stable pattern. The patients may benefit from early detection of CLRE and consequent epilepsy treatment including pedagogical and academic support. 


\section{References}

1. Aldenkamp, A. P., Weber, B., Overweg-Plandsoen, W. C., Reijs, R., \& van Mil, S. (2005). Educational underachievement in children with epilepsy: a model to predict the effects of epilepsy on educational achievement. J Child Neurol, 20(3), 175-180.

2. Berg, A. T., Lin, J., Ebrahimi, N., Testa, F. M., Levy, S. R., \& Shinnar, S. (2004). Modeling remission and relapse in pediatric epilepsy: application of a Markov process. Epilepsy Research, $60(1), 31-40$.

3. Eriksson, K. J., \& Koivikko, M. J. (1997). Prevalence, classification, and severity of epilepsy and epileptic syndromes in children. Epilepsia, 38(12), 1275-1282.

4. Waaler, P. E., Blom, B. H., Skeidsvoll, H., \& Mykletun, A. (2000). Prevalence, classification, and severity of epilepsy in children in western Norway. Epilepsia, 41(7), 802-810.

5. Commission on Classification and Terminology of the International League Against Epilepsy. Proposal for revised classification of epilepsies and epileptic syndromes. (1989). Epilepsia, 30(4), 389-399.

6. Reijs, R. P., van Mil, S. G., van Hall, M. H., Arends, J. B., Weber, J. W., Renier, W. O., et al. (2006). Cryptogenic localization-related epilepsy with childhood onset: The problem of definition and prognosis. Epilepsy \& Behavior, 8(4), 693-702.

7. Camfield, P., \& Camfield, C. (2002). Epileptic syndromes in childhood: clinical features, outcomes, and treatment. Epilepsia, 43 Supp/ 3, 27-32.

8. Berg, A. T., Shinnar, S., Levy, S. R., Testa, F. M., Smith-Rapaport, S., Beckerman, B., et al. (2001). Twoyear remission and subsequent relapse in children with newly diagnosed epilepsy. Epilepsia, 42(12), 1553-1562.

9. Shinnar, S., O'Dell, C., \& Berg, A. T. (1999). Distribution of epilepsy syndromes in a cohort of children prospectively monitored from the time of their first unprovoked seizure. Epilepsia, 40(10), 1378-1383.

10. Oostrom, K. J., Schouten, A., Kruitwagen, C. L., Peters, A. C., \& Jennekens-Schinkel, A. (2003). Behavloral problems in children with newly diagnosed idiopathic or cryptogenic epilepsy attending normal schools are in majority not persistent. Epilepsia, 44(1), 97-106.

11. Aldenkamp, A., \& Arends, J. (2004). The relative influence of epileptic EEG discharges, short nonconvulsive seizures, and type of epilepsy on cognitive function. Epilepsia, 45(1), 54-63.

12. Hoie, B., Mykletun, A., Sommerfelt, K., Bjornaes, H., Skeidsvoll, H., \& Waaler, P.E. (2005). Seizurerelated factors and non-verbal intelligence in children with epilepsy. A population-based study from Western Norway. Seizure, 14(4), 223-231.

13. Aldenkamp, A. P., \& Alpherts, W. C. J. (1999). Psychological assessment. In H. Meinardi (Ed.), Handbook of Clinical Neurology (part 1 ed., Vol. 72 (28), pp. 387-406). Amsterdam: Elsevier Science B.V.

14. Williams, J. (2003). Learning and behavior in children with epilepsy. Epilepsy \& Behavior, 4(2), 107-111.

15. Schoenfeld, J., Seidenberg, M., Woodard, A., Hecox, K., Inglese, C., Mack, K., et al. (1999). Neuropsychological and behavioral status of children with complex partial seizures. Dev Med Child Neurol, 41(11), 724-731.

16. Williams, J., Philips, T., Griebel, M.L., Sharp, G.B., Lange, B., Edgar, T., \& Simpson, P. (2001). Patterns of memory performance in children with controlled epilepsy on the CVLT-C. Child Neuropsychol., 7(1), 15-20.

17. Williams, J., Griebel, M.L., \& Dykman, R.A. (1998). Neuropsychological patterns in pediatric epilepsy. Seizure, $7(3), 223-8$

18. Bailet, L.L., \& Turk, W.R. (2000). The impact of childhood epilepsy on neurocognitive and behavioral performance: a prospective longitudinal study. Epilepsia, 41(4), 426-31.

19. Elger, C. E., Helmstaedter, C., \& Kurthen, M. (2004). Chronic epilepsy and cognition. Lancet Neurol, 3(11), 663-672.

20. Farwell, J., Dodrill, C., \& Batzel, L. . (1985). Neuropsychological abilities of children with epilepsy. Epilepsia 26(5), 395-400.

21. Bjornes, H., Stabell, K., Henriksen, O., \& Loyning, Y. (2001). The effects of refractory epilepsy on intellectual functioning in children and adults. A longitudinal study. Seizure, 10(4), 250-259.

22. Bourgeois, B., Prensky, A., Palkes, H., Talent, B., \& Busch, S. (1983). Intelligence in epilepsy: a prospective study in children. Annals of Neurology 14(4), 438-444.

23. Rodin, E., Schmaltz, S, \& Twitty, G. (1986). Intellectual functions of patients with childhood-onset epilepsy. Developmental Medicine and Child Neurolology, 28(1), 25-33. 
24. Fastenau, P. S., Shen, J., Dunn, D. W., Perkins, S. M., Hermann, B. P., \& Austin, J. K. (2004). Neuropsychological predictors of academic underachievement in pediatric epilepsy: moderating roles of demographic, seizure, and psychosocial variables. Epilepsia, 45(10), 1261-1272.

25. Vasconcellos, E., Wyllie, E., Sullivan, S., Stamford, L., Bulacio, J., Kotagal, P., \& Bingaman, W. (2001) Mental retardation in pediatric candidates for epilepsy surgery: the role of early seizure onset. Epilepsia, 42(2), 268-274.

26. Singhi, P., Bansal, U., Singhi, S., \& Pershad, D. (1992). Determinants of $1 Q$ profile in children with idiopathic generalized epilepsy. Epilepsia, 33(6), 1106-1114.

27. Bulteau, C., Jambaque, I., Viguier, D., Kieffer, V., Dellatolas, G, \& Dulac, O. (2000). Epileptic syndromes, cognitive assessment and school placement: a study of 251 children. Developmental Medicine and Child Neurolology, 42(5), 319-327.

28. Aldenkamp, A.P., \& Vermeulen, J. (2001). Cognitive side-effects of antiepileptic drugs. In: J.M. Pellock, W.E. Dodson, B.F.D. Bourgeois. Pediatric Epilepsy; diagnosis and therapy (2 edition, pp. 629-636). New York: Demos Medical Publishing.

29. Lagae, L. (2006). Cognitive side effects of anti-epileptic drugs. The relevance in childhood epilepsy. Seizure, 15(4), 235-241.

30. Northcott, E., Connolly, A.M., Berroya, A., Sabaz, M., Mclntyre, J., Christie, J., et al. (2005). The neuropsychological and language profile of children with benign rolandic epilepsy. Epilepsia, 46(6), 924-930.

31. Kema, G. M., \& Kema-van Leggelo, M. K. G. (1987). Handleiding G.S.O. [Manual Groninger school onderzoek]. Lisse: Swets\&Zeitlinger.

32. Reijs, R.P., van Mil, S.G.M., Arends, J.B.A.M., van Hall, M.H.J.A., Weber, J.W., Renier, W.O., \& Aldenkamp, A.P. (2007). Cryptogenic Localization Related Epilepsy in children from a tertiary outpatient clinic: Is neurological and neuropsychological outcome predictable? Clinical Neurology and Neurosurgery, 109(5), 422-430.

33. Piazzini, A., Turner, K., Chifari, R., Morabito, A., Canger, R., \& Canevini, M. P. (2006). Attention and psychomotor speed decline in patients with temporal lobe epilepsy: A longitudinal study. Epilepsy Research, 72(2-3), 89-96.

34. Renier, W.O. (1987). Restrictive factors in the education of children with epilepsy from a medical point of view. In: A.P. Aldenkamp, W.C.J. Alpherts, H. Meinardi, \& G. Stores (Eds.) Education and epilepsy (pp 314). Berwyn, Swets and Zeitlinger.

35. Strauss, E., Loring, D., Chelune, G., Hunter, M., Hermann, B., Perrine, K., et at. (1995). Predicting cognitive impairment in epilepsy: findings from the Bozeman epilepsy consortium. Journal of Clinical \& Experimental Neuropsychology, 17(6), 909-917.

36. Thompson, P. J., \& Duncan, J. S. (2005). Cognitive decline in severe intractable epilepsy. Epilepsia, $46(11), 1780-1787$. 


\title{
Chapter 4
}

\author{
The effect of duration of epilepsy \\ on IQ in children with CLRE; a \\ comparison to SLRE and IGE
}

Published as:

van Mil, SGM, Reijs, RP, van Hall, MHJA, Aldenkamp, AP. (2008)

The effect of duration of epilepsy on IQ in children with CLRE; a comparison to SLRE and IGE.

Seizure, 17(4): 308-13. 


\section{Abstract}

Up to one third of the children with epilepsy are classified as having cryptogenic localization epilepsy (CLRE). Unfortunately, not much is known on the prognosis of $C L R E_{;}$it is assumed to be somewhere between the benign course of many idiopathic epilepsies and the more malignant course of most symptomatic epilepsies. The risk of cognitive decline over time seems to be increased for children with epilepsy, but no data are available specifically for CLRE.

This study was a systematic cross-sectional open clinical and non-randomized investigation, which included 68 children with CLRE, 24 children with symptomatic localization related epilepsy (SLRE) and 21 children with idiopathic generalized epilepsy (IGE).

One-way between-groups ANOVAs with Tukey post-hoc testing were used to test differences in demographical variables and IQ between CLRE, SLRE and IGE and to test the influence of duration of epilepsy and other epilepsy-factors on IQ. To test whether there were IQ differences between the three types of epilepsy regarding duration of epilepsy and other epilepsy-factors, the Kruskal-Wallis test was used.

In CLRE, intelligence is stable over time; IQ scores do neither improve nor deteriorate. Age at onset, seizure type, seizure frequency and the use of AED appeared to have no influence on intelligence in CLRE. Furthermore, over time, there appeared to be no differentiation regarding IQ between CLRE, SLRE and IGE. 


\section{Introduction}

Up to one third of the children with epilepsy are diagnosed with cryptogenic localization epilepsy (CLRE) $[1,2,3]$. The term cryptogenic refers to a disorder whose cause is occult. It is presumed to be symptomatic, but the aetiology is not known. Localization related means that the seizure semiology or EEG findings at investigation disclose a localized origin of the seizures [4].

Unfortunately, the prognosis of CLRE is still unclear [5]. Camfield and Camfield [6] described a benign clinical course for about half of the children with CLRE, while for the other half, the outcome was uncertain. Also, both high remission rates $[7,8]$ and frequent relapses $[8,3]$ are described. Currently, the clinical prognosis of CLRE is assumed to be somewhere between the benign course of many idiopathic epilepsies and the more malignant course of most symptomatic epilepsies. This is confirmed by Dunn et al. [9] who studied the severity of paediatric epilepsy syndromes. Each syndrome was rated on a 10-point scale, with 1 being least severe and 10 being most severe. On this scale, CLRE scored 7 , symptomatic localization related epilepsies scored between 5 and 9 and idiopathic generalized epilepsies scored between 2 and 6.

Cognitive impairment is the most common comorbidity in epilepsy [10]. As yet it is unclear whether there is a specific risk to develop cognitive impairments for children with CLRE. Elger et al. [11] described that in most idiopathic epilepsies, cognition is normal or only mildly detoriated, while CLRE and symptomatic localization related epilepsy are accompanied by focal deficits. Bulteau et al. [12] and Nolan et al. [13] both described that children with symptomatic or cryptogenic generalized epilepsies had significantly lower $I Q$ scores than children with localization related epilepsies or idiopathic generalized epilepsies. Aldenkamp et al. [10] found lower $1 Q$ scores for children with localization related epilepsies and symptomatic generalized epilepsies than for children with idiopathic generalized epilepsies.

An important issue for prognosis is whether cognitive decline occurs over time. Some studies have shown intellectual deterioration in the course of epilepsy $[11,13,14,15,16]$. Bjornes et al. [17] described that children with a shorter seizure history had higher IQs than children with a longer duration of epilepsy. However, Aldenkamp et al. [18] could not find significant drops in mean IQ scores in a 4-year follow-up of children with epilepsy. The risk of cognitive decline over time seems to be increased for children with epilepsy, but no data are available specifically for CLRE.

The aim of this study is to investigate the influence of duration of epilepsy in a group of children with CLRE; are there IQ differences on short, middle and long term?

Furthermore, we will try to objectify the position of CLRE in comparison to symptomatic localization related epilepsy (SLRE) and idiopathic generalized epilepsy (IGE). 


\section{Patients and methods}

Design

A systematic cross-sectional open clinical and non-randomized design was used.

Subject selection

A total of 113 children and adolescents were included consecutively in this study. All these patients were referred to a specialized expert team in our epilepsy centre between January 1999 and December 2004 for assessment of relationships between epilepsy and learning difficulties.

The inclusion criteria were age between 6 and 16 years, the results of a WISC had to be available and a diagnosis of CLRE, SLRE or IGE made or confirmed by one of our (child) neurologists following the 1989 revised ILAE classification [4].

\section{Assessment procedures}

All patients were assessed with the Revised Wechsler Intelligence Scale for Children (WISC-R). The scale consists of six verbal subtests (information, similarities, arithmetic, vocabulary, comprehension and digit span) and of six performance subtests (picture completion, picture arrangement, block design, object assembly, coding and mazes). The verbal subtests measure acquired knowledge, verbal reasoning and comprehension of verbal information and the performance subtests measure nonverbal reasoning, spatial processing skills, attentiveness to detail and visuomotor integration.

Full-scale IQ (FSIQ), Verbal IQ (VIQ) and Performance IQ (PIQ) were computed.

\section{Statistical analysis}

Data were collected on record forms and entered into a database. To analyse these data, the Statistical Package for Social Sciences (SPSS), version 14.0 for Windows, was used.

Differences in demographical variables between CLRE, SLRE and IGE were tested using an one-way between-groups ANOVA with Tukey post-hoc testing in case of continuous variables and a Chi-square test in case of categorical variables.

IQ-differences between CLRE, SLRE and IGE were analysed using a one-way between-groups ANOVA, with Tukey post-hoc testing.

To analyse the influence of duration of epilepsy on intellectual functioning in CLRE, the children were subdivided into subgroups with a different duration of epilepsy; 0 48 months, 49-96 months and 97-168 months. The first category represents the newly diagnosed patients, the last category, patients with chronic epilepsy. The influence of duration of epilepsy was analysed using a one-way between-groups ANOVA. Post-hoc analysis was done using the Tukey-test. 
Other epilepsy characteristics have been documented in relation to cognitive impairment. These have to be controlled, to find out whether duration of epilepsy is the primary factor and is not confounded by other factors. The most important epilepsyfactors are seizure type $[15,19,20,21,22]$, seizure frequency $[13,16,17,20,21]$, age at onset $[11,13,20,23,24,25]$ and the use of anti-epileptic drugs (AED) $[13,15,20,21,26]$. To analyse the influence of these factors a one-way between-groups ANOVA, with Tukey post-hoc testing, was used. In case of a comparison between two groups, the Independent-Samples T-Test was done.

To analyse whether the influence of duration of epilepsy on $I Q$ is different for the three types of epilepsy, all children were subdivided in the above mentioned categories. To control for other epilepsy factors, IQ differences between CLRE, SLRE and IGE within age at onset, seizure type, seizure frequency and the use of AED were analysed. Both of these analyses were done by using the Kruskal-Wallis test.

A significance level of $5 \%$ was used.

\section{Results}

The cohort consisted of 68 children with cryptogenic localisation related epilepsy (CLRE), 24 with symptomatic localisation related epilepsy (SLRE) and 21 children with idiopathic generalised epilepsy (IGE). The demographical and clinical characteristics of these three groups are summarized in table 1.

Table 1 Demographic and clinical characteristics

\begin{tabular}{|c|c|c|c|c|c|c|}
\hline & \multicolumn{2}{|c|}{ CLRE $(n=68)$} & \multicolumn{2}{|c|}{ SLRE $(n=24)$} & \multicolumn{2}{|c|}{ IGE $(n=21)$} \\
\hline Gender $(m ; f)$ & \multicolumn{2}{|c|}{$40 ; 28$} & \multicolumn{2}{|c|}{$16 ; 8$} & \multicolumn{2}{|l|}{$6 ; 15$} \\
\hline Age (years;months) & $10 ; 3$ & $(\mathrm{sd} 2 ; 5)$ & $10 ; 1$ & $(\mathrm{sd} 3 ; 2)$ & $9 ; 1$ & $(\mathrm{sd} 2 ; 8)$ \\
\hline Age at onset (years;months) & $6 ; 3$ & $(\mathrm{sd} 3 ; 8)$ & $5 ; 0$ & $(\mathrm{sd} 3 ; 8)$ & $5 ; 2$ & (sd 3;1) \\
\hline Duration of epilepsy (years;months) & $4 ; 0$ & $(s d 3 ; 0)$ & $6 ; 3$ & $(s d 4 ; 0)$ & $4 ; 9$ & $(\mathrm{sd} 2 ; 5)$ \\
\hline \multicolumn{7}{|l|}{ Seizure type } \\
\hline Simple partial seizures & 9 & $(13.2 \%)$ & 1 & $(4.2 \%)$ & 0 & $(0 \%)$ \\
\hline Complex partial seizures & 37 & $(54.4 \%)$ & 18 & $(75 \%)$ & 0 & $(0 \%)$ \\
\hline Absences & 0 & $(0 \%)$ & 0 & $(0 \%)$ & 18 & $(85.7 \%)$ \\
\hline (secondary) generalized seizures & 22 & $(32.4 \%)$ & 5 & $(20.8 \%)$ & 3 & $(14.3 \%)$ \\
\hline \multicolumn{7}{|l|}{ Seizure frequency } \\
\hline Seizure free & 13 & $(19.1 \%)$ & 8 & $(33.3 \%)$ & 8 & $(38.1 \%)$ \\
\hline Low frequency" & 22 & $(32.4 \%)$ & 5 & $(20.8 \%)$ & 3 & $(14.3 \%)$ \\
\hline High frequency" & 33 & $(48.5 \%)$ & 11 & $(45.8 \%)$ & 10 & $(47.6 \%)$ \\
\hline \multicolumn{7}{|l|}{ Anti-epileptic drugs (AED) } \\
\hline No AED & 9 & $(13.2 \%)$ & 1 & $(4.2 \%)$ & 0 & $(0 \%)$ \\
\hline Monotherapy & 44 & $(64.7 \%)$ & 18 & $(75 \%)$ & 17 & $(81.0 \%)$ \\
\hline Polytherapy & 15 & $(22.1 \%)$ & 5 & $(20.8 \%)$ & 4 & $(19.0 \%)$ \\
\hline
\end{tabular}

low frequency: less than one seizure a month; high frequency: more than one seizure a month up to daily seizures. 
No differences between the three epilepsy cohorts existed regarding age $(F=.840$, $p=.434)$, age at onset $(F=1.247, p=.292)$, seizure frequency $\left(X^{2}=5.325, p=.256\right)$ and the use of AED $\left(X^{2}=4.721, p=317\right)$. The groups did however differ on gender $\left(X^{2}=7.643, p=.022\right)$, seizure type $\left(X^{2}=99.235, p=.000\right)$ and duration of epilepsy $(F=4.105, p=.019$; SLRE longer duration than CLRE, $p=.014)$.

Differences in IQ between the three epilepsy groups were analysed. The IQ-scores of CLRE, SLRE and IGE are summarized in table 2.

\begin{tabular}{|c|c|c|c|}
\hline & CLRE & SLRE & IGE \\
\hline Full-scale IQ & 87.74 & 82.17 & 86.57 \\
\hline Verbal IQ & 89.76 & 83.75 & 89.95 \\
\hline Performance IQ & 88.29 & 82.75 & 85.14 \\
\hline Information & 8.03 & 7.17 & 8.26 \\
\hline Similarities & 9.38 & 7.13 & 9.74 \\
\hline Arithmetic & 8.29 & 7.61 & 7.95 \\
\hline Vocabulary & 8.52 & 6.35 & 8.74 \\
\hline Comprehension & 8.51 & 7.87 & 9.00 \\
\hline Digit span & 8.25 & 8.83 & 8.16 \\
\hline Picture completion & 8.17 & 6.96 & 8.89 \\
\hline Picture arrangement & 8.98 & 7.91 & 8.79 \\
\hline Block design & 8.17 & 7.57 & 7.74 \\
\hline Object assembly & 7.14 & 7.43 & 6.58 \\
\hline Coding & 8.37 & 7.35 & 8.00 \\
\hline Mazes & 9.68 & 8.35 & 9.42 \\
\hline
\end{tabular}

General population: $1 Q$; mean $=100, s d=15$; subtests: mean $=10, s d=3$

The children with CLRE, SLRE and IGE had low average full-scale IQs; 87.7, 82.2 and 86.6.

No significant differences were found between the epilepsy groups on TIQ, VIQ or PIQ. Also most of the subtests did not show statistically significant differences, except for two of the verbal subtests: similarities $(F=5.428, p=.006)$ and vocabulary $(F=6.194, p=.003)$. On both tests children with CLRE and IGE performed significantly better than children with SLRE (similarities $p=.018, p=.008$; vocabulary $p=.014$, $\mathrm{p}=.003)$.

Next, it was studied whether IQ changes over time for CLRE patients (figure 1). For this purpose, the children with CLRE were subdivided into three categories of differ- 
ent durations of epilepsy; 0-48 months, 49-96 months and 97-168 months. No significant differences between the three duration categories were found.

To check whether other epilepsy-factors influence IQ in CLRE, age at onset, seizure type, seizure frequency and the use of AED were analysed. Age at onset was subdivided into three categories: 0-48 months, 49-96 months and 97-168 months. No significant IQ differences were found between these categories. Seizure type was subdivided into simple partial seizures (SPS), complex partial seizures (CPS), (secondary) generalised seizures ((S)GS) and absences. No significant $1 Q$-differences were found between these seizure categories. Seizure frequency was subdivided into seizure free, low seizure frequency and high seizure frequency. No significant IQ differences were found between these categories. The use of anti-epileptic drugs (AED) was also subdivided into three categories; no AED, monotherapy and polytherapy. No significant IQ differences were found between these categories.

We also looked at IQ differences between CLRE, SLRE and IGE over time (figure 1). Again, the children were subdivided into three categories of short (0-48 months), middle (49-96 months) and long (97-168 months) duration of epilepsy. Within these categories, no significant differences were found between CLRE, SLRE and IGE. However, on the long term, there was a trend towards significance on the verbal $I Q$ $\left(X^{2}=5.148, p=.076\right)$.

To control for other epilepsy factors, we analysed whether there were $1 Q$ differences between CLRE, SLRE and IGE within age at onset, seizure type, seizure frequency and the use of AED. No significant $I Q$ differences were found within any of these factors. 

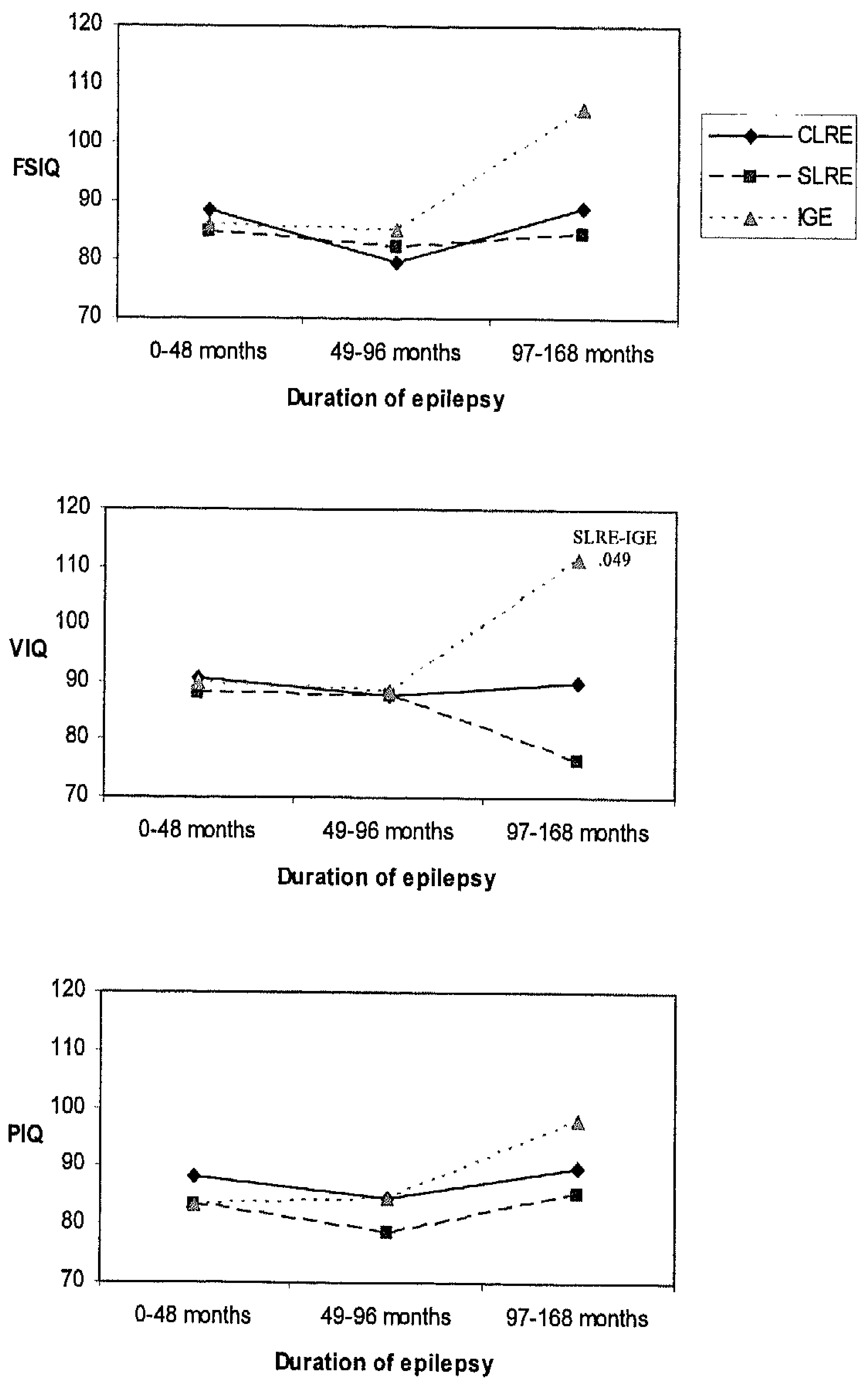

Figure 1 Duration of epilepsy

$F S \mid Q=$ full-scale $I Q, V I Q=$ verbal $I Q, P I Q=$ performance $I Q$. 


\section{Discussion}

In this study, intellectual functioning over time in a group of children with CLRE is analysed. Moreover, this is studied in relation to SLRE and IGE.

Our results show that within the group of CLRE patients, no significant IQ differences were found between children with a short (0-48 months), middle (49-96 months) and long (97-168 months) epilepsy duration. Therefore, IQ in CLRE appears to be stable over time.

We looked whether other epilepsy variables could possibly influence intellectual functioning in CLRE. In contrast to what is frequently found in literature for other types of epilepsy $[11,14,16,18]$, age at onset did not have a significant impact on intellectual performance in children with CLRE; children with an early onset did not show a lower IQ than children with a middle or late onset. Neither there were IQ differences found between children with a middle or late seizure onset. In literature, it is frequently described that complex partial or secondary generalized seizures have a large impact on cognitive functioning $[15,19,20,21,22]$. In this study, we found no IQ differences between children with simple partial seizures, complex partial seizures and secondary generalized seizures. Therefore, seizure type does not seem to influence cognition in children with CLRE. Contrary to other studies on cognitive development in children with epilepsy $[11,13,15,16,17,21]$, seizure frequency did not influence IQ in children with CLRE. Children who were seizure free for at least one year did not perform different from children with low or high seizure frequencies. Neither IQ differences were found between children with low and high seizure frequencies. In literature, it is described that polytherapy has a more severe impact on cognitive functioning than monotherapy $[15,20,21,26]$. In contrast to this, no significant IQ differences were found between children without AED, children on monotherapy and children on polytherapy. Hence, the number of AEDs does not influence cognitive functioning in children with CLRE.

Taken together, other epilepsy characteristics appeared to have no influence on the intellectual functioning of children with CLRE.

Before we started to look for differences in IQ between CLRE, SLRE and IGE, we checked whether there were differences between these three groups regarding their demographical and clinical characteristics. This was not the case for age, age at onset, seizure frequency and the use of AED. The groups did however differ on gender, seizure type and duration of epilepsy. Since gender does not influence IQ per se, this was not taken into account in the other analyses. The fact that seizure type differs between the groups is logical since most children with IGE had absences and this seizure type does not occur in CLRE and SLRE. At the same time, the seizure types occurring in CLRE and SLRE were uncommon in IGE. The fact that the group of children with SLRE had a longer duration of epilepsy than children with CLRE does not influence the other results of this study; in the rest of the analyses duration of 
epilepsy is subdivided into categories and these are the same for all types of epilepsy.

Next, we looked at IQ differences between CLRE, SLRE and IGE over time. Within the three duration categories, no significant differences were found. On the long term, there was however, a trend towards significance on the verbal $1 Q$. When comparing larger groups of children, this trend possibly reaches significance and CLRE, SLRE and IGE differentiate regarding the course of IQ.

To rule out the possibility that no differentiation was found between CLRE, SLRE and IGE because of the influence of other epilepsy-factors (age at onset, seizure type, seizure frequency and the use of AED), their influence on intellectual functioning was tested. However, no significant IQ differences were found within any of these factors.

We may conclude that intelligence in CLRE is stable over time; IQ scores do neither improve nor deteriorate. This is in line with our previous finding that children with CLRE show a stable neuropsychological profile with difficulties in mainly alertness, mental speed and memory [25]. Furthermore, in contrast to literature [6,9], there appeared to be no differentiation over time regarding IQ between CLRE, SLRE and IGE. 


\section{References}

1. Eriksson, K.J., Koivikko, M.J., 1997. Prevalence, classification, and severity of epilepsy and epileptic syndromes in children. Epilepsia 38 (12), 1275-1282.

2. Waaler, P.E., Blom, B. H., Skeidsvoll, H., Mykletun, A., 2000. Prevalence, classification, and severity of epilepsy in children in western Norway. Epilepsia 41 (7), 802-810.

3. Berg, A.T., Lin, J., Ebrahimi, N., Testa, F.M., Levy, S.R., Shinnar, S., 2004. Modeling remission and relapse in pediatric epilepsy: application of a Markov process. Epilepsy Res 60 (1), 31-40.

4. Commission on Classification and Terminology of the International League Against Epilepsy., 1989. Proposal for revised classification of epilepsies and epileptic syndromes. Epilepsia $30(4), 389-399$.

5. Reijs, R.P., van Mil, S.G.M., van Hall, M. H.J.A., Arends, J.B.A.M., Weber, J.W., Renier, W.O., Aldenk amp, A.P., 2006. Cryptogenic localization-related epilepsy with childhood onset: The problem of definition and prognosis. Epilepsy Behav 8 (4), 693-702.

6. Camfield, P., Camfield, C., 2002. Epileptic syndromes in childhood: clinical features, outcomes, and treatment. Epilepsia 43 (Suppl 3), 27-32.

7. Shinnar, S., O'Dell, C., Berg, A.T., 1999. Distribution of epilepsy syndromes in a cohort of children prospectively monitored from the time of their first unprovoked seizure. Epilepsia 40 (10), 1378-1383.

8. Berg, A.T., Shinnar, S., Levy, S.R., Testa, F.M., Smith-Rapaport, S., Beckerman, B., Ebrahimi, N., 2001. Two-year remission and subsequent relapse in children with newly diagnosed epilepsy. Epilepsia 42 (12), $1553-1562$.

9. Dunn, D.W., Buelow, J.M., Austin, J.K., Shinnar, S., Perkins, S.M., 2004. Development of syndrome severity scores for peadiatric epilepsy. Epilepsia $45(6), 661-666$.

10. Aldenkamp, A.P., Weber, B., Overweg-Plandsoen, W.C., Reijs, R., van Mil, S., 2005. Educational underachievement in children with epilepsy: a model to predict the effects of epilepsy on educational achievement. J Child Neurol, 20 (3), 175-180.

11. Elger, C.E., Helmstaedter, C., Kurthen, M., 2004. Chronic epilepsy and cognition. Lancet Neurol 3 (11), 663-672.

12. Bulteau C., Jambaque, I., Viguier, D., Kieffer, V., Dellatolas, G., Dulac, O., 2000. Epileptic syndromes, cognitive assessment and school placement : a study of 251 children. Dev Med Child Neurol 42 (5), 319327.

13. Nolan, M.A., Redoblado M.A., Lah, S., Sabaz, M., Lawson, J.A., Cunningham, A.M., Bleasel, A.F., Bye A.M., 2003. Intelligence in childhood epilepsy syndromes. Epilepsy Res 53 (1-2), 139-150.

14. Strauss, E., Loring, D., Chelune, G., Hunter, M., Hermann, B., Perrine, K., Westerveld, M., Trenerry, M., Barr, W., 1995. Predicting cognitive impairment in epilepsy: findings from the Bozeman epilepsy consortium. J Clin Exp Neuropsychol 17 (6), 909-917.

15. Hoie, B., Mykletun, A., Sommerfelt, K., Bjornaes, H., Skeidsvoll, H., Waaler, P.E., 2005. Seizure related factors and non-verbal intelligence in children with epilepsy: a population based study from WesternNorway. Seizure 14 (4), 223-231

16. Thompson, P.J., Duncan, J.S., 2005. Cognitive decline in severe intractable epilepsy. Epilepsia 46 (11), 1780-1787.

17. Bjornes, H., Stabell, K., Henriksen, O., Loying, Y., 2001. The effects of refractory epilepsy on intellectual functioning in children and adults. A longitudinal study. Seizure 10 (4), 250-259.

18. Aldenkamp, A.P., Alpherts, W.C.J., De Bruine-Seeder, D., Dekker, M.J.A., 1990. Test-retest variability in children with epilepsy - a comparison of WISC-R profiles. Epilepsy Res 7,165-172.

19. Aldenkamp, A.P., Alpherts, W.C.J., 1999. Handbook of Clinical Neurology, Elsevier Science B.V., Amsterdam, pp. 387-406.

20. Schoenfeld, J., Seidenberg, M., Woodard, A., Hecox, K., Inglese, C., Mack, K., Hermann, B., 1999. Neuropsychological and behavioral status of children with complex partial seizures. Dev Med Child Neurol 41 (11), 724-731.

21. Bailet, L.L., Turk, W.R., 2000. The impact of childhood epilepsy on neurocognitive and behavioural performance: a prospective longitudinal study. Epilepsia, 41 (4), 426-431.

22. Williams, J., 2003. Learning and behavior in children with epilepsy. Epilepsy Behav 4 (2), 107-111.

23. Fastenau, P.S., Shen, J., Dunn, D.W., Perkins, S.M., Hermann, B.P., Austin, J.K., 2004. Neuropsychological predictors of academic underachievement in pediatric epilepsy: moderating roles of demographic, seizure, and psychosocial variables. Epilepsia $45(10), 1261-1272$. 
24. Piazzini, A., Turner, K., Chifari, R., Morabito, A., Canger, R., Canevini, M. P., 2006. Attention and psychomotor speed decline in patients with temporal lobe epilepsy: A longitudinal study. Epilepsy Res 72 (23), 89-96.

25. van Mil, S.G.M., Reijs, R.P., van Hall, M.H.J.A., Aldenkamp, A.P., 2007. Neuropsychological profile of children with Cryptogenic Localization Related Epilepsy. Accepted for publication in Child Neuropsychology, acceptance date June $4^{\text {th }} 2007$

26. Aldenkamp, A.P., De Krom, M., Reijs, R., 2003. Newer antiepileptic drugs and cognitive issues. Epilepsia 44 (Suppl 4), 21-29. 


\section{Chapter 5}

\section{Behavioral status of children with cryptogenic localization related epilepsy}

Accepted for publication as:

van Mil, SGM, Reijs, RP, van Hall, MHJA, Snoeijen, SM, \& Aldenkamp, AP

Behavioral status of children with cryptogenic localization related epilepsy. Journal of Child Neurology

Acceptance date: August $20^{\text {th }} 2008$ 


\begin{abstract}
Using the Child Behavior Checklist, behavior of 51 children with cryptogenic localization related epilepsy was studied.

According to parent report, children with cryptogenic localization related epilepsy scored in the clinical range on the subscales 'internalizing behavior', 'total behavior' and 'attentional problems'. No relation between the epilepsy factors seizure frequency, age at onset, duration of epilepsy or the number of anti-epileptic drugs and the subscales of the Child Behavior Checklist was found. Only for seizure type a relationship was found. Although in the normal range, the more severe the seizure type, the more delinquent, aggressive and externalizing behavioral problems.

Other studies have demonstrated that in children with epilepsy, internalizing problems are more common than externalizing problems, and that attentional, social and thought problems are relatively specific. Therefore, we can conclude that the behavioral problems we found in our cohort are not very different from behavioral problems described in other epilepsy types.
\end{abstract}




\section{Introduction}

Epilepsy is the most common neurological disorder in childhood. In general, children with epilepsy are known to have an increased risk for behavioral problems $[1,2,3,4,5]$. Moreover, children with epilepsy appear to have substantially more behavioral problems than children with other chronic illnesses, such as diabetes, asthma, heart diseases, and rheumatoid arthritis $[1,2,4,6,7]$.

Behavioral problems can roughly be subdivided into internalizing and externalizing problems. Internalizing problems refer to problems like withdrawal, somatic complaints, anxiety and depression. Externalizing behavior refer to problems like delinquency and aggression. In general, externalizing behavioral problems get more attention than internalizing behavioral problems since this kind of behavior is visible and annoying to the child's environment. However, despite of the fact that internalizing behavioral problems are less noticeable to the child's environment, the consequences for developing children are not less serious.

Children with epilepsy show behavioral problems in the whole range, although internalizing behavioral problems are more common than externalizing problems $[1,8,9]$. Attentional problems, thought problems, social problems, somatic complaints, and withdrawal are frequently described $[2,3,7,8]$. Rodenburg et al. [1] found that attentional problems, social problems and thought problems are relatively specific to children with epilepsy in contrast to children with other chronic diseases.

In literature, several epilepsy-related factors are suggested representing potential etiologies of psychopathology in epilepsy. Age at onset, duration of the epilepsy, seizure type, seizure frequency and the number of used anti-epileptic drugs are all studied previously, but the results are contradictory. Bailet and Turk [10] found no relation between age at onset and behavioral problems. However, age at onset is also described as contributor to behavioral difficulties in children with epilepsy $[8,11,12]$; both early [13] and late [14] epilepsy onset was associated with behavioral problems. Datta et al. [15] found that longer epilepsy duration was a predictor of behavioral problems, while Schoenfeld et al. [8] found no relationship between duration of epilepsy and the presence of behavioral difficulties. Also seizure type is described as predictor of behavioral problems [6,14]. Nevertheless, both Hermann et al. [13] and Bailet and Turk [10] found no correlation. Furthermore, while most studies found seizure frequency to be associated with behavioral problems $[4,6,8,13,14,15]$, Bailet and Turk [10] found no relationship. And lastly, the number of anti-epileptic drugs seems to be related to behavioral difficulties. It is described that children on monotherapy showed less behavioral disturbances than children on polytherapy $[5,12,15]$, but Schoenfeld at al. [8] found no differences between children on monoor polytherapy.

Up to one third of the children with epilepsy are diagnosed with cryptogenic localization epilepsy [16]. The term cryptogenic refers to a disorder whose cause is occult. It 
is presumed to be symptomatic, but the etiology is not known. Localization related means that the seizure semiology or EEG findings at investigation disclose a localized origin of the seizures [17].

Contrary to the knowledge on behavioral problems in epilepsy in general, more specific data are lacking on the behavioral effects of cryptogenic localization related epilepsy. Oostrom et al. [18] found that children with cryptogenic epilepsy were having more behavioral problems than children with idiopathic epilepsy or controls. After a follow up of three to four years, they still found that children with epilepsy had more behavioral problems than healthy controls. However, no differences were found between children with an idiopathic or cryptogenic etiology [19].

The aim of this study is to investigate the behavioral status of children with cryptogenic localization related epilepsy. What kind of behavioral problems do these children have and which epilepsy-factors are related to these problems?

\section{Patients and methods}

\section{Design}

A systematic cross-sectional open clinical and non-randomized design was used.

\section{Subject selection}

Patients were included in the period 1999-2004. All patients were referred to a specialized expert team for child epileptology in our epilepsy centre between January 1999 and December 2004. In this period 620 patients with epilepsy were referred. The Child Behavior Checklist was presented to all parents of patients in the agerange of the Child Behavior Checklist. None of the parents refused to complete the scale.

The inclusion criteria were age between 6 and 16 years and a diagnosis of cryptogenic localization related epilepsy, which was made or confirmed by one of our (child) neurologists following the 1989 revised epilepsy classification of the International League Against Epilepsy'17, including normal neuroimaging. The exclusion criteria were $1 Q<70$ (children with a localization related epilepsy and an IQ below 70 were regarded as having a symptomatic etiology), absence of neuroimaging (since normal neuroimaging is one of the criteria for cryptogenic localization related epilepsy), a neurological disease other than epilepsy or any other chronic disease. After applying these inclusion- and exclusion criteria a total of 51 children remained.

This study was approved by the local Medical Ethics committee. 


\section{Assessment procedures}

During the assessment, the parents were asked to complete the Child Behavior Checklist [20].

The Child Behavior Checklist is a questionnaire for parents of children between 4 and 18 years of age. It consists of 113 behavioral items on which parents rate how well the behavior describes the behavior of their child. All these items are answered on a 3-point scale: 0 (not true or not applicable), 1 (somewhat or something true) and 2 (very or often true). The Child Behavior Checklist measures behavioral problems on 3 broadband subscales (internalizing behavior, externalizing behavior and total behavior) and 8 narrowband subscales (withdrawal, somatic complaints, anxiety / depression, social problems, thought problems, attention problems, delinquent behavior and aggressive behavior). Internalizing/externalizing behavioral patterns refers to the general dichotomy to react either with 'acting-out' behaviors or with 'withdrawal patterns'.

The narrowband scales are specific syndrome scales of the Child Behavior Checklist. They are deduced from factor analyses of the individual problem items. The broadband scales 'internalizing and externalizing behavior', are more general scales, deduced from factor analyses of the eight syndrome scales. The subscale 'internalizing behavior consists of the narrowband subscales withdrawal, somatic complaints and anxiety / depression; the subscale 'externalizing behavior' consists of the narrowband subscales delinquent behavior and aggressive behavior. The broadband subscale 'total behavior' is a calculation over all individual problem items.

The subscale scores are converted into standardized t-scores. On the narrowband scales, a t-score between 67 and 70 is seen as borderline; scores above 70 are seen as clinical scores (i.e. representing clinical relevant behavior problems). On the broadband scales, the borderline range is between 60 and 63 ; above 63 is the clinical range.

Epilepsy-related variables were recorded for each patient. Seizure type was subdivided into simple partial seizures, complex partial seizures and secondary generalized seizures. The dominant seizure type is used in the analyses. Seizure frequency was subdivided into seizure free (for at least one year), low seizure frequency (less than one seizure a month) and high seizure frequency (more than one seizure a month). The number of anti-epileptic drugs the children used was subdivided into no anti-epileptic drugs, monotherapy and polytherapy.

\section{Statistical analysis}

Data were collected on record forms and entered into a database. The Statistical Package for Social Sciences (SPSS), version 15.0 for Windows was used to analyze the data. Possible relationships between the epilepsy-factors (seizure type, seizure frequency, age at onset, duration of epilepsy and number of AED) and the behavioral subscales were studied using Pearson correlations.

Significance level was set at the $5 \%$ level. 


\section{Results}

The demographical characteristics of these children are summarized in table 1.

Table 1 Demographical characteristics of the cryptogenic localization related epilepsy cohort.

\begin{tabular}{|c|c|}
\hline$\overline{\text { Characteristic }}$ & $\mathrm{n} /$ mean \\
\hline$\overline{\mathbf{N}}$ & 51 \\
\hline \multicolumn{2}{|l|}{ Age } \\
\hline Mean & 10 years; 3 months \\
\hline \multicolumn{2}{|l|}{ Gender } \\
\hline Male / female & $26 / 25$ \\
\hline \multicolumn{2}{|l|}{ IQ } \\
\hline Full-scale IQ & 88.1 \\
\hline Verbal IQ & 90.4 \\
\hline Performance IQ & 88.2 \\
\hline \multicolumn{2}{|l|}{ Seizure type } \\
\hline Simple partial seizures & 5 \\
\hline Complex partial seizures & 30 \\
\hline Secondary generalized seizures & 16 \\
\hline \multicolumn{2}{|l|}{ Seizure frequency } \\
\hline Seizure free & 10 \\
\hline Low seizure frequency & 13 \\
\hline High seizure frequency & 28 \\
\hline \multicolumn{2}{|l|}{ Age at onset } \\
\hline Mean & 6 years; 7 months \\
\hline \multicolumn{2}{|l|}{ Duration op epilepsy } \\
\hline Mean & 3 years; 9 months \\
\hline \multicolumn{2}{|l|}{ Number of anti-epileptic drugs } \\
\hline No anti-epileptic drugs & 6 \\
\hline Monotherapy & 34 \\
\hline Polytherapy & 11 \\
\hline
\end{tabular}

*Seizure free: seizure free for at least one year; low seizure frequency: up to one seizure a month; high seizure frequency: more than one seizure a month.

The cohort consists of 51 children; 26 boys and 25 girls with a mean age of 10 years and 3 months and a mean full-scale IQ of 88.14 . The mean age at onset is approximately six-and-a-half years; the mean duration of epilepsy four years. About $60 \%$ of the children is suffering from complex partial seizures as dominant seizure type, while the others had simple partial seizures $(10 \%)$ or secondary generalized seizures $(31 \%)$ as dominant seizure type. $55 \%$ of the patients had a high seizure frequency (more than one seizure a month), $25 \%$ a low seizure frequency (less than one sei- 
zure a month) and $20 \%$ was seizure free (no seizures for at least one year). Most children $(67 \%)$ were on monotherapy.

As shown in figures $1 \mathrm{a}$ and $1 \mathrm{~b}$, most subscales of the Child Behavior Checklist were within the normal range. No subscales were in the borderline range. Children with cryptogenic localization related epilepsy scored in the clinical range on the broadband subscales 'internalizing behavior' and 'total behavior', and on the narrowband subscale 'attention problems'.

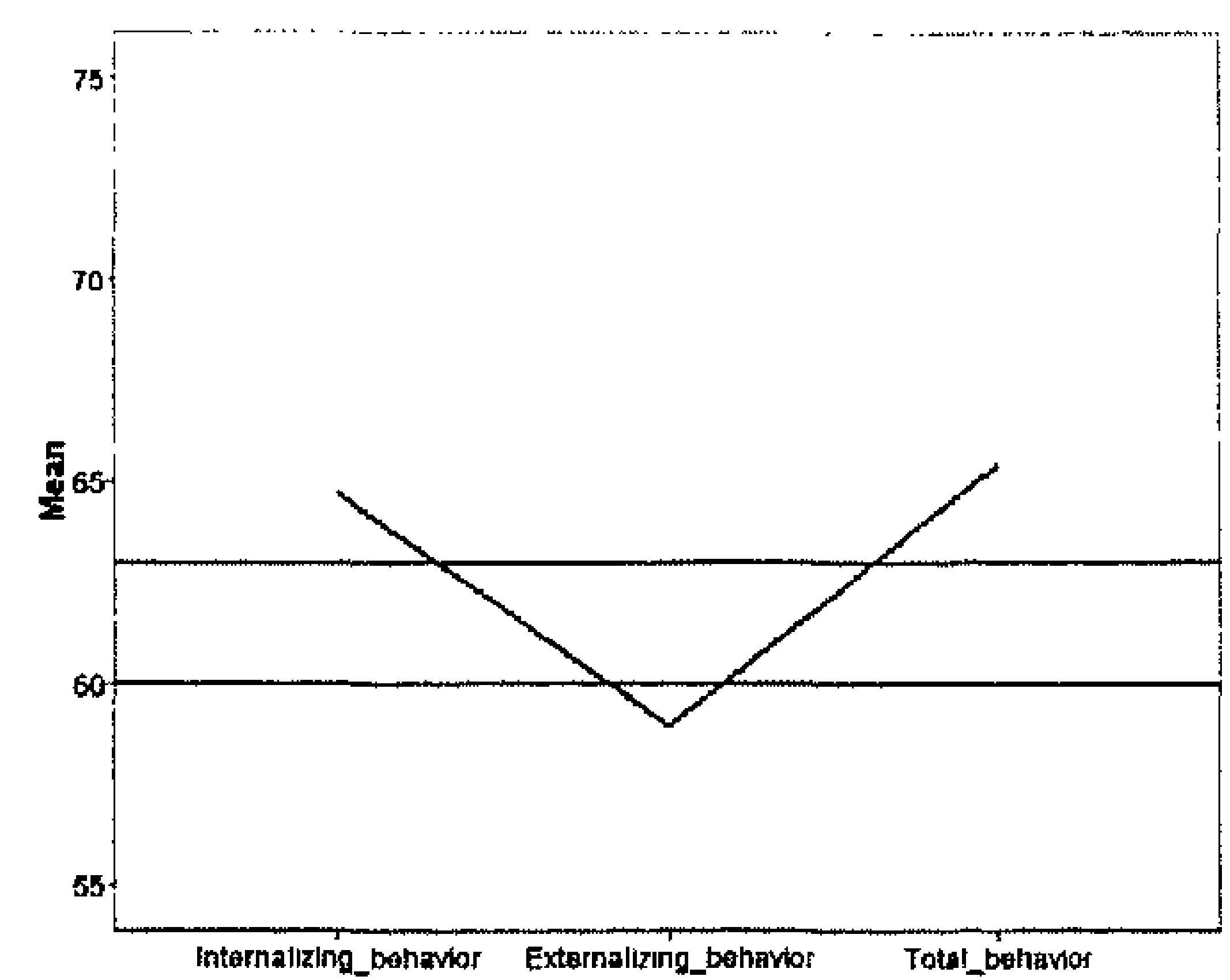

Figure 1a Broadband subscales.

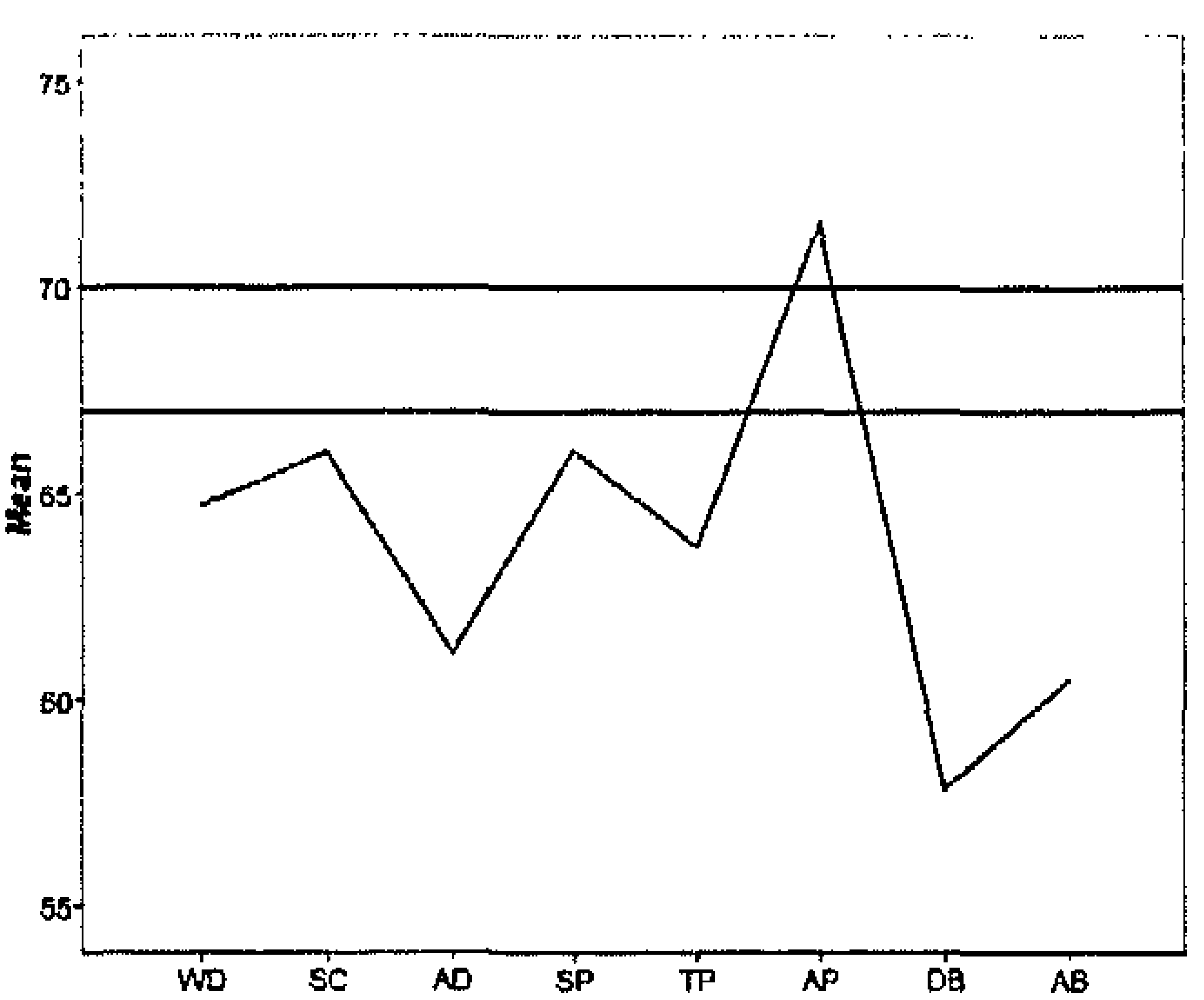

Figure 1b Narrowband subscales.

The bottom bold line indicates the borderline range; the upper bold line indicates the clinical range.

WD: withdrawal, SC: somatic complaints, AD: anxiety / depression, SP: social problems, TP: thought problems, AP: attention problems, $D B$ : delinquent behavior, $A B$ : aggressive behavior.

Next, it was studied whether the epilepsy-factors seizure type, seizure frequency, age at onset, duration of epilepsy and number of AED were possibly related to the outcome on the behavior scales. Significant positive correlations were found between seizure type and delinquent behavior $(r=.416, p=.002)$, aggressive behavior $(r=.304$, $p=.030)$ and externalizing behavior $(r=.382, p=.006)$. Even though, for the group as total, these behavioral problems scored in the normal range, children with simple partial seizures appeared to have less behavioral problems than children with complex partial seizures or secondary generalized seizures and children with complex partial seizures had less behavioral problems than children with secondary generalized seizures. In other words, the more severe the seizure type, the more likely behavioral problems were reported.

No significant correlations were found between seizure frequency, age at onset, duration of epilepsy, number of AED and the different behavioral scales. 


\section{Discussion}

This article describes a cohort study, evaluating the behavioral status of children with cryptogenic localization related epilepsy. Children were studied using the Child Behavior Checklist. Besides, the influence of several epilepsy-factors (seizure type, seizure frequency, age at onset, duration of epilepsy and the use of anti-epileptic drugs) is explored.

In literature, it is described that in general children with epilepsy have more behavioral problems than children without epilepsy $[1,2,3,4,5]$ or with other kinds of chronic illnesses $[1,2,4,6,7]$. Our finding that children with cryptogenic localization related epilepsy showed 'total behavioral problems' in the clinical range, is in line with this. Furthermore, in their meta-analysis, Rodenburg et al. [1] found that children with epilepsy have more internalizing than externalizing problems. This is confirmed in our study.

On the narrowband scales, we found children with cryptogenic localization related epilepsy to score in the clinical range on attention problems. This is in line with other studies reporting attentional problems, social problems and thought problems to be relatively specific for children with epilepsy in contrast to children with other chronic illnesses [1]. Possibly the attentional problems in cryptogenic localization related epilepsy reflect the effect of seizures. As we did not find a relationship with seizure type, it is possible that attention problems are related to suffering from seizures in general and not to any particular seizure type.

For delinquent behavior, aggressive behavior and externalizing behavior, we found that the more severe the seizure type (ranging from simple partial to secondary generalized seizures), the more serious the reported behavioral problems in children with cryptogenic localization related epilepsy. The influence of epilepsy on behavior is still debated in literature. Our findings are not in line with Bailet and Turk [10], who found no differences in behavior between children with generalized convulsive seizures, absences and complex partial seizures. Also Williams, Griebel, \& Dykman [21] found that differences in behavioral function were not based on seizure type. On the other hand, Aldenkamp and Bodde [14] report that the risk of behavioral impairment is increased for secondary generalized seizures. Hoie et al. [22] report that children with atypical absences had the highest and those with absences and simple partial seizures the lowest risk for developing psychosocial problems.

No behavioral differences were found between children who were seizure free, children with a low seizure frequency or children with a high seizure frequency. This is in contrast with many studies $[4,6,8,13,14,15]$ where a higher seizure frequency is usually associated with more behavioral problems. However, also Bailet and Turk [10] found no influence of seizure frequency on the presence of behavioral difficulties.

In accordance to Bailet and Turk [10] and Sabaz et al. [23], we did not find a relationship between age at onset and behavior. Aldenkamp and Bodde [14], however, 
reported behavioral symptoms to be associated with late seizure onset, whereas Hoie et al. [22], Hoare and Kerley [24] and Hermann et al. [13]. Hoie et al. [22] found that children with an age at onset before the age of four had more behavioral problems than children with a later onset. Hermann et al. [13] found that early age at onset was associated with increased externalizing behavior problems.

Longer duration of epilepsy is described in literature as a predictor of behavioral problems [15], although this is sometimes debated [8]. In this study, no relationship between duration of epilepsy and behavior was found for cryptogenic localization related epilepsy.

Finally the effect of anti-epileptic drug treatment (number of anti-epileptic drugs) was studied. Similar to Hoie et al. [22], we found no relationship between the number of anti-epileptic drugs and behavioral problems. Most studies $[5,12,15]$ do however find differences between children on monotherapy and children on polytherapy.

In conclusion, according to parent report, children with cryptogenic localization related epilepsy showed behavioral problems in the clinical range on the broadband subscales 'internalizing behavior problems' and 'total behavior problems', and on the narrowband subscale 'attention problems'. These behavioral problems were described to be relatively specific for children with epilepsy [1], and therefore, concerning behavior, children with cryptogenic localization related epilepsy are not very different from children with epilepsy in general.

Of the epilepsy related factors only seizure type showed a statistically significant relationship with the occurrence of behavioral problems with secondary generalized seizures associated with the highest risk. 


\section{References}

1. Rodenburg RMA, Stams GJ, Meijer AM, et al. Psychopathology in children with epilepsy: a metaanalysis. J Pediatr Psychol, 2005; 30(6): 453-468.

2. Williams J. Learning and behavior in children with epilepsy. Epilepsy Behav. 2003; 4: 107-111.

3. Keene DL, Manion I, Whiting $S$, et al. A survey of behavior problems in children with epilepsy. Epilepsy Behav. 2005; 6: 581-586.

4. Dunn DW. Neuropsychiatric aspects of epilepsy in children. Epilepsy Behav. 2003; 4: 101-106.

5. Cornaggia CM, Beghi $M$, Provenzi $M$, Beghi E. Correlation between cognition and behavior in epilepsy. Epilepsia. 2006; 47 (Suppl 2): 34-9.

6. McDermott S, Mani S, Krishnaswami S. A population-based analysis of specific behavior problems associated with childhood seizures. J Epilepsy. 1995; 8: 110-118.

7. Austin JK, Dunn DW. Chapter 37: Progressive behavioral changes in children with epilepsy. In: Sutula T, Pitkanen A. (eds.) Progress in Brain Research. Amsterdam: Elsevier Science BV.; 2002; 419-427.

8. Schoenfeld J, Seidenberg $M$, Woodard $A$, et al. Neuropsychological and behavioral status of children with complex partial seizures. Dev Med Child Neurol. 1999; 41(11): 724-731.

9. Caplan R, Siddarth P, Gurbani S, et al. Psychopathology and pediatric complex partial seizures: seizurerelated, cognitive, and linguistic variables. Epilepsia. 2004; 45(10): 1273-1281.

10. Bailet $L L$, Turk WR. The impact of childhood epilepsy on neurocognitive and behavioral performance: a prospective longitudinal study. Epilepsia. 2000; 41(4): 426-431.

11. Meador KJ, Gilliam FG, Kanner AM, Pellock JM. Cognitive and behavioral effects of antiepileptic drugs. Epilepsy Behav. 2001; 2: S1-S17.

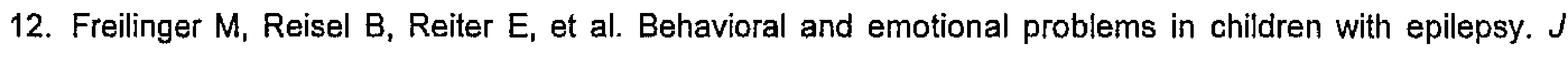
Child Neurol. 2006; 21(11): 939-45.

13. Hermann BP, Whitman S, Hughes JR, et al. Multietiological determinants of psychopathology and social competence in children with epilepsy. Epilepsy Res. 1988; 2: 51-60.

14. Aldenkamp AP, Bodde N. Behavior, cognition and epilepsy. Acta Neurol Scand. 2005; 112 (suppl 182): 19-25.

15. Datta SS, Premkumar TS, Chandy $S$, et al. Behavior problems in children and adolescents with seizure disorder: association and risk factors. Seizure, 2005; 14: 190-197.

16. Van Mil SGM, Relis RP, van Hall MHJA, \& Aldenkamp AP. Neuropsychological profile of children with cryptogenic localization related epilepsy. Child Nouropsychol. 2007; accepted for publication.

17. Commission on Classification and Terminology of the International League Against Epilepsy. Proposal for revised classification of epilepsies and epileptic syndromes. Epilepsia. 1989; 30(4): 389-399.

18. Oostrom KJ, Schouten A, Kruitwagen CLJJ, et al. Behavioral problems in children with newly diagnosed idiopathic or cryptogenic epilepsy attending normal school are in majority not persistent. Epilepsia, 2003 44(1): 97-106.

19. Oostrom KJ, van Teeseling $H$, Smeets-Schouten A, et al. Three to four years after diagnosis: cognition and behaviour in children with 'epilepsy only'. A prospective, controlled study. Brain, 2005; 128: 1546 1555.

20. Verhulst FC, van der Ende J, \& Koot HM. Handleiding voor de CBCL/4-18. Rotterdam: Afdeling kinderen jeugdpsychiatrie, Sophia Kinderziekenhuis; 1996. Dutch translation of: Achenbach TM. Manual for the child behavior checklist/4-18 and 1991 profiles. Burlington, VT: University of Vermont, Department of psychiatry; 1991.

21. Williams J, Griebel ML, \& Dykman RA. Neuropsychological patterns in pediatric epilepsy. Seizure, 1998; 7: $223-228$.

22. Hoie B, Sommerfelt $K$, Waaler PE, et al. Psychosocial problems and seizure-related factors in children with epilepsy. Dev Mod Child Neurol. 2006; 48: 213-219.

23. Sabaz M, Cairns DR, Lawson JA, et al. The health-related quality of life of children with refractory epilepsy: a comparison of those with and without intellectual disability. Epilepsia, 2001; 42: 621-628.

24. Hoare P, Kerley S. Psychosocial adjustment of children with chronic epilepsy and their families. Dev Med Child Neurol. 1991; 33: 201-215. 


\section{Chapter 6}

\section{Psychomotor and motor functioning in children with cryptogenic localization related epilepsy.}

van Mil, SGM, Reijs, RP, van Hall, MHJA, Steenbeek, L, Nieuwenhuis, S, Renier, WO, Aldenkamp, AP.

Psychomotor and motor functioning in children with cryptogenic localization related epilepsy.

Developmental Medicine and Child Neurology 


\begin{abstract}
The aim of this study is to investigate psychomotor and motor functioning in children with cryptogenic localization related epilepsy (CLRE) and to explore possible relationships between these two functions. Eighty-nine children ( 41 boys, 48 girls; mean age: 9 years, 5 months, SD: 1 year, 10 months) were included in this study. Results of reaction times measurements and motor functioning (movement Assessment Battery for Children) tasks were compared to age-related normative values. Correlations between the psychomotor and motor tasks were computed.

Manual dexterity and balance problems are present in about $35 \%$ of the children with CLRE. Ball skills are problematic in approximately $55 \%$ of the children. Simple reaction time measurements showed significantly slowing for the CLRE children relative to the reference values and also the performance on the $m-A B C$ was significantly lower than the reference values. The better the child's performance on the simple reaction time measurements, the better is his or hers performance on the $m-A B C$.
\end{abstract}




\section{Introduction}

Epilepsy is the most common chronic neurological disorder in childhood. Patients with epilepsy often have additional disabilities. Besides cognitive and behavioural disabilities [1,2], problems in motor functioning are frequently described in children with epilepsy $[3,4,5,6]$. Sometimes, motor disability is reported to be one of the most common types of comorbidity associated with epilepsy [7, 8]. Beckung and Uvebrant $[9,10]$ found problems in gross and fine motor function, balance, (bilateral) coordination, sensory parameters, running speed, response speed, upper-limb speed, and dexterity.

Furthermore, psychomotor slowing is often mentioned in relation to comorbidities of epilepsy. Aldenkamp et al. [11] found that children with epilepsy are characterized by slowing on reaction-time measurement. Also Boelen et al. [12] found a significant slowing of psychomotor speed in the group of children with epilepsy.

A relationship between cognitive and motor behaviour has been described. However, the nature of this relationship is still unclear. Since many children show problems in both areas, a continuum ranging from children who perform well on both cognitive and motor tasks to those who perform poorly on both types of tasks, can be assumed [13].

Contrary to this assumption is the finding of Boelen et al. [12]; while a significant slowing of psychomotor speed in the group with epilepsy was found, the overall motor development of children with epilepsy appeared to be comparable to controls.

Up to one third of the paediatric epilepsy population consists of children with cryptogenic localization related epilepsy (CLRE) $[14,15,16]$. The seizures have a localized origin and the cause is occult; it is presumed to be symptomatic, but the aetiology is unknown [17].

Not much is known about the course of CLRE [18]. Also the psychomotor and motor development of these children has not been mapped before.

Therefore, the aim of this study is to describe psychomotor and motor functioning of children with CLRE and to explore whether a relationship exists between these two functions. 


\section{Patients and methods}

\section{Design}

A systematic cross-sectional open clinical and non-randomized design was used.

\section{Participant selection}

A total of 89 children were included consecutively in this study. All these children were referred to a specialized expert team in our epilepsy centre for assessment in a program for children with epilepsy.

The inclusion criteria were age 6 up to and including 12 years, neuropsychological and motor screening and a diagnosis of CLRE, which was made or confirmed by one of our (child) neurologists following the 1989 revised ILAE classification [17], including normal neuroimaging. The exclusion criteria were $1 Q<70$, absence of neuroimaging, a neurological disease other than epilepsy.

To evaluate the results of the children, age-related normative values derived from standardization samples were used as reference values.

\section{Assessment procedures}

During a three day admission at our epilepsy centre, a standardized assessment battery was used containing, amongst others, motor screening and neuropsychological testing.

The following neuropsychological tests measuring psychomotor functioning were used:

Finger tapping task: measuring psychomotor speed and fluency in five consecutive trials for the index finger of the dominant and the non-dominant hand separately.

Simple reaction time measurement: the patient has to react as quickly as possible on either auditory ( $800 \mathrm{~Hz}$ tones) or visual (white square on the screen) stimuli that were presented at random intervals by the computer. This test measures psychomotor speed, activation and alertness.

To measure motor functioning, the movement Assessment Battery for Children ( $\mathrm{m}$ $A B C$ ) was used [19]. This test consists of 8 items measuring three different main motor skills of school aged children; manual dexterity, ball skills and balance.

Manual dexterity:

- speed task for each hand separately (=manual dexterity_1)

- coordination of both hands (=manual dexterity_2)

- eye-hand-coordination with the dominant hand (=manual dexterity_3)

Ball skills:

- catching a moving object (=ball skills_1)

- throwing at a target (=ball skills_2) 
Balance (static and dynamic):

- $\quad$ stand still balance (=static balance)

- dynamic balance during fast movements (=dynamic balance_1)

- dynamic balance during slow movements (=dynamic balance_2)

On each item, the child can obtain an age-adjusted score between 0 and 5 . The higher the score, the worse the performance. For the total test, the score varies between 0 and 40.

\section{Statistical analysis}

Data were collected on record forms and entered into a database. To analyse these data, the Statistical Package for Social Sciences (SPSS), version 15.0 for Windows, was used.

Differences between the 8 items (within the three main categories) were tested with the Paired Samples T-test. Differences on the tasks measuring psychomotor functioning and motor functioning between the children with CLRE and the reference values were also tested with the Paired Samples T-test. To compare the results on the psychomotor tasks and the motor tasks, Z-scores were computed.

Lastly, Pearson correlations were computed between the Z-scores of the psychomotor tasks and the motor tasks.

The significance level (two-tailed testing) was set at $5 \%$.

\section{Results}

Eighty-nine children ( 41 boys, 48 girls) with cryptogenic localization related epilepsy were included in this study. Their mean age was 9 years and 5 months (SD 1 year; 10 months). They had a mean total IQ of 89.21 , a mean verbal $I Q$ of 90.32 and a mean performance IQ of 90.06 .

The performance on the $\mathrm{m}-\mathrm{ABC}$ can be seen in table 1. About a quarter of the patients show manual dexterity movement problems. About $14 \%$ has some problems, while the rest of the children score normal on the manual dexterity items. Approximately the same distribution was found for the items measuring balance. For the ball skills the distribution is quite different; almost $40 \%$ of the children are in the range of movement problems, about $14 \%$ show some problems, while only $47 \%$ of the children score in the normal range.

The eight sub-categories of the $m-A B C$ were analyzed (see table 2 for the statistical details). Looking at the manual dexterity categories, no significant differences were found between manual dexterity_ 1 and 2 . Significant differences were found between manual dexterity_1 and 3 and between 2 and 3; eye-hand-coordination with the dominant hand appears to be better than a speed task for the separate hands or a task measuring the coordination of both hands. 
Table 1 Performance distribution of children with CLRE on the m-ABC

\begin{tabular}{lllll}
\hline Percentile & \multicolumn{1}{l}{ Manual dexterity } & Ball skills & Balance \\
\hline $0-5$ & Indication of movement-problems & $n=21$ & $n=35$ & $n=19$ \\
& & $(23.6 \%)$ & $(39.3 \%)$ & $(21.3 \%)$ \\
$5-15$ & Borderline movement-problems & $n=12$ & $n=12$ & $n=12$ \\
& & $(13.5 \%)$ & $(13.5 \%)$ & $(13.5 \%)$ \\
$>15$ & Age-adequate or above-average motor system & $n=56$ & $n=42$ & $n=58$ \\
& & $(62.9 \%)$ & $(47.2 \%)$ & $(65.2 \%)$ \\
\hline
\end{tabular}

No significant differences were found between the two items measuring ball skills. Differences were found between the dynamic balance items and the static balance item; dynamic movement during fast or slow movement is better than the stand still balance. No differences were found between dynamic balance_ 1 and 2 .

Table 2 Analyses of the eight sub-categories of the $m-A B C$.

\begin{tabular}{|c|c|c|c|c|}
\hline & Mean & & $\mathbf{t}$ & $\mathbf{p}$ \\
\hline Manual dexterity_1 & 1.719 & manual dexterity_1 vs manual dexterity_2 & 1.042 & .300 \\
\hline Manual dexterity_2 & 1.494 & manual dexterity__ 1 vs manual dexterity_3 & 3.025 & 008 \\
\hline Manual dexterity_3 & 1.034 & manual dexterity_2 vs manual dexterity_3 & 2.125 & 036 \\
\hline Ball skills_1 & 1.747 & ball skills_1 vs ball skills_2 & -.579 & .564 \\
\hline Ball skills_2 & 1.876 & & & \\
\hline Static balance & 2.107 & static balance vs dynamic balance_ 1 & 4.486 & 000 \\
\hline Dynamic balance_1 & 1.118 & static balance vs dynamic balance_2 & 6.270 & 000 \\
\hline Dynamic balance_2 & .989 & dynamic balance_1 vs dynamic balance_2 & 699 & .487 \\
\hline
\end{tabular}

The score varies between 0 and 5 per item.

The performance of the children with CLRE on the tasks measuring psychomotor functioning and the tasks measuring motor functioning were compared to reference values (table 3 \& figure 1 ).

No significant differences were found on the tapping task for the dominant hand, while the performance of the nondominant hand was even better compared to the reference values. The simple reaction time measurements showed significantly slowing for the CLRE children relative to the reference values on both the auditory and the visual tasks.

Significant differences were also found on the $m-A B C$; the performance of both the total score and the three subscores were significantly lower than the reference values.

Finally, the relationship between psychomotor functioning and motor functioning was explored. As can be seen in table 4, many significant correlations exist between the $m-A B C$ and the simple reaction time measurements. In general, the better the child's performance on the simple reaction time measurements, the better is his or hers performance on the $m-A B C$. 
Table 3 Performance on psychomotor and motor tasks compared to reference values.

\begin{tabular}{|c|c|c|c|c|c|c|c|}
\hline \multirow[b]{2}{*}{ tap_dom } & \multicolumn{3}{|c|}{ CLRE } & \multicolumn{2}{|c|}{ Reference values } & \multirow{2}{*}{$\frac{\text { t-value }}{1.533}$} & \multirow{2}{*}{$\frac{\text { p-value }}{.132}$} \\
\hline & 45.62 & (sd & $7.48)$ & 44.04 & (sd 1.30) & & \\
\hline tap_ndom & 40.05 & (sd & $7.03)$ & 37.37 & (sd 1.34) & 2.757 & .008 \\
\hline aud_dom & 340.11 & (sd 1 & 10.05) & 312.88 & (sd 20.82) & 2.435 & .017 \\
\hline aud_ndom & 338.00 & (sd 1 & $10.06)$ & 299.73 & (sd 30.65) & 3.629 & 000 \\
\hline vis_dom & 396.96 & (sd 1 & 11.49) & 325.04 & (sd 22.82) & 6.644 & .000 \\
\hline vis_ndom & 425.84 & (sd 1 & $27.00)$ & 338.96 & (sd 27.77) & 7.019 & 000 \\
\hline m-ABC_total & 12.05 & (sd & $8.12)$ & 5.06 & $\left(\begin{array}{ll}\mathrm{sd} & .93\end{array}\right)$ & 7.019 & 000 \\
\hline manual dexterity & 4.25 & (sd & $3.40)$ & 2.10 & $\left(\begin{array}{ll}\text { sd } & .00\end{array}\right)$ & 5.951 & .000 \\
\hline ball skills & 3.62 & (sd & $2.64)$ & 1.40 & $\left(\begin{array}{ll}\mathrm{sd} & .00\end{array}\right)$ & 7.934 & .000 \\
\hline balance & 4.21 & (sd & $3.76)$ & 1.30 & $\left(\begin{array}{ll}s d & .00\end{array}\right)$ & 7.315 & 000 \\
\hline
\end{tabular}

The score on manual dexterity and balance varies between 0 and 15 . The score on ball skills varies between 0 and 10. The score on $\mathrm{m}-\mathrm{ABC}$. total varies between 0 and 40 .

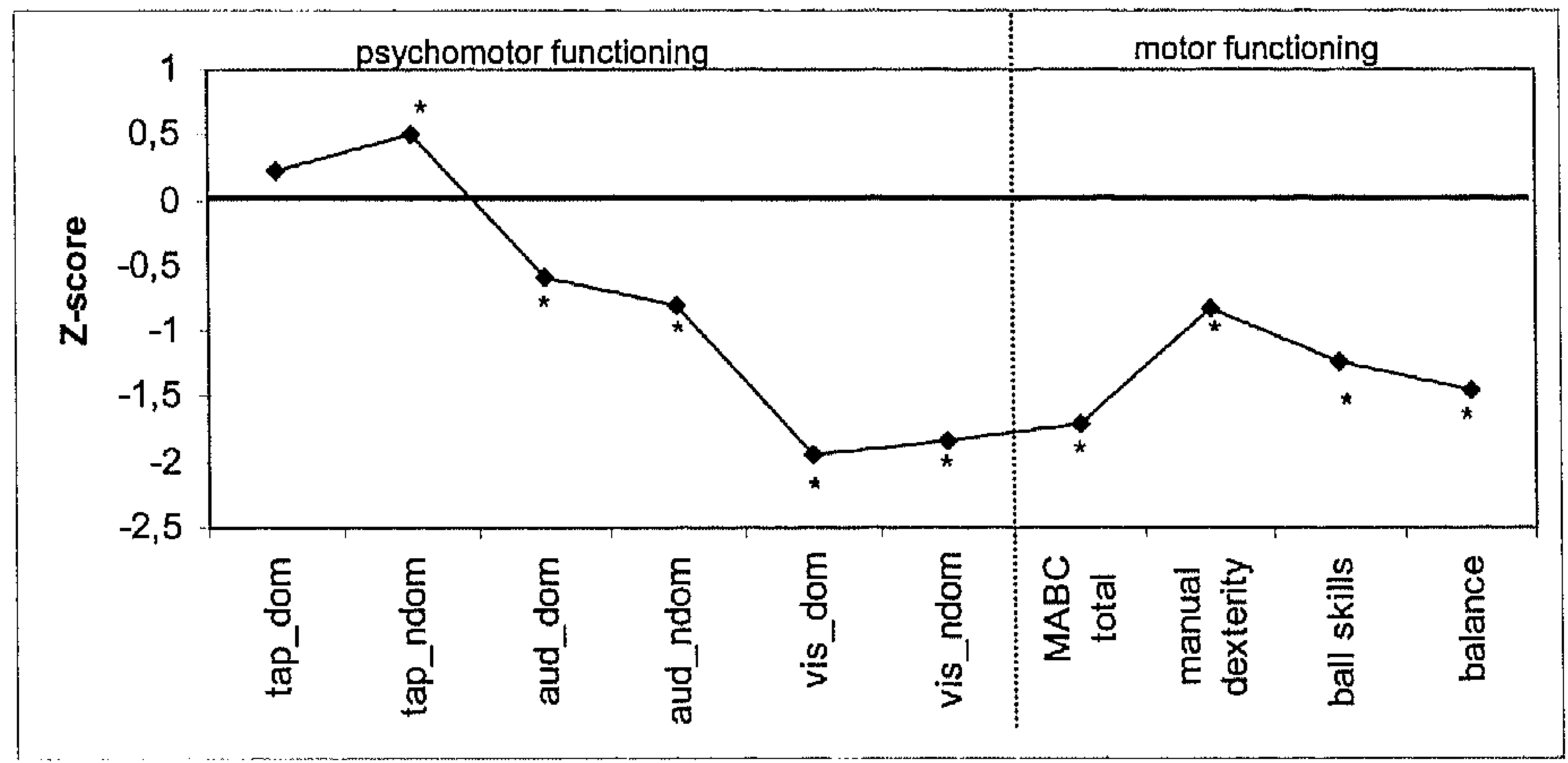

Figure 1 Performance on psychomotor and motor tasks compared to reference values.

* Significant compared to the reference $(Z=0)$

Table 4 Correlations between the $\mathrm{m}-\mathrm{ABC}$ and the psychomotor functioning tasks.

\begin{tabular}{|c|c|c|c|c|c|c|}
\hline & tap_dom & tap_ndom & aud_dom & aud_ndom & vis_dom & vis_ndom \\
\hline m-ABC_total & $\begin{array}{l}r=.198 \\
p=.168\end{array}$ & $\begin{array}{l}r=.157 \\
p=.275\end{array}$ & $\begin{array}{c}r=.334 \\
p=000\end{array}$ & $\begin{array}{l}r=.258 \\
\mathrm{p}=\mathrm{s}=\mathrm{at}\end{array}$ & $\begin{array}{c}r=.406 \\
p=000 \\
p=00\end{array}$ & $\begin{array}{l}r=.285 \\
p=007\end{array}$ \\
\hline manual dexterity & $\begin{array}{l}r=.265 \\
p=.063\end{array}$ & $\begin{array}{l}\Gamma=.154 \\
p=.287\end{array}$ & $\begin{array}{l}r=.295 \\
\mathrm{p}=005\end{array}$ & $\begin{array}{l}r=.247 \\
p=020\end{array}$ & $\begin{array}{r}r=.360 \\
p=000\end{array}$ & $\begin{array}{l}r=.270 \\
p=0101\end{array}$ \\
\hline ball skills & $\begin{array}{l}r=.198 \\
p=.168\end{array}$ & $\begin{array}{l}r=.300 \\
p=004\end{array}$ & $\begin{array}{l}r=.307 \\
p=004\end{array}$ & $\begin{array}{l}r=.237 \\
p=026\end{array}$ & $\begin{array}{l}r=.194 \\
p=.068\end{array}$ & $\begin{array}{l}r=219 \\
p=039^{2}\end{array}$ \\
\hline balance & $\begin{array}{l}\Gamma=.122 \\
p=.399\end{array}$ & $\begin{array}{l}r=.044 \\
p=.761\end{array}$ & $\begin{array}{r}r=.292 \\
0=006\end{array}$ & $\begin{array}{l}r=.270 \\
p=0.1\end{array}$ & $\begin{array}{l}r=402 \\
\mathrm{p}=000\end{array}$ & $\begin{array}{l}r=.273 \\
p=070\end{array}$ \\
\hline
\end{tabular}




\section{Discussion}

The performance of 89 children with cryptogenic localization related epilepsy (CLRE) on motor and psychomotor tasks was analysed in this study, and a possible relationship between these two functions was explored.

Looking at the items of manual dexterity and balance, more than $60 \%$ of the children score in the age-adequate or above average range, while the other children show borderline or even serious movement problems. For the ball skills items, only about half of the children score age-adequate or above average, the other half shows (serious) movement problems. This finding for ball skills collaborates with the findings of Gløersen et al. [4], who found in more than half of the children test results consistent with motor difficulties. However, they found that these problems were most pronounced in children with MRI-detectable brain lesions and symptomatic localisationrelated epilepsy; a group in which more serious problems are expected because of the underlying pathology. Assuming that scores for motor development are normally distributed in the general population, scores within two times the standard deviation are considered to be normal. This means that about $5 \%$ of the people in the normal population have an abnormal score; abnormally low (about $2.5 \%$ ) or abnormally high (about 2.5\%).

In our study, the percentages of children scoring in the problem-range are much higher; 15 times higher for manual dexterity, 14 times higher for balance and 21 higher times for ball skills. This means that in the paediatric CLRE population many more children have (serious) motor problems than in the general population.

Within these three motor categories, possible differences between the items were further analysed. For manual dexterity we found that children performed better on an eye-hand coordination task than on a speed task for the separate hands or on a task measuring the coordination of both hands. Since the task measuring the coordination of both hands is also a speed task, probably speed is the underlying factor that causes the problems here. These findings are in agreement with those of Beckung and Uvebrant [10], who described problems with dexterity. Unfortunately their study was not subdivided in different items.

We found for the ball skills no differences between "catching a moving object" and "throwing at a target". For the balance items, the performance on both dynamic balance tasks was better than the performance on the static balance task.

The performances of the CLRE children on the $\mathrm{m}-\mathrm{ABC}$ are all below the age-adjusted reference values. This is in line with many other articles describing problems in motor functioning in children with epilepsy $[3,4,5,6]$, but in contrast to Boelen et al. [12] who found the overall motor development of children with epilepsy comparable to controls. Also on the tasks measuring psychomotor speed (simple reaction times tasks), a worse performance of children with CLRE compared to reference values was found. In terms of the magnitude of the effects, psychomotor slowing ranged from $9 \%$ to 
$26 \%$ ((CLRE-reference value) / reference value). This concurs with the findings of Boelen et al. [12] and Aldenkamp et al. [11] who both found slowing of psychomotor speed. Only on the tapping task (dominant hand), measuring psychomotor speed and motor fluency, no differences were found between CLRE and the reference values. Also Boelen et al. [12] found no differences between children with epilepsy and controls on this task. However, this was probably caused by the nature of their control group, a surrogate non-epileptic control group; children who were referred to the assessment programme, but who had no epilepsy, other neurological disorders, or cognitive impairment.

For children with CLRE, apparently no problems exist on psychomotor speed per se, but when cognitive functions are needed for performing the task, psychomotor slowing emerges.

Taken all these findings together, the question remains whether a relationship between the motor problems and psychomotor slowing exist in our population. Correlational analysis between these two functions confirms this relationship; the more pronounced psychomotor slowing, the more severe the problems in motor functioning found in children with CLRE. This corresponds with the general assumption that a global relationship between cognitive and motor functioning exists.

Also Wassenberg et al. [13] have found some relationships between aspects of motor functioning and cognitive functioning. However, a more global relationship between these two areas was not found. But Boelen et al. [12] did not obtain such a relationship; while no differences in motor functioning has been found between children with and without epilepsy, children with epilepsy showed a significant slowing of psychomotor speed compared to controls.

In conclusion, children with cryptogenic localization related epilepsy have considerable motor problems. Also psychomotor slowing seems to be a problem for these children. A relationship between these two areas was found; the larger the psychomotor slowing, the larger the problems in motor functioning. However, this relation seems to be a more complex one.

Based on our results, we advise that besides the treatment of the epilepsy and the attention for cognitive problems, motor development should be monitored and whenever necessary, physical therapy should be administered. 


\section{References}

1. Aldenkamp AP, Weber B, Overweg-Plandsoen WC, Reijs R, van Mil S. (2005) Educational underachievement in children with epilepsy: a model to predict the effects of epilepsy on educational achievement. J Child Neurol 20(3): 175-180.

2. Rodenburg RMA, Stams GJ, Meijer AM, Aldenkamp AP, Dekovic M. (2005) Psychopathology in children with epilepsy: a meta-analysis. J Pediatr Psychol 30(6): 453-468.

3. van Empelen R, Jennekens-Schinkel A, Gorter JW, Volman MJM, van Nieuwenhuizen O, Helders PJM (2005) Epilepsy surgery does not harm motor performance of children and adolescents. Brain 128: $1536-$ 1545.

4. Gløersen G, Løyning T, Nakken KO. (2000) [Hidden motor dysfunctions in children with epilepsy]. Tidsskr Nor Laegeforen 120(18): 2115-2117.

5. Hernandez MT, Sauerwein HC, Jambaqué I, De Guise $E$, Lussier F, Lortie A, Dulac $O$, Lassonde $M$. (2002) Deficits in executive functions and motor coordination in children with frontal lobe epilepsy. Neuropsychologia 40(4): 384-400.

6. Maalouf M, Takahashi CD, Reinkensmeyer DJ, Cooper DM, Rho JM. (2006) Impaired motor control in patients with benign focal epilepsy of childhood. J Child Neurol 21(2): 157-160.

7. Cowan LD, Bodensteiner JB, Leviton A, Doherty L. (1989) Prevalence of the epilepsies in children and adolescents. Epilepsia 30(1): 94-106.

8. Kowalski K, Di Fabio RP. (1995) Gross motor and balance impairments in children and adolescents with epilepsy. Dev Med Child Neurol 37(7): 604-619.

9. Beckung $E$, Uvebrant P. (1993) Motor and sensory impairments in children with intractable epilepsy Epilepsia 34(5): 924-929.

10. Beckung E, Uvebrant P. (1997) Hidden dysfunction in childhood epilepsy. Dev Med Child Neuro/ 39(2): 72-78.

11. Aldenkamp AP, van Bronswijk K, Braken M, Diepman LAM, Verwey LEW, van de Wiftenboer, G. (2000) A clinical comparative study evaluating the effect of epilepsy versus ADHD on timed cognitive tasks in children. Child Neuropsychol 6(3): 209-217.

12. Boelen $S$, Nieuwenhuis $S$, Steenbeek $L$, Veldwijk $H$, van de Ven-Verest $M$, Tan IY, Aldenkamp AP. (2005) Effect of epilepsy on psychomotor function in children with uncomplicated epilepsy. Dev Med Child Neurol 47(8): 546-550.

13. Wassenberg R, Feron FJ, Kessels AG, Hendriksen JG, Kalff AC, Kroes M, Hurks PP, Beeren M, Jolles J Vles JS. (2005) Relation between cognitive and motor performance in 5- to 6-year-old children: results from a large-scale cross-sectional study. Child Dev 76(5): 1092-1103.

14. Berg AT, Lin J, Ebrahimi N, Testa FM, Levy SR, Shinnar S. (2004) Modeling remission and relapse in pediatric epilepsy: application of a Markov process. Epilepsy Res 60(1): $31-40$

15. Eriksson KJ, Koivikko MJ. (1997) Prevalence, classification, and severity of epilepsy and epileptic syndromes in children. Epilepsia 38(12): 1275-1282

16. Waaler PE, Blom BH, Skeidsvoll $H$, Mykletun A. (2000) Prevalence, classification, and severity of epilepsy in children in western Norway. Epilepsia 41(7): 802-810.

17. Commission on Classification and Terminology of the International League Against Epilepsy. (1989) Proposal for revised classification of epilepsies and epileptic syndromes. Epilepsia 30(4): 389-399.

18. Reijs RP, van Mil SGM, van Hall MHJA, Arends JBAM, Weber JW, Renier WO, Aidenkamp AP (2006) Cryptogenic localization-related epilepsy with childhood onset: The problem of definition and prognosis. Epilepsy Behav 8(4): 693-702.

19. Henderson SE, Sugden DA. (1992) Movement MABC. London: Psychological Corporation Harcourt Brace and Co. 


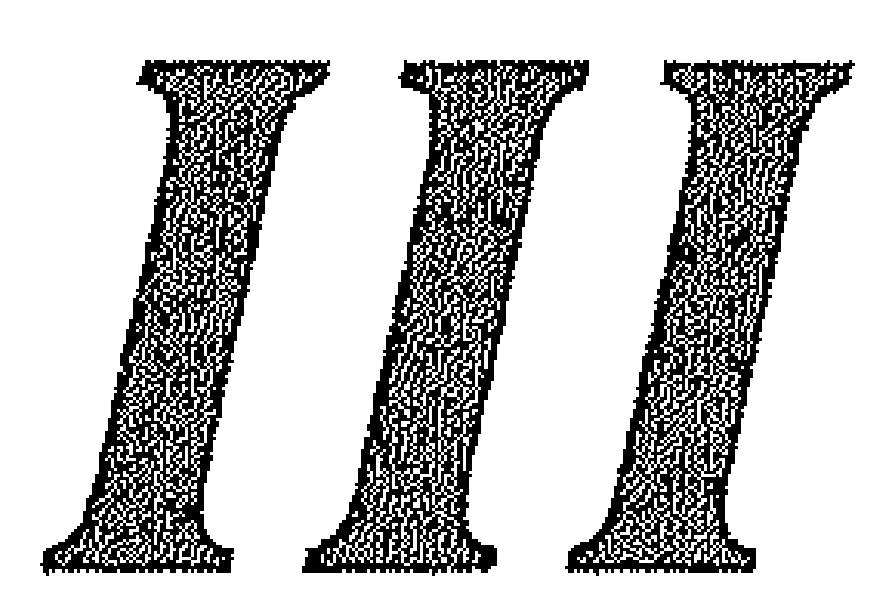

\section{Follow-up studies}




\title{
Chapter 7
}

\author{
Neuropsychological functioning in \\ children with cryptogenic \\ localization related epilepsy; a \\ follow-up study.
}

Submitted for publication as:

van Mil, SGM, Reijs, RP, van Hall, MHJA, Renier, WO, Aldenkamp, AP.

Neuropsychological functioning in children with cryptogenic localization related epilepsy; a follow-up study.

Epilepsia 


\begin{abstract}
Purpose Even though up to one third of the pediatric epilepsy population consists of cryptogenic localization related epilepsy (CLRE), not much is known about its prognosis. To determine the effect of CLRE on the neuropsychological development, we prospectively followed a cohort of children in a tertiary outpatient clinic.

Methods In this clinical and non-randomized prospective follow up study, 24 children were followed one to four years. A standardized neuropsychological assessment battery was used. Furthermore, information on various epilepsy-factors was collected. Paired Samples T-tests and Wilcoxon Signed Ranks Tests were used to analyze differences between measuring points $t_{1}$ and $t_{2}$ in epilepsy-factors and neuropsychological test results. Pearson correlations were computed to test whether changes in psychological test results were influenced by changes in epilepsy-factors. Results After a follow up of one to four years, the performance on some neuropsychological tests was unchanged, while other tests improved significantly. The tasks measuring school performances showed no improvement. Furthermore, psychoneurotic symptoms improved. Some of these changes were related to a longer follow up period. No relationship was found with the improvement in seizure frequency.

Discussion The factor time in combination with a lower seizure frequency is a possible explanation for our findings. When seizure control increases, children have the chance to regain their cognitive functions. This process goes in phases; abilities like attention, activation and memory improve first, followed by IQ-scores. The school performances (acquired abilities) improve lastly. The follow up of this study is probably too short to find this kind of improvement.
\end{abstract}




\section{Introduction}

Epilepsy is the most common neurological disorder in childhood. Up to one third of the pediatric epilepsy population consists of children with cryptogenic localization related epilepsy (CLRE) $[1,2,3]$. The term cryptogenic refers to a disorder whose cause is occult. It is presumed to be symptomatic, i.e. the result of an underlying pathology, but the etiology is not known. Localization related means that the seizure semiology or EEG findings at investigation disclose a localized origin of the seizures [4].

Frequently described comorbid disorders of epilepsy are cognitive impairment and educational underachievement [5]. Several epilepsy-factors influence these disabilities. Seizure type has often been described in relationship to cognitive impairment $[6,7,8,9,10]$. Seizure frequency seems to be a strong predictor for cognitive decline $[9,11,12]$. Also age at onset seems to be an important risk factor for cognition $[9,13,14]$. Duration of epilepsy is often linked to cognitive development $[11,12]$. Also the use of antiepileptic drugs (AED) is mentioned in relation to cognition $[9,15,16]$. And finally, interictal epileptiform activity seems to influence cognitive functioning $[17,18,19]$.

Although the CLRE population is quite large, not much is known about its prognosis [20]. In general, it is thought to be somewhere between the benign course of many idiopathic epilepsies and the more malignant course of most symptomatic epilepsies $[21,22]$.

Concerning seizure control, Berg et al. [1] suggest the existence of a wave-like pattern with recurring remissions and relapses. Furthermore, even though behavioral problems [23] and academic difficulties [17] are described before, no conclusive information exists on the neuropsychological course of children with cryptogenic localization related epilepsy.

Recently, we retrospectively studied the neuropsychological profile of a group of children with CLRE [24]. A characteristic neuropsychological profile with difficulties on a wide range of areas in particular alertness, mental speed and memory was found. This profile was not affected by varying epilepsy-factors, such as seizure type, seizure frequency, duration of epilepsy or drug load.

The question how the epilepsy interferes with the cognitive development in the long term, remains unanswered. Therefore, the aim of this study is to prospectively investigate how children with CLRE are functioning one to four years later. Furthermore, we will study whether possible changes in their performance are due to changes in epilepsy factors. 


\section{Methods}

Design

A clinical and non-randomized prospective follow up design was used. Children were assessed at baseline (first admission to our centre; $t_{1}$ ) and at follow-up 12 to 48 months later $\left(\mathrm{t}_{2}\right)$.

\section{Subject selection}

A total of 24 children were included consecutively and assessed at baseline (admission to our epilepsy centre in a child neurological program) and reassessed at endpoint. Although the children in our study were referred to a tertiary epilepsy for assessment in a multidisciplinary team, we consider them as representative for the entire CLRE population and not just for the part of the CLRE population consisting of children with more severe CLRE. The reason for this is that our program is easily accessible for physicians of primary and secondary centres. They use the program for fast multidisciplinary screening of the children. And since most patients return to their own physician after the screening, the results of the analyses are used as indication for further treatment. Consequently, all kinds of patients are referred to our screening program and not only patients with difficult-to-control seizures or severe comorbidities.

The inclusion criteria were age between 6 and 16 years and a diagnosis of CLRE, which was made or confirmed by one of our (child) neurologists following the 1989 revised ILAE classification [4], including normal neuroimaging. A previous admission to our program had to be 12 to 48 months earlier. The exclusion criteria were $I Q<70$, absence of neuroimaging, a neurological disease other than epilepsy.

The study was approved by the Medical Ethical Committee of the Maastricht University Hospital and all participants provided informed written consent prior to participation.

\section{Assessment procedures}

The children were assessed during a three day admission at our epilepsy centre. The assessment consisted of neurological investigation, EEG recording, and neuropsychological testing.

The children were assessed using the following neuropsychological tests:

\section{Intelligence:}

$I Q$ : full-scale $I Q$, verbal $I Q$ and performance $I Q$ were measured by the Revised Wechsler Intelligence Scale for Children (WISC-R). 


\section{Psychomotor speed and fluency:}

Finger tapping task: measuring motor speed and fluency in five consecutive trials for the index finger of the dominant and the non-dominant hand separately.

\section{Psychomotor speed / alertness:}

Simple reaction time measurement: the patient has to react as quickly as possible on either auditory $(800 \mathrm{~Hz}$ tones) or visual (white square on the screen) stimuli that were presented at random intervals by the computer. Activation and alertness are measured by these tests and a strong motor component is involved.

\section{Central information processing speed:}

Binary choice reaction-time measurement (BCRT): a reaction time test with a decision component. The patient has to react differentially to a red square on the left side of the screen and to a green square at the right side of the screen. The reaction time does not only reflect motor speed, but also the decision making process. Also the number of errors made during the test is included in this study.

Computerized visual searching task (CVST): an adaptation of Goldstein's Visual Searching Task. A centered grid pattern has to be compared with 24 surrounding patterns. Only one of them is identical to the target pattern. The test consists of 24 trials and gives an indication of the information processing speed and perceptual mental strategies. Also the number of errors made during the test is included in this study.

\section{Memory:}

Digit span (forwards and backwards): digit span is a subtest of the WISC. A sequence of numbers is orally presented and the child has to repeat the numbers in the same order in the forwards part and in the reversed order in the backwards part. The sequence of numbers enlarges.

The 15 word test ( 15 woordentest Kalverboer):

- Reproduction: a list of 15 words is orally presented five times. After every presentation, immediate recall is requested.

- Recall: after five consecutive trials with direct recall, a delayed recall is requested after a 20 minutes interval.

- Recognition: a list of thirty words is presented orally. The child has to say whether the word is one of the words learned earlier. The number of errors made in this part is the variable in this study.

\section{Visual motor integration:}

Beery VMI: the extent to which individuals can integrate their visual and motor abilities is measured. The test presents drawings of geometric forms arranged in order of increasing difficulty that the individual is asked to copy.

\section{School achievement:}

Reading words: a test comparable to Wide-Range Achievement Test (WRAT) in English-speaking countries. Children have to read as many words as possible in 1 minute. 
Reading sentences: a test comparable to Wide-Range Achievement Test (WRAT) in English-speaking countries. Children have to read as much sentences of a story as possible in 1 minute.

Arithmetic: a test comparable to Wide-Range Achievement Test (WRAT) in Englishspeaking countries. Children have to make as many sums as possible in five times (five columns with different kinds of sums) 1 minute.

\section{Personality factors:}

ABVK (Amsterdamse Biografische Vragenlijst voor Kinderen): the ABVK measures the degree of neuroticism during psychological testing. It gives an impression of the emotional stability and the degree of social extraversion. The ABVK includes four subscales: neurotic instability - psychoneurotic symptoms, neurotic instability - somatic symptoms, extroversion and test-attitude.

At re-admission 12 to 48 months later, the same assessments were repeated, during a two-day admission.

\section{Statistical analysis}

Data were collected on record forms and entered into a database. The Statistical Package for Social Sciences (SPSS), version 15.0 for Windows was used to analyze the data.

Differences in epilepsy-factors between $t_{1}$ and $t_{2}$, were analyzed with the Paired Samples T-test for duration of epilepsy and with the Wilcoxon Signed Ranks Test for seizure type, seizure frequency, AED treatment and interictal epileptiform activity.

Differences in performance on the psychological tests between $t_{1}$ and $t_{2}$ were tested with the Paired Samples T-test.

To test whether the changes in psychological test results were influenced by changes in the epilepsy-factors duration of epilepsy and seizure frequency, correlation analyses was done. Pearson correlations were computed between duration of epilepsy and seizure frequency and the significantly changed psychological tests.

Significance level was set at the $5 \%$ level.

\section{Results}

The cohort in this study consists of 24 children with cryptogenic localization related epilepsy (CLRE). Table 1 summarizes the demographic and clinical characteristics of these children at the first $\left(t_{1}\right)$ and second $\left(t_{2}\right)$ measuring point. 
Table 1 Demographic and clinical characteristics

\begin{tabular}{|c|c|c|}
\hline & $t_{1}$ & $t_{2}$ \\
\hline \multicolumn{3}{|l|}{ Gender } \\
\hline$m: f$ & $11: 13$ & $11: 13$ \\
\hline \multicolumn{3}{|l|}{ Age } \\
\hline mean (years;months) & $9 ; 4$ & $11 ; 8$ \\
\hline \multicolumn{3}{|l|}{ Age at onset } \\
\hline mean (years;months) & $6 ; 9$ & $6 ; 9$ \\
\hline \multicolumn{3}{|l|}{ Duration of epilepsy } \\
\hline mean (years;months) & $2 ; 6$ & $4 ; 9$ \\
\hline \multicolumn{3}{|l|}{ Seizure type } \\
\hline simple partial & 1 & 1 \\
\hline complex partial & 15 & 16 \\
\hline (secondary) generalized & 8 & 7 \\
\hline \multicolumn{3}{|l|}{ Seizure frequency } \\
\hline seizure free & 5 & 13 \\
\hline low seizure frequency & 9 & 9 \\
\hline high seizure frequency & 10 & 2 \\
\hline \multicolumn{3}{|l|}{ AED } \\
\hline no $A E D$ & 1 & 4 \\
\hline monotherapy & 18 & 15 \\
\hline polytherapy & 5 & 5 \\
\hline \multicolumn{3}{|c|}{ Interictal epileptiform activity (IEA) } \\
\hline no IEA & 9 & 16 \\
\hline$<1 \%$ IEA & 10 & 3 \\
\hline$>1 \%$ IEA & 5 & 5 \\
\hline \multicolumn{3}{|l|}{ Follow up period } \\
\hline mean (years;months) & & $2 ; 3$ \\
\hline
\end{tabular}

low seizure frequency: less than one seizure a month; high seizure frequency: more than one seizure a month.

First, we checked whether the epilepsy-factors duration of epilepsy, seizure type, seizure frequency, the number of anti-epileptic drugs and the amount of interictal epileptiform activity changed from $t_{1}$ to $t_{2}$. Because of the follow-up nature of this study, duration of epilepsy changed significantly $(t=-14.315, p=.000)$. Seizure type did not change significantly $(z=-.447, p=.665)$, neither did the number of AED $(z=-.791$, $p=.429)$ nor did the amount of interictal epileptiform activity $(z=-1.538, p=.124)$. Sejzure frequency improved significantly $(z=-3.087, p=.002)$.

Differences in performance on psychological tests between $t_{1}$ and $t_{2}$ were studied. Details are summarized in table 2 . 
Table 2 Statistical details of the neuropsychological test results

\begin{tabular}{|c|c|c|c|c|}
\hline & Mean $t_{1}$ & Mean $t_{2}$ & t-score & p \\
\hline \multicolumn{5}{|l|}{ Intelligence } \\
\hline FSIQ & 92.2 & 95.2 & -2.084 & .048 \\
\hline VIQ & 93.1 & 92.9 & .111 & .912 \\
\hline $\mathrm{PIQ}$ & 93.0 & 99.2 & -3.542 & .002 \\
\hline \multicolumn{5}{|l|}{ WISC-subtests } \\
\hline Information & 8.04 & 8.46 & -.910 & .372 \\
\hline Similarities & 10.25 & 10.21 & .089 & .930 \\
\hline Arithmetic & 9.13 & 9.88 & -1.238 & .228 \\
\hline Vocabulary & 9.21 & 8.42 & 1.961 & .062 \\
\hline Comprehension & 9.13 & 8.38 & 1.633 & .116 \\
\hline Digit span & 8.33 & 8.63 & -.603 & .552 \\
\hline Picture completion & 9.08 & 9.67 & -1.242 & .227 \\
\hline Picture arrangement & 9.54 & 10.46 & -1.771 & .090 \\
\hline Block design & 9.00 & 9.54 & -1.327 & .197 \\
\hline Object assembly & 8.46 & 8.83 & -.562 & .579 \\
\hline Coding & 8.67 & 10.13 & -2.554 & 0,0 \\
\hline Mazes & 9.83 & 10.79 & -1.870 & .074 \\
\hline \multicolumn{5}{|l|}{ Psychomotor speed / fluency } \\
\hline Tapping dominant hand & 41.1 & 51.5 & -10.444 & .000 \\
\hline Tapping non-dominant hand & 36.3 & 45.0 & -7.640 & .076 \\
\hline \multicolumn{5}{|l|}{ Psychomotor speed / alertness } \\
\hline Auditory dominant hand - reaction time & 335.9 & 265.9 & 5.205 & .000 \\
\hline Auditory non-dominant hand - reaction time & 332.3 & 275.6 & 3.569 & .002 \\
\hline Visual dominant hand - reaction time & 382.9 & 323.3 & 3.565 & .002 \\
\hline Visual non-dominant hand - reaction time & 406.2 & 340.9 & 4.705 & 000 \\
\hline \multicolumn{5}{|l|}{ Central information processing speed } \\
\hline Binary choice task - reaction time & 478.1 & 406.1 & 2.980 & 007 \\
\hline Binary choice task - errors & 7.5 & 6.0 & .803 & .431 \\
\hline CVST - reaction time & 23.7 & 15.9 & 4.395 & 001 \\
\hline CVST - errors & 4.1 & 2.8 & 1.209 & .247 \\
\hline \multicolumn{5}{|l|}{ Memory } \\
\hline Digit span forwards & 4.3 & 5.0 & -5.254 & 000 \\
\hline Digit span backwards & 3.4 & 3.5 & -1.447 & .162 \\
\hline 15 word test - reproduction & 40.9 & 49.0 & -3.907 & 001 \\
\hline 15 word test - recall & 8.6 & 10.6 & -3.197 & 004 \\
\hline 15 word test - recognition errors & 1.8 & 6 & 2.746 & 011 \\
\hline \multicolumn{5}{|l|}{ Visual motor integration } \\
\hline Beery (months delay) & -1.6 & 4.8 & -1.057 & .303 \\
\hline
\end{tabular}




\begin{tabular}{lcccc}
\hline & Mean $\mathbf{t}_{\mathbf{1}}$ & Mean $\mathbf{t}_{\mathbf{2}}$ & $\mathbf{t}$-score & $\mathbf{p}$ \\
\hline School achievement & & & & \\
$\quad$ Reading words (months delay) & 5.1 & 12.3 & -4.190 & .001 \\
Reading sentences (months delay) & 8.3 & 15.7 & -2.534 & .021 \\
Arithmetic (months delay) & 3.6 & 7.0 & -1.301 & .209 \\
Personality & & & & \\
ABVK - Neurotic instability, psychoneurotic symptoms & 53.2 & 32.1 & 2.803 & .021 \\
ABVK - Neurotic instability, somatic symptoms & 52.6 & 49.4 & .377 & .715 \\
ABVK - Extroversion & 71.7 & 79.2 & -.846 & .419 \\
ABVK - Test-attitude & 42.0 & 50.8 & -.769 & .462 \\
\hline
\end{tabular}

A significant improvement of the full-scale $I Q$ and the performance IQ was found. Verbal IQ did not change significantly. Of the subtests, only 'coding' improved significantly.

A tapping task, measuring psychomotor speed and fluency, showed a significant improvement for the dominant hand, but not for the non-dominant hand.

On the simple reaction time measurements, assessing psychomotor speed and alertness, children were significantly faster at $t_{2}$ than at $t_{1}$. This was found for the dominant and the nondominant hand in reaction to both auditory and visual stimuli. On the binary choice reaction task and the CVST (both assessing central information processing speed), significant improvements were found for the reaction times. The number of errors made by the children did not change significantly.

The memory task of the WISC [25], digit span, showed significant improvement on the forwards part. However, the backwards part did not change significantly. All three parts of the 15 word test improved significantly; children could reproduce more words, could remember more words at recall and made fewer errors at the recognition part.

A task measuring visual motor integration did not show significant differences between $t_{1}$ and $t_{2}$.

A school achievement test, comparable to the Wide-Range Achievement Test (WRAT) in English-speaking countries [26], showed a significant decline at the reading tasks, reading words and reading sentences. The arithmetic task did not show a significant change.

On the ABVK, only the scale for neurotic instability (psychoneurotic symptoms) gives a significant result; at $t_{2}$ children showed less psychoneurotic symptoms than at $t_{1}$.

Since the epilepsy-factors duration of epilepsy and seizure frequency changed significantly from $t_{1}$ to $t_{2}$, we explored in a secondary analysis whether the changes in psychological test results were influenced by these changes.

The improvements on the simple reaction time measurements were related to the change in duration of epilepsy; the larger the change in duration of epilepsy (i.e. the longer the follow up period), the larger the improvement on the simple reaction time measurements (auditory dominant hand: $r=-.472, p=.023$; auditory nondominant 
hand: $r=-.446, p=.033$; visual dominant hand: $r=-.436, p=.038$; visual nondominant hand: $r=-.496, p=.016$ ).

Also two memory tasks were related to the change in duration of epilepsy. For the digit span forwards and the recognition part of the 15 word test we found that the larger the change in duration of epilepsy, the larger the improvement on these tasks $(r=.435, p=.043$ and $r=-.463, p=.026)$.

The school achievement test reading words was also related to changes in duration of epilepsy; the larger the change in duration of epilepsy, the larger the decline on the reading task $(r=, .513, p=.025)$.

Changes in seizure frequency were not related to any of the changes in neuropsychological test results.

\section{Discussion}

The purpose of this study was to explore the cognitive development of children with CLRE. We wanted to study whether changes in epilepsy-factors (e.g. changes in seizure frequency) were influencing possible changes in cognitive functioning.

First, we checked whether several epilepsy-factors changed between the two measuring points $\left(t_{1}\right.$ and $\left.t_{2}\right)$. Duration of the follow-up was not similar for all children as this varied from one to four years. Consequently, the change in duration of epilepsy is equal to the follow-up period in this study.

The type of seizures the children are suffering from did not change from $t_{1}$ to $t_{2}$. At both moments, about two third of the children are suffering from complex partial seizures as their dominant seizure type, while almost all the others are suffering from secondary generalized seizures as dominant seizure type.

Seizure frequency improved significantly between the two measuring moments; at $t_{1}$ only $20 \%$ of the children were seizure free, while at $t_{2}$ this is increased up to more than $50 \%$. At the same time, the number of patients with a high seizure frequency (more than 1 seizure a month) decreased from about $40 \%$ to about $8 \%$. The number of patients with a low seizure frequency did not change.

The number of anti-epileptic drugs (AED) used by the children did not change significantly from $t_{1}$ to $t_{2}$; at both moments, most children were on monotherapy.

And lastly, the amount of interictal epileptiform activity (IEA) did not change significantly from $t_{1}$ to $t_{2}$. At both moments, most children had no or less than $1 \%$ of the time IEA.

Second, we checked whether there were changes in neuropsychological functioning from $t_{1}$ to $t_{2}$ and whether possible changes were related to the changes in duration of epilepsy and seizure frequency as described above. These results will be discussed and compared to earlier findings $[24,27]$ on basis of the cognitive functions that were measured by the different tests. 


\section{Intelligence:}

The full-scale and performance IQs showed a statistically significant improvement between the two measuring moments. The verbal IQ on the other hand, did not change. The improvement in performance and full-scale IQ's were mainly an effect of the statistically significant improvement in the 'coding' subtest (which is part of the performance subtests).

These changes in FSIQ, PIQ and 'coding' appeared to be unrelated to the change in duration of epilepsy or the change in seizure frequency.

Previously we reported that $I Q$ in children with CLRE was not related to duration of epilepsy; no differences were found between children with a short, middle or long epilepsy duration. We therefore concluded that intelligence in CLRE is stable over time [27]. In line with these former findings is the fact that in this study we again found no relationship between $I Q$ and follow up period. However, the 'coding' subtest is a true attention/activation test and therefore related to the reaction times tasks described below. These tasks appeared to be related to the change in duration of epilepsy. Consequently, the improved IQs are probably indirectly due to a longer follow up period.

\section{Psychomotor speed / fluency:}

A finger tapping task was used to measure psychomotor speed and fluency. Psychomotor speed increased from $t_{1}$ to $t_{2}$ for the dominant hand. For the non-dominant hand, no changes were found. There was no relationship between this improvement and the change in duration of epilepsy or seizure frequency.

In our previous study on the neuropsychological profile of children with CLRE, we found no problems for these children on the tapping task [24]. They even showed a higher motor fluency rate on the nondominant hand compared to reference values. Since the improvement in this study was found for the dominant hand and not for the non-dominant hand, the performance on the tapping task seems to be equalized for the dominant and the non-dominant hand.

The influence of age at onset described in our previous study is not a factor in this study since we compared the children with themselves now and age at onset does not change over time. Consistency between both studies is the lack of relationship with duration of epilepsy and seizure frequency.

\section{Psychomotor speed / alertness:}

Psychomotor speed and alertness were measured using an auditory and a visual reaction times task. The performance on both tasks improved from $t_{1}$ to $t_{2}$ with both the dominant as the nondominant hand. These changes appeared to be related to change in duration of epilepsy; the larger the change in duration of epilepsy, the larger the improvement on these reaction times tasks. No relationship with change in seizure frequency was found.

Previously, we described that children with CLRE performed inadequate on these tasks and this was unrelated to duration of epilepsy [24]. The results of this study 
indicate that a longer follow up probably allows the improvement in seizure frequency to result in normalization of the performance on tasks measuring psychomotor speed and alertness.

Central information processing speed:

A binary choice reaction times test (BCRT) and a computerized visual searching task (CVST) were used to measure the central information processing speed. An improvement of the reaction times was found for both tasks. No change was found for the number of errors the children made during these tasks. The better performance on these tasks was not related to changes in duration of epilepsy or seizure frequency.

In an earlier article we described no differences between CLRE and reference values on the binary choice reaction-time task, while their performance on the CVST was significantly slower [24]. The improvement on both tasks found in the current study probably reflects normalization of the performance of the children with CLRE. In both studies no relationship with duration of epilepsy or seizure frequency was found.

\section{Memory:}

Memory was measured using the digit span task of the WISC (forwards and backwards) and the 15 word test (direct reproduction, recall, number of errors made during recognition). The performance on the forwards part of the digit span improved; no changes were found on the backwards part. The improvement on the digit span forwards was related to duration of epilepsy; the larger the change in duration of epilepsy, the larger the improvement on this task. No relationship was found with changes in seizure frequency.

The digit span was not part of our previous study, so we cannot compare the results of both studies. Other short term memory tasks scored little below the reference values in our previous study [24]. The improvement on the digit span forwards in this study probably implies normalization of the performance of children with CLRE. The longer the duration of the epilepsy, the better the 'number part' of the short term memory works.

All parts of the 15 word test improved from $t_{1}$ to $t_{2}$. For the direct reproduction and the recall of the 15 word test, no relationship was found with changes in duration of epilepsy or seizure frequency. The number of errors made during the recognition part was not related to changes in seizure frequency. It was, however, related to change in duration of epilepsy; the larger the change in duration of epilepsy, the larger the improvement.

Also the short term memory part of the 15 word test improved. In our previous study, the performance on this task was relatively normal [24]. Hence, also the 'word part' of the short term memory gets better over time. However this improvement is not related to duration of epilepsy.

Long term memory tasks scored below reference values in our former study [24]. Also this function seems to normalize over time, with some aspects being influenced by duration of epilepsy. 


\section{Visual motor integration:}

Visual motor integration was measured using the Beery. No significant differences between $t_{1}$ and $t_{2}$ were found on this task.

\section{School achievement:}

School achievement was measured on three areas, reading words, reading sentences and arithmetic. The delay on both the reading tasks enlarged, while no significant changes were found on the arithmetic task. The enlarged delay on reading words was related to duration of epilepsy; the larger the follow-up, the larger the delay. No relationship exists with change in seizure frequency. Reading sentences was not related to changes in duration of epilepsy or seizure frequency.

Rather than seeing these enlarged delays as decline, it should be seen as stagnation. When children get older while no progress is seen in the development of reading, the delay in months gets larger.

Delays in educational attainment in this population have been reported before $[17,24]$.

\section{Personality:}

Personality factors were measured using the questionnaire ABVK. On the subscale 'neurotic instability, psychoneurotic symptoms' an improvement from $t_{1}$ to $t_{2}$ was found. This improvement was not related to changes in duration of epilepsy or seizure frequency. No changes were found on the other subscales.

Children with CLRE describe less psychoneurotic symptoms over time, even though the score is still in the average range. Apparently, children with CLRE learn to deal with their epilepsy over time and are not excessively anxious or worried.

A reduction of somatic symptoms would have been expected because of the large improvement in seizure frequency. This was, however, not the case.

Taken all these results together, cognitive functioning of children with CLRE appears to improve after a follow up of one to four years. Some of these changes apparently need time to develop as they are only observed with a longer follow-up period. Most changes, however, cannot be related to any of the measured epilepsy-factors. So, the question remains how this improvement can be explained.

The factor time might be the most probable explanation. Children get older; have longer time to get used to and learn to deal with their epilepsy. Of course, an older age and a longer duration of epilepsy are extricably bounded up with each other. Therefore time and age cannot be an unambiguous explanation.

Elaborating on this time factor, it might be possible that after improvement of the seizure frequency, or even becoming seizure free, children need a longer time before performances on neuropsychological tests straighten out and even some longer time before school performances will. When the epilepsy is better controlled, children get the chance to regain their cognitive functions. This process goes in phases; progress is seen earliest in the most state-dependent processes (functions that are more tran- 
sient in nature; are more sensitive to change), while the trait-dependent functions (functions that require accumulation of knowledge over longer periods) improve later [17]. First, abilities like attention, activation and memory improve, followed by the executive functions. Then improvements on intelligence tests become visible and, last, acquired abilities (e.g. scholastic abilities) recover.

This is in line with our current findings. Improvements on tasks measuring psychomotor speed and alertness or memory are the only tasks related to a longer duration of epilepsy. This relationship is already visible after a follow up of approximately two years. No relationship was found between duration of epilepsy and the other improved cognitive functions. However, probably after a longer follow up, this relationship becomes clear for these abilities too.

The tasks measuring school performances showed no improvement (yet). Since these functions (trait-dependent) are the last to recover, probably the follow up of this study is too short to find this kind of improvements. After the recovery of many other cognitive functions it is very well possible that the school performances improve later too, but the children need more time for these functions; a longer duration of their epilepsy. In the mean time it is very important to monitor the scholastic abilities of these children very carefully. And if necessary, give them some extra help at school or even another educational approach. Delays at school are things to always worry about!

It seems very important to re-examine these children again in a couple of years to find out whether the current improvements continues.

In conclusion, the results of this study show that the performance of children with CLRE improves; it even seems to normalize in one to four years. The positive relationship of a longer duration of epilepsy with these improvements requires some consideration. It appears that children with CLRE belong to a group that can achieve seizure remission or at least fair seizure control. However, this requires a certain amount of time and several changes in types of medication (unpublished data). Only after a considerable time, these improvements in seizure control allow for cognition to become normalized. Improvements of school performances will require even longer periods to normalize and without careful control of cognitive effects, the delay in school results may become irreversible. 


\section{References}

1. Berg, AT, Lin, J, Ebrahimi, N, Testa, FM, Levy, SR, \& Shinnar, S (2004). Modeling remission and relapse in pediatric epilepsy: application of a Markov process. Epilepsy Res. 60(1): 31-40.

2. Eriksson, KJ, \& Koivikko, MJ (1997). Prevalence, classification, and severity of epilepsy and epileptic syndromes in children. Epilepsia. 38(12): 1275-1282.

3. Waaler, PE, Blom, BH, Skeidsvoll, H, \& Mykletun, A (2000). Prevalence, classification, and severity of epilepsy in children in western Norway. Epilepsia. 41(7): 802-810.

4. Commission on Classification and Terminology of the International League Against Epilepsy. Proposal for revised classification of epilepsies and epileptic syndromes. (1989). Epilepsia, 30(4): 389-399.

5. Aldenkamp, AP, Weber, B, Overweg-Plandsoen, WC, Reijs, R, \& van Mil, S (2005). Educational underachievement in children with epilepsy: a model to predict the effects of epilepsy on educational achievement. J Child Neurol. 20(3): 175-180.

6. Hoie, B, Mykletun, A, Sommerfelt, K, Bjornaes, H, Skeidsvoll, H, \& Waaler, PE (2005). Seizure-related factors and non-verbal intelligence in children with epilepsy. A population-based study from Western Norway. Seizure. 14(4): 223-231.

7. Aldenkamp, AP, \& Alpherts, WCJ (1999). Psychological assessment. In H. Meinardi (Ed.), Handbook of Clinical Neurology (part 1 ed., Vol. 72 (28)). Elsevier Science B.V., Amsterdam, pp. 387-406.

8. Williams, $J$ (2003). Learning and behavior in children with epilepsy. Epilepsy Behav. 4(2): 107-111.

9. Schoenfeld, J, Seidenberg, M, Woodard, A, Hecox, K, Inglese, C, Mack, K, \& Hermann, B (1999). Neuropsychological and behavioral status of children with complex partial seizures. Dev Med Child Neurol. 41(11): 724-731.

10. Williams, J, Philips, T, Griebel, ML, Sharp, GB, Lange, B, Edgar, T, \& Simpson, P (2001). Patterns of memory performance in children with controlled epilepsy on the CVLT-C. Child Neuropsychol. 7(1): 1520.

11. Elger, CE, Helmstaedter, C, \& Kurthen, M (2004). Chronic epilepsy and cognition. Lancet Neurol. 3(11): 663-672.

12. Bjornes, $H$, Stabell, $K$, Henriksen, $O$, \& Loyning, $Y(2001)$. The effects of refractory epilepsy on intellectual functioning in children and adults. A longitudinal study. Seizure. 10(4): 250-259.

13. Fastenau, PS, Shen, J, Dunn, DW, Perkins, SM, Hermann, BP, \& Austin, JK (2004). Neuropsychological predictors of academic underachievement in pediatric epilepsy: moderating roles of demographic, seizure, and psychosocial variables. Epilepsia. 45(10): 1261-1272.

14. Vasconcellos, E, Wyllie, E, Sullivan, S, Stamford, L, Bulacio, J, Kotagal, P, \& Bingaman, W (2001) Mental retardation in pediatric candidates for epilepsy surgery: the role of early seizure onset. Epilepsia. 42(2): $268-274$.

15. Aldenkamp, AP, \& Vermeulen, J (2001). Cognitive side-effects of antiepileptic drugs. In: JM Pellock, WE Dodson, \& BFD Bourgeois. Pediatric Epilepsy; diagnosis and therapy ( $2^{\text {nd }}$ edition), Demos Medical Publishing, New York, pp. 629-636.

16. Lagae, L (2006). Cognitive side effects of anti-epileptic drugs. The relevance in childhood epilepsy. Seizure. 15(4): 235-241.

17. Aldenkamp, AP, \& Arends, J (2004). The relative influence of epileptic EEG discharges, short nonconvulsive seizures, and type of epilepsy on cognitive function. Epilepsia. 45(1): 54-63.

18. Aldenkamp, AP \& Arends, $J(2004)$. Effects of epileptiform EEG discharges on cognitive function: is the concept of "transient cognitive impairment" still valid? Epilepsy Behav. 5(suppl 1): 25-34.

19. Baglietto, MG, Battaglia, FM, Nobili, L, Tortorelii, S, De Negri, E, Calevo, MG, Vaneselli, E, \& De Negri, M (2001). Neuropsychological disorders related to interictal epileptic discharges during sleep in benign epilepsy of childhood with centrotemporal or Rolandic spikes. Dev Med Child Neurol. 43: 407-412.

20. Reijs, RP, van Mil, SG, van Hall, MH, Arends, JB, Weber, JW, Renier, WO, \& Aldenkamp, AP (2006). Cryptogenic localization-related epilepsy with childhood onset: The problem of definition and prognosis. Epilepsy Behav. 8(4): 693-702.

21. Dunn, DW, Buelow, JM, Austin, JK, Shinnar, S, Perkins, SM, 2004. Development of syndrome severity scores for peadiatric epilepsy. Epilepsia. 45(6): 661-666.

22. Camfield, P, \& Camfield, C (2002). Epileptic syndromes in childhood: clinical features, outcomes, and treatment. Epilepsia. 43(Suppl 3); 27-32. 
23. Oostrom, KJ, Schouten, A, Kruitwagen, CL, Peters, AC, \& Jennekens-Schinkel, A (2003). Behavioral problems in children with newly diagnosed idiopathic or cryptogenic epilepsy attending normal schools are in majority not persistent. Epilepsia. 44(1): 97-106.

24. van Mil, SGM, Reijs, RP, van Hall, MHJA, Aldenkamp, AP (2007). Neuropsychological profile of children with Cryptogenic Localization Related Epilepsy. Accepted for publication in Child Neuropsychology, acCeptance date June $4^{\text {th }} 2007$.

25. Wechsler, D. (1974). Manual for the Wechsler Intelligence Scale for Children-Revised. The Psychological Corporation, New York.

26. Kema, GM, \& Kema-van Leggelo, MKG (1987). Handleiding G.S.O. [Manual Groninger school onderzoek]. Swets\&Zeitlinger, Lisse.

27. van Mil, SGM, Reijs, RP, van Hall, MHJA, Aldenkamp, AP (2007). The effect of duration of epilepsy on IQ in children with CLRE; a comparison to SLRE and IGE. Accepted for publication in Seizure, acceptance date October $5^{\text {th }} 2007$; Epub: November $13^{\text {th }} 2007$; PMID: 18023367. 


\title{
Chapter 8
}

\author{
Behavior in children with \\ cryptogenic localization related \\ epilepsy; a follow up study.
}

Submitted for publication as:

van Mil, SGM, Reijs, RP, van Hall, MHJA, Snoeijen, SM, Aldenkamp, AP.

Behavior in children with cryptogenic localization related epilepsy; a follow up study.

Pediatric Neurology 


\begin{abstract}
Using the Child Behavior Checklist ( $\mathrm{CBCL}$ ), behavior of 16 children with cryptogenic localization related epilepsy (CLRE) was assessed twice; at first admission to our epilepsy centre and approximately two years later.

Behavior improved substantial from $t_{1}$ to $t_{2}$ on almost all subscales of the CBCL; at $t_{2}$ all subscales scored in the normal range. Furthermore, seizure frequency improved considerably from $t_{1}$ to $t_{2}$.

In conclusion, after a period of approximately two years, normalization of behavior in children with cryptogenic localization related epilepsy occurred.
\end{abstract}




\section{Introduction}

Epilepsy is the most common neurological disorder in childhood. Behavioral problems are frequently described as comorbid disorders $[1,2,3,4,5]$. In general, studies have reported that children with epilepsy have behavioral problems in the whole range, although internalizing behavioral problems are more common than externalizing problems $[1,6,7]$. Attention problems, thought problems, social problems, somatic complaints, and withdrawal are frequently described $[2,3,6,8]$. Furthermore, in comparison to children with other chronic illnesses, such as diabetes, asthma, heart diseases, and rheumatoid arthritis, children with epilepsy appear to have substantially more behavioral problems $[1,2,4,8,9]$. Especially attention problems, social problems and thought problems appear to distinguish children with epilepsy from children with other chronic diseases [1].

About one third of the pediatric epilepsy population consists of children with cryptogenic localization related epilepsy (CLRE). The term cryptogenic refers to a disorder whose cause is occult. It is presumed to be symptomatic, but the etiology is not known. Localization related means that the seizure semiology or EEG findings at investigation disclose a localized origin of the seizures [10].

Unfortunately, the knowledge about the prognosis of CLRE is poor [11]. In particular, the behavioral prognosis is studied only in a few studies. Oostrom et al. [12] described that children with cryptogenic epilepsy had more behavioral problems than children with idiopathic epilepsy. However, this difference disappeared after a follow up of three to four years [13].

In a previous study (unpublished data), we found that the neurological prognosis of CLRE is acceptable. Children with cryptogenic localization-related epilepsy belong to the group that can achieve seizure remission or at least fair seizure control, but only after several types of medication have been used. This requires on average a period of three years. With regards to the behavioral outcome this is of some concern as in such a period behavioral reactions may stabilize over time and become irreversible.

The aim of this study is therefore to investigate the course of behavior in children with cryptogenic localization related epilepsy over time. Are there indications that show stabilization, or does the behavioral status improve over time? 


\section{Patients and methods}

Design

A clinical and non-randomized prospective follow up design was used. Children were assessed at baseline (first admission to our centre; $t_{1}$ ) and at follow-up one to four years later $\left(\mathrm{t}_{2}\right)$.

Subject selection

A total of 16 children were included consecutively and assessed when admitted to our epilepsy centre $\left(t_{1}\right)$ and reassessed after approximately two years $\left(t_{2}\right)$.

The inclusion criteria were age between 6 and 16 years and a diagnosis of CLRE, which was made or confirmed by one of our (child) neurologists following the 1989 revised ILAE classification [10], including normal neuroimaging. The exclusion criteria were $I Q<70$, absence of neuroimaging, a neurological disease other than epilepsy. The study was approved by the Medical Ethical Committee of the Maastricht University Hospital and all participants provided informed written consent prior to participation.

\section{Assessment procedures}

During both the first assessment and the follow up assessment, the parents were asked to complete the Child Behavior Checklist (CBCL) [14].

The Child Behavior Checklist is a questionnaire for parents of children between 4 and 18 years of age. It consists of 113 behavioral items on which parents rate how well the behavior describes the behavior of their child. All these items are answered on a 3-point scale: 0 (not true or not applicable), 1 (somewhat or something true) and 2 (very or often true). The CBCL measures behavioral problems on 3 broadband subscales (internalizing behavior, externalizing behavior and total behavior) and 8 narrowband subscales (withdrawal, somatic complaints, anxiety / depression, social problems, thought problems, attention problems, delinquent behavior and aggressive behavior).

The narrowband scales are specific syndrome scales of the CBCL. They are deduced from factor analyses of the individual problem items. The broadband scales 'internalizing and externalizing behavior', are more general scales, deduced from factor analyses of the eight syndrome scales. The subscale 'internalizing behavior consists of the narrowband subscales withdrawal, somatic complaints and anxiety / depression; the subscale 'externalizing behavior' consists of the narrowband subscales delinquent behavior and aggressive behavior. The broadband subscale 'total behavior' is a calculation over all individual problem items.

The subscale scores are converted into standardized t-scores. On the narrowband scales, a t-score between 67 and 70 is seen as borderline; scores above 70 are seen as clinical scores (i.e. representing clinical relevant behavior problems). On the 
broadband scales, the borderline range is between 60 and 63; above 63 is the clinical range.

Epilepsy-related variables were collected from the medical files at $t_{1}$. At $t_{2}$, this information was collected during interviewing the parents of the children. Seizure type was subdivided into simple partial seizures, complex partial seizures and secondary generalized seizures. Seizure frequency was subdivided into seizure free (for at least one year), low seizure frequency (less than one seizure a month) and high seizure frequency (more than one seizure a month). The number of AED the children used was subdivided into no AED, monotherapy and polytherapy.

\section{Statistical analysis}

Data were collected on record forms and entered into a database. The Statistical Package for Social Sciences (SPSS), version 15.0 for Windows was used to analyze the data.

Differences between $t_{1}$ (baseline) and $t_{2}$ (follow up) were analyzed. To evaluate whether there were differences in the epilepsy characteristics (seizure type, seizure frequency and number of AED) of the children, Wilcoxon Signed Ranks Tests were used. To test whether the scores on the $\mathrm{CBCL}$ subscales were significantly different between $t_{1}$ and $t_{2}$, Paired Samples T-tests were used.

Significance level was set at the $5 \%$ level.

\section{Results}

The cohort of this study consists of 16 children with cryptogenic localization related epilepsy. The mean follow-up period was two years and two months.

Demographical characteristics of this part of the study are summarized in table 1.

Seizure type and number of AEDs were not significantly different when comparing $t_{1}$ and $t_{2}(Z=-.447, p=.655 ; Z=-1.089, p=.276)$. Seizure frequency changed significantly $(Z=-2.739, p=.006)$; a considerable improvement of seizure control was found. At baseline three patients were seizure free, while at follow up, approximately two years later, ten patients were in remission. Furthermore, the number of children with a high seizure frequency decreased from eight to two children.

As shown in figures $1 \mathrm{a}$ and $1 \mathrm{~b}$, the scores on the CBCL-subscales improved considerably at $t_{2}$; all subscales are in the normal range at $t_{2}$. All the differences between $t_{1}$ and $t_{2}$ were significant, except for the subscale delinquent behavior. 
Table 1 Demographical characteristics of the CLRE cohort

\begin{tabular}{|c|c|c|}
\hline & $t_{1}$ & $\mathbf{t}_{\mathbf{2}}$ \\
\hline $\mathbf{N}$ & 16 & 16 \\
\hline \multicolumn{3}{|l|}{ Age } \\
\hline Mean & 9 years; 2 months & 11 years; 5 months \\
\hline \multicolumn{3}{|l|}{ Gender } \\
\hline Male / female & $7 / 9$ & $7 / 9$ \\
\hline \multicolumn{3}{|l|}{ IQ } \\
\hline Full-scale IQ & 92.4 & 94.0 \\
\hline Verbal IQ & 93.4 & 92.1 \\
\hline Performance IQ & 92.8 & 97.9 \\
\hline \multicolumn{3}{|l|}{ Seizure type } \\
\hline Simple partial seizures & 1 & 1 \\
\hline Complex partial seizures & 10 & 11 \\
\hline Secondary generalized seizures & 5 & 4 \\
\hline \multicolumn{3}{|l|}{ Seizure frequency } \\
\hline Seizure free & 3 & 10 \\
\hline Low seizure frequency & 5 & 4 \\
\hline High seizure frequency & 8 & 2 \\
\hline \multicolumn{3}{|l|}{ Duration of epllepsy } \\
\hline Mean & 2 years; 11 months & 5 years; 1 month \\
\hline \multicolumn{3}{|l|}{ Number of AED } \\
\hline No AED & 0 & 2 \\
\hline Monotherapy & 13 & 12 \\
\hline Polytherapy & 3 & 2 \\
\hline
\end{tabular}

\section{Follow-up}

Mean (range)

2 years; 2 months $(1 ; 4-3 ; 8)$

Sd

9 months

*Seizure free: seizure free for at least one year; low seizure frequency: up to one seizure a month; high seizure frequency: more than one seizure a month.

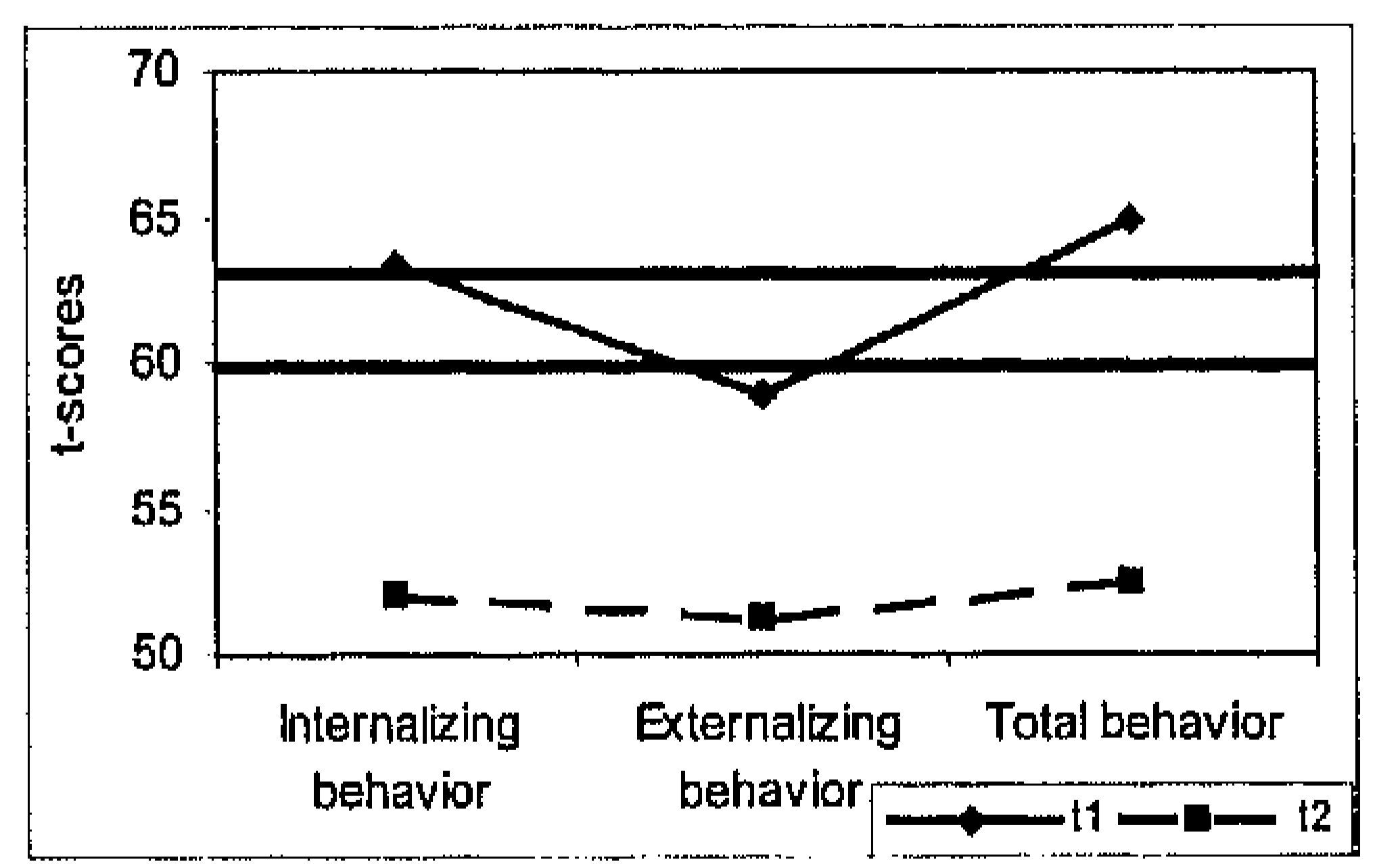

Figure 1a Broadband subscales.

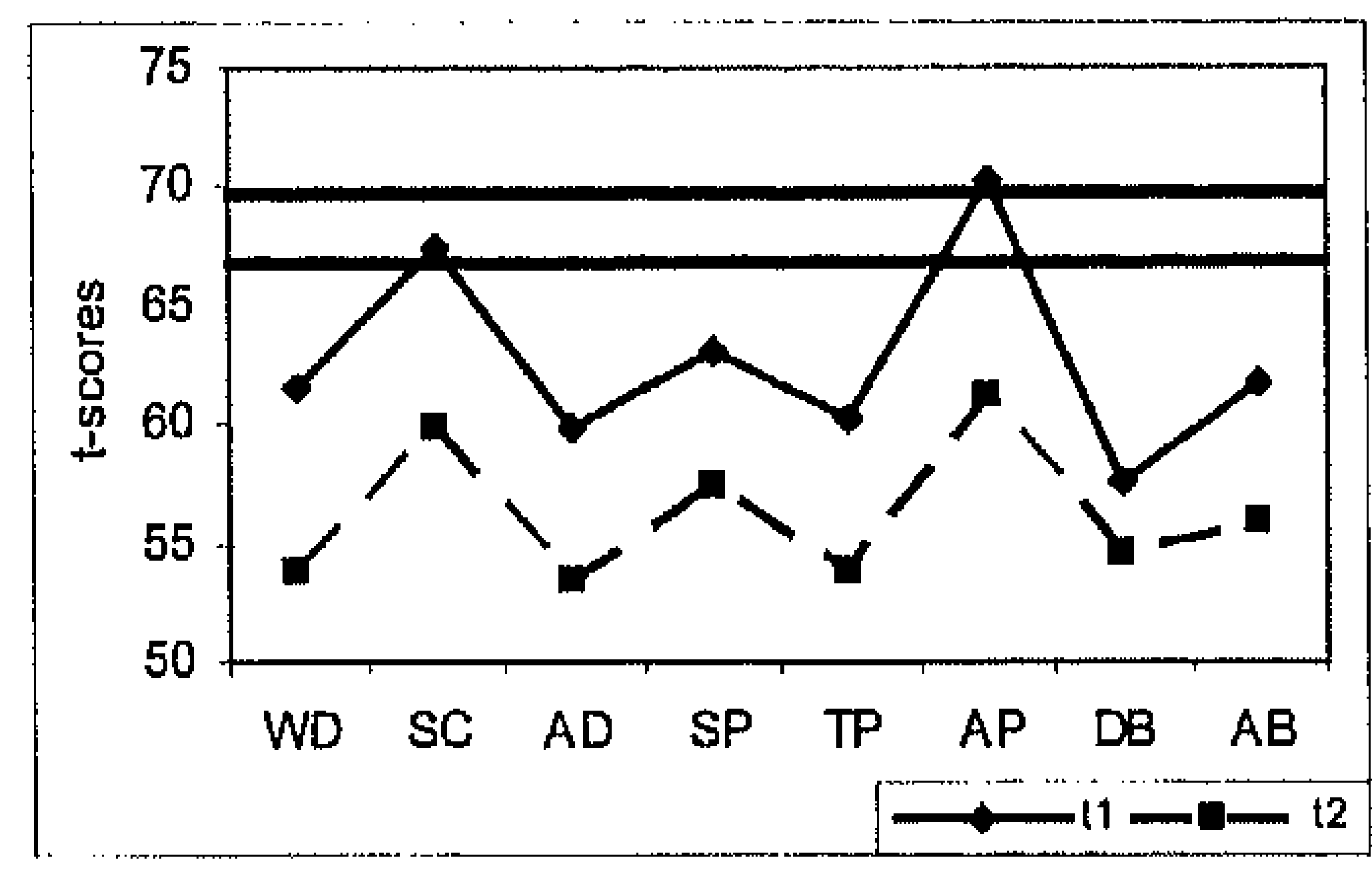

Figure 1b Narrowband subscales.

The bottom bold line indicates the borderline range; the upper bold line indicates the clinical range. WD: withdrawal, SC: somatic complaints, AD: anxiety / depression, SP: social problems, TP: thought problems, $A P$ : attention problems, $D B$ : delinquent behavior, $A B$ : aggressive behavior. 


\section{Discussion}

In a previous study, we reported that children with cryptogenic localization-related epilepsy belong to a group that can achieve seizure remission or at least fair seizure control, but only after several types of medication have been used which requires a certain amount of time (approximately 3-4 years) (unpublished data). This causes concern as in 3 or 4 years time temporary reactions to the epilepsy may become stabilized and therefore may be irreversible. In such a situation behavioral disorders will then persist, also when the patient becomes seizure free.

In this study, we firstly checked whether the epilepsy-factors seizure type, seizure frequency and number of AED changed significantly from $t_{1}$ to $t_{2}$. No significant change was found for seizure type or AED treatment (number of AED). At endpoint (approximately 2 years later) a considerable improvement was found in seizure frequency; at $t_{1}$ three children were seizure free and eight children had a high seizure frequency, at $t_{2}$, about two years later, this improved to ten seizure free children and only two children with a high frequency.

In contrast to our previous concern, however, there appeared to be a considerable improvement in the behavior of children with CLRE. The scores on all scales, both broadband and narrowband scales, improved significantly, except for the subscale delinquent behavior. However, the score on this subscale at $t_{1}$ was not very high and therefore, the score could not improve very much. So after a period of about two years, the scores on all subscales are in the normal range.

It is tempting to assume that the behavioral improvement is a consequence of the improved seizure control. The group is, however, too small to confirm such a relationship. Therefore, larger prospective studies on CLRE are needed.

After a period of approximately two years the behavioral status of children with CLRE improved considerably. Behavioral disorders are therefore probably a reaction to the epilepsy, the diagnosis and maybe even a sign of adaptation problems but not per se an inherent characteristic of cryptogenic localization related epilepsy. 


\section{References}

1. Rodenburg RMA, Stams GJ, Meijer AM, Aldenkamp AP, Dekovic M. Psychopathology in children with epilepsy: a meta-analysis. J Pediatr Psychol. 2005; 30(6): 453-468.

2. Williams J. Learning and behavior in children with epilepsy. Epilepsy Behav. 2003; 4: 107-111.

3. Keene DL, Manion I, Whiting S, Belanger E, Brennan R, Jacob P, Humphreys, P. A survey of behavior problems in children with epilepsy. Epilepsy Behav. 2005; 6: 581-586.

4. Dunn DW. Neuropsychiatric aspects of epilepsy in children. Epilepsy Behav 2003; 4: 101-106.

5. Cornaggia $\mathrm{CM}$, Beghi $M$, Provenzi $M$, Beghi $E$. Correlation between cognition and behavior in epilepsy. Epilepsia, 2006; 47(Suppl 2): 34-39.

6. Schoenfeld J, Seidenberg M, Woodard A, Hecox K, Inglese C, Mack K, Hermann, B. Neuropsychological and behavioral status of children with complex partial seizures. Dev Med Child Neurol. 1999; 41(11): 724731.

7. Caplan R, Siddarth P, Gurbani S, Ott D, Sankar R, Shields WD. Psychopathology and pediatric complex partial seizures: seizure-related, cognitive, and linguistic variables. Epilepsia. 2004; 45(10): 1273-1281.

8. Austin JK, Dunn DW. Chapter 37: Progressive behavioral changes in children with epilepsy. In: Sutula T, Pitkanen A. (eds.) Progress in Brain Research. Amsterdam: Elsevier Science BV. 2002; 419-427.

9. MCDermott S, Mani S, Krishnaswami S. A population-based analysis of specific behavior problems associated with childhood seizures. J Epilepsy. 1995; 8: 110-118.

10. Commission on Classification and Terminology of the international League Against Epilepsy. Proposal for revised classification of epilepsies and epileptic syndromes. Epilepsia. 1989; 30(4): 389-399.

11. Reijs, RP, van Mil, SGM, van Hall, MHJA, Arends, JBAM, Weber, JW, Renier, WO, Aldenkamp, AP. Cryptogenic localization-related epilepsy with childhood onset: The problem of definition and prognosis. Epilepsy Behav. 2006; 8(4): 693-702.

12. Oostrom KJ, Schouten A, Kruitwagen CLJJ, Peters ACB, Jennekens-Schinkel A. Behavioral problems in children with newly diagnosed idiopathic or cryptogenic epilepsy attending normal school are in majority not persistent. Epilepsia, 2003; 44(1): 97-106.

13. Oostrom KJ, van Teeseling H, Smeets-Schouten $A$, Peters ACB, Jennekens-Schirkel $A$. Three to four years after diagnosis: cognition and behaviour in children with 'epilepsy only'. A prospective, controlled study. Brain, 2005; 128: 1546-1555.

14. Verhulst FC, van der Ende J, Koot HM. Handleiding voor de CBCL4-18. Rotterdam: Afdeling kinder en jeugdpsychiatrie, Sophia Kinderziekenhuis; 1996. Dutch transiation of: Achenbach TM. Manual for the child behavior checklist/4-18 and 1991 profiles. Burlington, VT: University of Vermont, Department of psychiatry; 1991. 


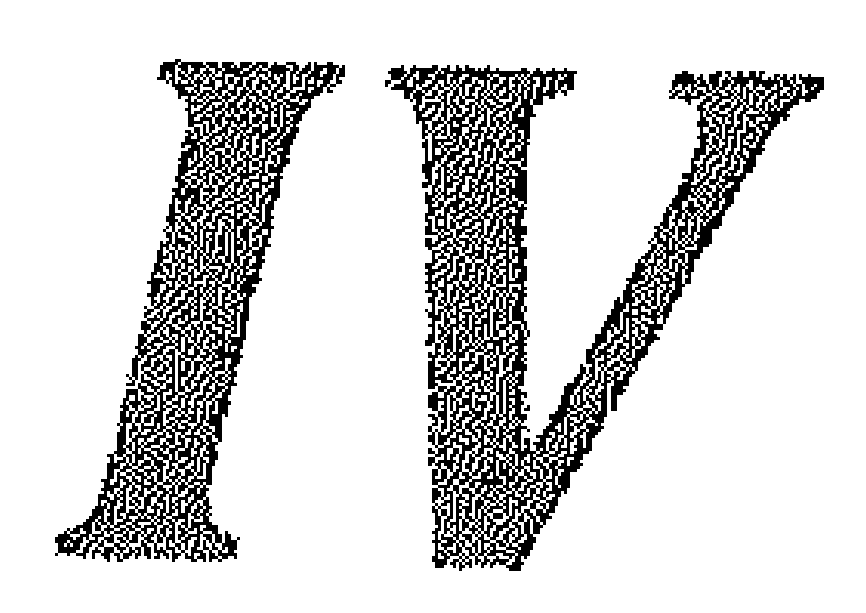

General discussion 


\section{Chapter 9}

General conclusions and discussion 
The point prevalence of epilepsy in children in the Netherlands is about $0.7 \%$, yielding approximately 40,000 children [1]. Since up to one third of the paediatric epilepsy population consists of children with cryptogenic localization related epilepsy (CLRE) $[2,3,4,5]$, about 13,000 children have the diagnosis of CLRE in the Netherlands at any point of time.

When these children and their parents seek advice from a neurologist, understandably they would like to be informed about the prognosis of the epilepsy. Questions arise such as "will the seizures persist", "will it get worse", "what will be the effect on learning and school", and "will the epilepsy influence behaviour". Unfortunately, answers will be difficult to provide since not much is known about the prognosis of CLRE [6].

Camfield and Camfield [7] described widely differing seizure outcomes; about half of their cohort had a truly benign course, while the prognosis in the other half was uncertain. Also in other studies, both high remission rates and relapses are described $[4,8,9]$. In a study of Berg et al. [4], a wavelike pattern of remission and relapses was suggested. Although it is suggested that this could be characteristic for CLRE, this finding has yet to be confirmed.

Although one of the most frequently occurring complexities of epilepsy consists of the cognitive comorbidity, little research on neuropsychological functions has been done in children with CLRE. Oostrom et al. [10] found no differences in attention and reaction times between children with cryptogenic and idiopathic epilepsy. In a study of Hoie et al. [11] severe nonverbal problems were found in $20 \%$ of the children with CLRE compared to $7 \%$ in the idiopathic localization related epilepsy (ILRE) group, $62 \%$ in the symptomatic localization related epilepsy (SLRE) group and only $3 \%$ in the control group.

Also the behavioural outcome of CLRE has not been studied thoroughly. Oostrom et al. [12] found that children with CLRE showed more behavioural problems than children with idiopathic epilepsy or controls. After a follow up of three to four years, they still found that children with epilepsy had more behavioural problems than healthy controls. However, no differences were found between children with an idiopathic or cryptogenic aetiology [13]. Scholastic problems have been reported for children with CLRE. Aldenkamp and Arends [14] studied reading and arithmetic and found delays of almost two school years.

In literature these comorbidities are frequently associated with epilepsy-related factors. Age at onset $[15,16,17,18]$, duration of epilepsy $[19,20,21,22]$, seizure type $[11,23,24,25]$, seizure frequency $[18,22,26,27]$, the use of anti-epileptic drugs (AED) $[28,29,30,31]$ and interictal epileptiform activity (IEA) $[14,32,33]$ are mentioned in relation to cognition and behaviour. Although these studies describe conflicting results, most articles describe a negative influence. It is important to realize, though that all these relationships have been reported for different groups, consisting of different types of epilepsies, and mostly studied cohort contain of mixed groups of children with idiopathic, cryptogenic or symptomatic epilepsies and children with 
generalized or localisation-related epilepsies. Studies with more homogeneous cohort, i.e. studies including only children with CLRE are extremely rare.

Taken these findings together, it is clear that no unambiguous prognosis for cryptogenic localization related epilepsy can be provided. This was exactly our starting point when studying cryptogenic localisation related epilepsy.

The patients included in our studies were referred to a specialized expert team in our epilepsy centre for assessment in a program for children with epilepsy. This program consists of a standardized assessment battery containing neurological assessment, psychomotor screening, EEG recording, observation by specialized nurses, neuropsychological testing, and assessment of school achievement.

Although our epilepsy centre is a tertiary centre, we consider the children in our study as representative for the entire CLRE population and not just for the part of the CLRE population consisting of children with more severe CLRE. The reason for this is that our program is easily accessible for physicians of primary and secondary centres. They use the program for fast multidisciplinary screening of the children. And since most patients return to their own physician after the screening, the results of the analyses are used as indication for further treatment. Consequently, all kinds of patients are referred to our screening program and not only patients with difficult-tocontrol seizures or severe comorbidities.

\section{Cohort studies}

Four cohort studies were used to study the impact of CLRE. In these studies, the results of the children with CLRE were evaluated relative to the performance in the "normal" population.

In a cohort consisting of 68 children ( 40 boys, 28 girls) with a mean age of 10 years and 3 months, we found a characteristic cognitive profile for children with CLRE. They experience cognitive difficulties on a wide range of areas, but in particular on alertness, mental speed and memory. These problems were related to age at onset; the earlier the age at onset, the worse the cognitive performance. However, after the Bonferroni-correction, this influence was present only for the tapping task. There was no relationship with seizure type, seizure frequency, duration of epilepsy and drug load (chapter 3).

A second study focused on a more general measurement for cognitive functioning: intelligence. This cohort was similar to the previous study and showed that the fullscale IQ, verbal IQ and performance IQ of children with CLRE appeared to be in the low average range. These low average IQs were not related to the specific epilepsy factors such as seizure type or seizure frequency (chapter 4). In addition, intelligence was studied in relationship to two other types of epilepsy; symptomatic localization related epilepsy (SLRE) (24 children, mean age 10 years; 11 months) and idiopathic generalized epilepsy (IGE) (21 children, mean age 9 years; 11 months). In literature, 
the severity of CLRE is assumed to be somewhere between the relative benign idiopathic epilepsies and the more malignant symptomatic epilepsies $[34,35]$. In contrast, we found no significant IQ-differences between these three types of epilepsy. Also when the children were subdivided in three groups based on duration of epilepsy (048 months, 49-96 months and 97-168 months), to study the effect of this factor on intelligence, no differences between the three types of epilepsy were found. For the verbal IQ there was, however, a trend towards significance in the long duration group; IGE performed better than CLRE and CLRE performed better than SLRE.

The explanation of our findings could probably be found in the very diverse courses of the three epilepsy types in this study. IGE is known to have a very severe onset with a high seizure frequency. When after some time the medication is well established, the negative influence of the epilepsy diminishes; seizure remission or at least fair seizure control will be achieved. The negative impact on $1 Q$-scores will therefore be largest at the onset of the epilepsy (lower IQ-scores) and reduce with a longer duration of epilepsy (normalization of the IQ-scores). The course of SLRE is quite different; it is characterized by a slowly progressive course. The negative impact on the cognitive performances is mostly less perceptible at the beginning and grows with the years; the IQ-scores of children with SLRE will decline over the years. For CLRE, the course was very uncertain. A wavelike pattern of seizure remission and relapse was suggested [4]. Within the group of children with CLRE, this would imply a varying (negative) impact of the seizures on cognition over the years. Consequently, the mean IQ-scores of the total group are probably constant throughout the years.

In our study we found that the courses of IQ-scores follow the same patterns as described above. Therefore, this could be a good explanation.

Also the fact that we did not find any IQ-differences between CLRE, SLRE and IGE (without specifying for duration of epilepsy) can be explained from this point of view. The three populations existed of children with different durations of epilepsy. If IQscores of these children are compared without specifying for duration of epilepsy, the mean IQ-scores will be equalized and no differentiation between CLRE, SLRE and IGE will become visible.

Another important aspect for the prognosis of CLRE is behaviour. This was studied in the third cohort study (chapter 5). This cohort consisted of 51 children (26 boys and 25 girls) with a mean age of 10 years and 3 months. According to parent report (CBCL), children with CLRE scored in the clinical range on the subscales 'internalizing behaviour', 'total behaviour' and 'attentional problems'. These behavioural problems are the same kind of behavioural problems as described for children with other types of epilepsy. Therefore, these problems cannot be seen as specific for CLRE.

We also studied the influence of epilepsy-related factors to find out whether the origin of the behavioural problems might be specific for CLRE. Some behavioural scales were related to seizure type; the more severe the seizure type, the more delinquent, aggressive and externalizing behavioural problems. However, since these three subscales scored still in the normal range, the influence of seizure type seems to be only small. No influence of other epilepsy-related factors was found. The lack of influ- 
ence of epilepsy-related factors suggests that the described behavioural problems are a global characteristic for CLRE, independent of specific factors.

Besides cognition and behaviour, motor functioning is an important aspect of daily life functioning. Eighty-nine children (41 boys, 48 girls) were studied (chapter 6 ). Their mean age was 9 years and 5 months. On the movement Assessment Battery for Children, we found significant lower scores for children with CLRE compared to agerelated reference values. Manual dexterity and balance problems were present in about $35 \%$ of the children with CLRE; ball skills were problematic in approximately $55 \%$ of the children. Furthermore, in terms of the magnitude of the effects, psychomotor slowing ranged from $9 \%$ to $26 \%$ in children with CLRE. A relationship appeared to exist between the psychomotor slowing and the affected motor functioning; the larger the psychomotor slowing, the larger the problems in motor functioning.

Because of the large amount of literature on the influence of epilepsy-related factors on cognition and behaviour, it seems quite contradictory that in our studies we found so minimal influence of these factors. Consequently, we suggest that the problems we described in these children are a global characteristic for CLRE, independent of specific factors.

\section{Follow up studies}

Next, changes of these findings over time were studied in two follow up studies; one on the neuropsychological functioning of these children (chapter 7) and one on their behaviour (chapter 8 ). In chapter 7, twenty-four children (11 boys, 13 girls) were followed. At $t_{1}$ they had a mean age of 9 years and 4 months; at $t_{2}$ their mean age was 11 years and 8 months. The behavioural follow up study (chapter 8 ) consisted of 16 children; 7 boys and 9 girls. Their mean age at $t_{1}$ was 9 years and 2 months. At $t_{2}$ they had a mean age of 11 years and 5 months.

Functioning in children with cryptogenic localization related epilepsy showed some improvement from $t_{1}$ to $t_{2}$. Many aspects of intelligence, psychomotor speed/fluency, psychomotor speed/alertness, central information processing speed, memory, personality and behaviour showed normalization in the one to four years of follow up. Besides neuropsychological improvement, we found that seizure frequency improved considerably (chapter 7 and 8).

More specifically, the full-scale and performance IQs improved. The performance of the dominant hand improved on the psychomotor speed/fluency task. Of the psychomotor speed/alertness task, all parts improved. Also both central information processing tasks improved. Of the memory tasks, only digit span backwards remained stable, all the other parts improved. For the digit span forwards and the number of errors made during the recognition of the 15 word test, a positive relationship was found with changes in duration of epilepsy; the larger the change in duration of epilepsy, the larger the improvement on these tasks. This relationship with duration of epilepsy probably reflects a time aspect. Since in our cohort studies the performance 
on these tasks was below-average, the improvements can be seen as normalization that needs some time.

For most of these tasks, a positive relationship was found with changes in duration of epilepsy; the larger the change in duration of epilepsy, the larger the improvement on these tasks. This indicates that a longer follow up probably allows the improvement in seizure frequency (that was also found in this study) to result in normalization of the performance on tasks measuring $I Q$, psychomotor speed and alertness.

Three school achievement tasks were administered. The delays on both reading tasks enlarged, while no change was found on the arithmetic task. For the reading words task, a negative relationship with duration of epilepsy was found; the larger the follow up, the larger the delay. Rather than seeing this enlarged delay as decline, it should be seen as stagnation. When children get older while no progress is seen in the development of reading, the delay in months gets larger. Apparently improvement of cognition (that already required some time after seizure control improved) did not yet lead to better school performance. And as a consequence of increasing norms over the year, this leads to worsened school results. It is also possible that the drop in cognitive abilities, although temporarily in this group leads to ineffective learning strategies in the children that are not easily 'unlearned'.

Of the personality task, one of the four scales improved (Neurotic instability, psychoneurotic symptoms), while the other three remained stable. And lastly, behaviour (measured with the $\mathrm{CBCL}$ ) improved considerably.

\section{CLRE in daily life; relevance for daily practice}

The results of the cohort studies indicate that children with cryptogenic localization related epilepsy perform worse than the 'normal' population. Not many relations between epilepsy-related factors and the different aspects of prognosis in CLRE were found. The neuropsychological performance was influenced only marginally by age at onset and seizure type.

This indicates that a stable influence of CLRE on cognition exists, an effect that is independent from the variable factors such as seizure type. Apparently there is a characteristic cognitive profile for CLRE that all children will demonstrate when assessed neuropsychologically. For clinical practice, this implicates that the identified impairments need careful follow-up and control when a diagnosis of CLRE is made in a child.

The results of the follow up studies show that the performance of these children improves; it even seems to normalize in one to four years. These improvements are partly related to changes in duration of epilepsy; the larger the change in duration of epilepsy, the larger the improvements. It seems strange to state that when the epilepsy gets more time to influence cognition, the neuropsychological performances of children with CLRE will improve. A logical explanation of this apparent inconsistency is that children with cryptogenic localization related epilepsy appear to belong to a group that can achieve seizure remission or at least fair seizure control. However, 
this requires a certain amount of time and several changes in types of medication. Only after a considerable time, improvements in seizure control allow for cognition to become normalized.

Improvements of school performances will require even longer periods to normalize and our study shows evidence that without careful control of cognitive effects, the delay in school results may become irreversible. In chapter 7 we suggested a phaselike recovery process of neuropsychological functions. Progress is seen earliest in the most state-dependent processes (functions that are more transient in nature; are more sensitive to change), while the trait-dependent functions (functions that require accumulation of knowledge over longer periods) improve later [14]. In practice, this means that abilities like attention, activation and memory improve first, followed by the executive functions. Then improvements on intelligence tests become visible and, last, acquired abilities (e.g. scholastic abilities) recover.

At the beginning of this chapter, we mentioned some questions patients and their parents might have during their visit to their neurologist; "will the seizures persist", "will it get worse", "what will be the effect on learning and school", and "will the epilepsy influence behaviour". After completing the studies in this thesis, we are able to answer these questions, at least partially.

There is a substantial chance that the children achieve seizure remission or at least fair seizure control. However, this will take some changes in AED and therefore take quite some time. When there is no fast and/or good response to the medication, neuropsychological functioning, behaviour and scholastic performances might be influenced negatively. Therefore, the child needs to be multidisciplinary assessed, coached and followed as fast as possible. When this is not done, cognitive, behavjoural and scholastic problems will absolutely be probable in the future.

\section{Limitations of the studies and ideas for future research}

Despite the fact that we were able to answer these questions, some limitations of this study should be mentioned.

The main limitation of the studies in this thesis is the lack of a control group. Because of the clinical background of the program in which the children were assessed, no 'normal' or 'healthy' children could be included in the studies. Therefore, normative age-related data were used as control group. Only in the study on intelligence, we were able to compare the data of the children with CLRE to children with two other types of epilepsy. In the other cohort studies, unfortunately not sufficient children with other types of epilepsy were available. Another limitation of our study is the short follow up. Afterwards, it appeared that some changes in functioning could not be made visible. We believe that after a longer period of seizure remission or seizure freedom, these changes would become clear. A study with other contrast groups in the form of children with other types of epilepsy would be very useful, to better be able to objectify the position of CLRE in the large spectrum of epilepsies. 
To be able to collect large numbers of newly diagnosed patients, it could be useful to plan a multi-centred study. Cooperation with other epilepsy centres and probably even with secondary and primary caregivers, would enable us to study large patient groups.

And lastly, concerning the study on behaviour, an addition to our findings would be the inclusion of teacher and child report forms of the $\mathrm{CBCL}$. 


\section{References}

1. Nationaal Epilepsie Fonds, Schoolkinderen met epilepsie. Utrecht: PlantijnCasparie, 2004.

2. Eriksson, KJ, \& Kolvikko, MJ (1997). Prevalence, classification, and severity of epilepsy and epileptic syndromes in children. Epilepsia. 38(12): 1275-1282.

3. Waaler, PE, Blom, BH, Skeidsvoll, H, \& Mykletun, A (2000). Prevalence, classification, and severity of epilepsy in children in western Norway. Epilepsia. 41(7): 802-810.

4. Berg, AT, Lin, J, Ebrahimi, N, Testa, FM, Levy, SR, \& Shinnar, S (2004). Modeling remission and relapse in pediatric epilepsy: application of a Markov process. Epilepsy Res. 60(1): 31-40.

5. Durá-Travé T, Yoldi-Petri ME, \& Gallinas-Victoriano F. (2007). Epilepsy in children in Navarre, Spain: epileptic seizure types and epileptic syndromes. J Child Neurol: 22(7): 823-828.

6. Reijs, RP, van Mil, SG, van Hall, MH, Arends, JB, Weber, JW, Renier, WO, \& Aldenkamp, AP (2006). Cryptogenic localization-related epilepsy with childhood onset: The problem of definition and prognosis. Epilepsy Behav. 8(4): 693-702.

7. Camfield, C. and P. Camfield, Predicting the outcome of childhood epilepsy; A population-based study yielding a simple scoring system. J Pediatr, 1993. 122; p. 861-868.

8. Berg, A. T., Shinnar, S., Levy, S. R., Testa, F. M., Smith-Rapaport, S., Beckerman, B., et al. (2001). Twoyear remission and subsequent relapse in children with newly diagnosed epilepsy. Epilepsia, 42(12), 1553-1562.

9. Shinnar, S., O'Dell, C., \& Berg, A. T. (1999). Distribution of epilepsy syndromes in a cohort of children prospectively monitored from the time of their first unprovoked seizure. Epilepsia, 4O(10), 1378-1383.

10. Oostrom, K.J., et al., Attention deficits are not characteristic of schoolchildren with newly diagnosed idiopathic or cryptogenic epilepsy. Epilepsia, 2002. 43(3): p. 301-10.

11. Hoie, B., Mykletun, A., Sommerfelt, K., Bjornaes, H., Skeidsvoll, H., \& Waaler, P.E. (2005). Seizurerelated factors and non-verbal intelligence in children with epilepsy. A population-based study from Western Norway. Seizure, 14(4), 223-231.

12. Oostrom, K. J., Schouten, A., Kruitwagen, C. L., Peters, A. C., \& Jennekens-Schinkel, A. (2003). Behavioral problems in children with newly diagnosed idiopathic or cryptogenic epilepsy attending normal schools are in majority not persistent. Epilepsia, 44(1), 97-106.

13. Oostrom, K.J., et al., Three to four years after diagnosis: cognition and behaviour in children with 'epilepsy only'. A prospective, controlled study. Brain, 2005. 128(Pt 7): p. 1546-55.

14. Aldenkamp, A., \& Arends, J. (2004). The relative influence of epileptic EEG discharges, short nonconvulsive seizures, and type of epilepsy on cognitive function. Epilepsia, 45(1), 54-63.

15. Fastenau, PS, Shen, J, Dunn, DW, Perkins, SM, Hermann, BP, \& Austin, JK (2004). Neuropsychological predictors of academic underachievement in pediatric epilepsy: moderating roles of demographic, seizure, and psychosocial variables. Epilepsia. 45(10): 1261-1272.

16. Vasconcellos, E, Wyllie, E, Sullivan, S, Stamford, L, Bulacio, J, Kotagal, P, \& Bingaman, W (2001). Mental retardation in pediatric candidates for epilepsy surgery: the role of early seizure onset. Epilepsia. 42(2): 268-274.

17. Aldenkamp AP, \& Bodde N. (2005). Behavior, cognition and epilepsy. Acta Neurologica Scandinavica, 112 (suppl 182), $19-25$.

18. Bailet LL, \& Turk WR. (2000). The impact of childhood epilepsy on neurocognitive and behavioral performance: a prospective longitudinal study. Epilepsia, 41 (4), 426-431.

19. Elger, CE, Helmstaedter, C, \& Kurthen, M (2004). Chronic epilepsy and cognition. Lancet Neurol. 3(11): 663-672.

20. Farwell, J., Dodrill, C., \& Batzel, L. . (1985). Neuropsychological abilities of children with epilepsy. Epilepsia 26(5), 395-400.

21. Datta SS, Premkumar TS, Chandy S, Kumar S, Kirubakaran C, Gnanamuthu C, et al. (2005). Behavior problerns in children and adolescents with seizure disorder: association and risk factors. Seizure, 14, 190-197.

22. Schoenfeld, J, Seidenberg, M, Woodard, A, Hecox, K, Inglese, C, Mack, K, \& Hermann, B (1999). Neuropsychological and behavioral status of children with complex partial seizures. Dev Med Child Nourol. 41(11): 724-731.

23. Aldenkamp, AP, \& Alpherts, WCJ (1999). Psychological assessment. In H. Meinardi (Ed.), Handbook of Clinical Neurology (part 1 ed., Vol. 72 (28)). Elsevier Science B.V., Amsterdam, pp. 387-406.

24. Williams, $J$ (2003). Learning and behavior in children with epilepsy. Epilepsy Behav. 4(2): 107-111. 
25. McDermott S, Mani S, \& Krishnaswami S. (1995). A population-based analysis of specific behavior problems associated with childhood seizures. Journal of Epilepsy, 8, 110-118.

26. Bjornes, H, Stabell, K, Henriksen, O, \& Loyning, $Y(2001)$. The effects of refractory epilepsy on intellectual functioning in children and adults. A longitudinal study. Seizure. 10(4): 250-259.

27. Dunn DW. Neuropsychiatric aspects of epilepsy in children. Epilepsy Behav 2003; 4: 101-106.

28. Aldenkamp, AP, \& Vermeulen, J (2001). Cognitive side-effects of antiepileptic drugs. In: JM Pellock, WE Dodson, \& BFD Bourgeois. Pediatric Epilepsy; diagnosis and therapy ( $2^{\text {nd }}$ edition), Demos Medical Publishing. New York, pp. 629.636.

29. Lagae, L (2006). Cognitive side effects of anti-epileptic drugs. The relevance in childhood epilepsy. Seizure. 15(4): 235-241.

30. Cornaggia CM, Beghi M, Provenzi M, \& Beghi E. (2006). Correlation between cognition and behavior in epilepsy. Epilepsia, 47 (Suppl 2), 34-9

31. Freilinger $M$, Reisel $B$, Reiter $E$, Zelenko $M$, Hauser $E$, \& Seidl R. (2006). Behavioral and emotional problems in children with epilepsy. Journal of Child Neurology, 21(11), 939-45.

32. Aldenkamp, AP \& Arends, J (2004b). Effects of epileptiform EEG discharges on cognitive function: is the concept of "transient cognitive impairment" still valid? Epilepsy Behav. 5(suppl 1): 25-34.

33. Baglietto, MG, Battaglia, FM, Nobill, L, Tortorelli, S, De Negri, E, Calevo, MG, Vaneselli, E, \& De Negri, M (2001). Neuropsychological disorders related to interictal epileptic discharges during sleep in benign epilepsy of childhood with centrotemporal or Rolandic spikes. Dov Med Child Neurol. 43: 407-412.

34. Camfield, P, \& Camfield, C (2002). Epileptic syndromes in childhood: clinical features, outcomes, and treatment. Epilepsia. 43(Suppl 3): 27-32.

35. Dunn, DW, Buelow, JM, Austin, JK, Shinnar, S, Perkins, SM, 2004. Development of syndrome severity scores for peadiatric epilepsy. Epilepsia, 45(6): 661-666. 


\section{Summary}

In the Netherlands about 13,000 children are suffering from cryptogenic localization related epilepsy (CLRE). When these children and their parents visit their neurologist, they receive the message that, unfortunately, no clear prognosis of CLRE exists. Questions like "how will the seizures develop", "what will be the effect of the epilepsy on learning and school", and "will the epilepsy influence the child's behavior" remain unanswered.

To give these children and their parents something more to hold on to for the future, we tried to answer these questions in this thesis.

The patients included in our studies were referred to a specialized expert team in our epilepsy centre for assessment in a program for schoolgoing children with epilepsy. This program consists of a standardized assessment battery containing neurological assessment, psychomotor screening, EEG recording, observation by specialized nurses, neuropsychological testing, and assessment of school achievement.

This thesis is subdivided into four sections. Section I contains the general introduction (chapter 1) and a literature review on cryptogenic localization related epilepsy (chapter 2). In section II, four cohort studies are described; neuropsychological functioning is outlined in chapter 3 , chapter 4 describes the effect of duration of epilepsy on $I Q$, chapter 5 is a study on behavior, and psychomotor and motor functioning are described in chapter 6 . Section III contains two follow up studies on neuropsychological functioning (chapter 7) and behavior (chapter 8). And the last section, section IV consists of the general discussion (chapter 9).

Chapter 1 describes some background information on epilepsy, more specifically on CLRE and on comorbidities related to epilepsy. This description leads to the main question of this thesis: how is the neuropsychological prognosis of children with CLRE?

Furthermore, an outline of this thesis is given. 
Chapter 2 is a review describing the current knowledge on cryptogenic localization related epilepsy. Twenty-five articles describing aspects of CLRE were included in this review. Since a lack of a clear diagnosis makes it impossible to formulate a clear prognosis, the diagnostic reliability of CLRE within the current classification system is discussed first. In addition, an overview of the knowledge on two aspects of prognosis is given; seizure control and cognitive and psychosocial prognosis. Since there is a lack of consensus between the studies on the definition of remission, it is difficult to compare the studies discussing remission. Both high remission rates and frequent relapses are described. Furthermore, children with CLRE appeared to have more behavioral problems than children with idiopathic epilepsy or than children without epilepsy. Also educational problems were found; delays up to two school years in reading and arithmetic have been reported.

Chapter 3 focuses on the question whether a group of children with CLRE differ from age-related normative values on several neuropsychological tests. Furthermore, this study aims to determine whether a characteristic neuropsychological profile of CLRE exists and which epilepsy-factors might influence this profile.

There seems to be a characteristic cognitive profile for children with CLRE; children with CLRE experience cognitive difficulties on a wide range of areas in particular alertness, mental speed and memory. Seizure type, seizure frequency, duration of epilepsy and drug load do not influence this neuropsychological profile. Age at onset was an important risk factor; the earlier the age at onset, the worse the cognitive performance. In spite of the influence of age at onset, the revealed profile can be seen as a stable, independent of temporary factors, neuropsychological profile for children with CLRE.

Chapter 4 presents a study on IQ in a group of children with CLRE. The influence of duration of epilepsy on IQ is studied. Besides, the impact of CLRE on IQ in comparison to symptomatic localization related epilepsy (SLRE) and idiopathic generalized epilepsy (IGE) is investigated. No significant differences were found between the three epilepsy groups on TIQ, VIQ or PIQ. Also most of the subtests did not show statistically significant differences, except for two of the verbal subtests: similarities and vocabulary. On both tests children with CLRE and IGE performed significantly better than children with SLRE. In CLRE, intelligence is stable over time; IQ scores do neither improve nor deteriorate. Age at onset, seizure type, seizure frequency and the use of AED appeared to have no influence on intelligence in CLRE. Furthermore, over time, there appeared to be no differentiation regarding IQ between CLRE, SLRE and IGE.

In chapter 5 the behavioural status of children with CLRE is described. This study aims to answer the question what kind of behavioural problems exists in children with CLRE and which epilepsy-factors are related to these problems.

According to the parent report, children with CLRE scored in the clinical range on the subscales 'internalizing behavior', 'total behavior' and 'attentional problems'. No rela- 
tion between the epilepsy factors seizure frequency, age at onset, duration of epilepsy or the number of AED and CBCL-subscales was found. Only for seizure type a relationship was found. Although in the normal range, the more severe the seizure type, the more delinquent, aggressive and externalizing behavioral problems. We concluded that the behavioral problems we found in our CLRE cohort are not very different from the behavioral problems described in other types of epilepsy.

Chapter 6 describes psychomotor and motor functioning in children with cryptogenic localization related epilepsy. Furthermore, a possible relationship between these two functions is explored.

Manual dexterity and balance problems are present in about $35 \%$ of the children with CLRE. Ball skills are problematic in approximately $55 \%$ of the children. Simple reaction time measurements showed significantly slowing for the CLRE children relative to the reference values and also the performance on the $m-A B C$ was significantly lower than the reference values. The better the child's performance on the simple reaction time measurements, the better is his or hers performance on the m-ABC.

Chapter 7 aims to answer the question how the epilepsy interferes with the cognitive development on the long term in children with CLRE. It is also studied whether possible changes in performance are due to changes in epilepsy factors.

Cognitive functioning in children with cryptogenic localization related epilepsy showed some improvement from $t_{1}$ to $t_{2}$. Besides neuropsychological improvement, we found that seizure frequency improved considerably.

Many aspects of intelligence, psychomotor speed/fluency, psychomotor speed/alertness, central information processing speed, memory, and personality showed normalization in the one to four years of follow up. For most of these tasks, a positive relationship was found with changes in duration of epilepsy; the larger the change in duration of epilepsy, the larger the improvement on these tasks. This indicates that a longer follow up probably allows the improvement in seizure frequency to result in normalization of the performance on tasks measuring $1 \mathrm{Q}$, psychomotor speed and alertness.

Chapter 8 is a description of the course of behaviour in children with cryptogenic localization related epilepsy. The question whether there are indications for stabilization or improvement over time is attempted to be answered.

Behavior improved substantial from $t_{1}$ to $t_{2}$ on almost all subscales of the $\mathrm{CBCL}_{;}$at $t_{2}$ all subscales scored in the normal range. Furthermore, seizure frequency improved considerably from $t_{1}$ to $t_{2}$, while no changes in seizure type and number of antiepileptic drugs were found.

Finally, the findings provided in the preceding chapters are combined and discussed in chapter 9. Furthermore, we discussed CLRE in daily life; the relevance of our results for daily practice. We stated that there is a substantial chance that children with CLRE achieve seizure remission or at least fair seizure control. However, this will 
take some changes in AED and therefore take quite some time. When there is no fast and/or good response to the medication, neuropsychological functioning, behaviour and scholastic performances might be influenced negatively. Therefore, the child needs to be multidisciplinary assessed, coached and followed as soon as possible after the epilepsy onset. When this is not done, cognitive, behavioural and educational problems can have a large impact on further development of the child. 


\section{Samenvatting}

Epidemiologisch onderzoek toont dat er op ieder moment (dus de punt prevalentie) circa 13000 kinderen met een cryptogeen lokalisatie gebonden epilepsie (CLRE) zijn. Als deze kinderen en hun de ouders de neuroloog bezoeken, zijn er op hun vragen over de prognose niet altijd 'evidence based' antwoorden voorhanden. Vragen als 'hoe zal het gaan met de aanvallen', 'wat zal het effect van de epilepsie zijn op leren en school', en 'zal de epilepsie het gedrag van het kind beïnvloeden' kunnen niet altijd beantwoord worden.

Om deze kinderen en hun ouders wat meer houvast voor de toekomst te geven, hebben we geprobeerd deze vragen in dit proefschrift te beantwoorden. Het accent ligt in de effecten op gedrag en ontwikkeling.

De patiënten die in onze studies zijn geïncludeerd, werden verwezen naar een gespecialiseerd team binnen ons epilepsiecentrum, voor onderzoek binnen een programma voor schoolgaande kinderen met epilepsie. Binnen dit programma wordt gebruik gemaakt van een protocol, bestaande uit een neurologisch onderzoek, psychomotore screening, EEG analyse, observatie door gespecialiseerde verpleegkundigen, neuropsychologisch onderzoek en analyse van schoolprestaties.

Dit proefschrift is onderverdeeld in vier secties. Sectie I bestaat uit de algemene introductie (hoofdstuk 1) en een literatuur review over cryptogeen lokalisatie gebonden epilepsie (hoofdstuk 2). In sectie II worden vier cohort studies beschreven; neuropsychologisch functioneren in hoofdstuk 3 , hoofdstuk 4 beschrijft het effect van duur van de epilepsie op IQ, hoofdstuk 5 is een studie over gedrag en de effecten op psychomotorisch en motorisch functioneren zijn beschreven in hoofdstuk 6. Sectie III bevat twee follow up studies over neuropsychologisch functioneren (hoofdstuk 7 ) en gedrag (hoofdstuk 8). En de laatste sectie, sectie IV, beslaat de algemene discussie (hoofdstuk 9).

Hoofdstuk 1 beschrijft enige achtergrond informatie over epilepsie, specifieker over CLRE en over comorbiditeiten gerelateerd aan epilepsie. Deze beschrijving leidt tot de hoofdvraag van dit proefschrift: wat is de neuropsychologische prognose van kinderen met CLRE? 
Verder wordt er in dit hoofdstuk ook een overzicht gegeven van wat er in dit proefschrift staat beschreven.

Hoofdstuk 2 is een literatuur review waarin de huidige kennis over cryptogeen lokalisatiegebonden epilepsie wordt beschreven. Vijfentwintig artikelen die aspecten van CLRE beschrijven, zijn geïncludeerd in deze review. Patiënten met de diagnose CLRE behoren tot geen ander duidelijk beschreven epilepsietype of epilepsiesyndroom, waardoor CLRE gezien kan worden als een soort restgroep binnen de huidige classificatie. Daarom wordt de diagnostische betrouwbaarheid van CLRE binnen het huidige classificatiesysteem eerst bediscussieerd. Vervolgens wordt er een overzicht gegeven van de kennis van twee aspecten van prognose: aanvalscontrole en cognitieve en psychosociale prognose. Aangezien er tussen de verschillende studies een gebrek is aan overeenstemming over de definitie van remissie, is het moeilijk om deze studies te vergelijken. Kinderen met CLRE blijken meer gedragsproblemen te vertonen dan kinderen met idiopathische epilepsie of kinderen zonder epilepsie. Daarnaast worden er ook schoolproblemen gevonden: achterstanden tot zelfs twee schooljaren voor lezen en rekenen zijn beschreven.

Hoofdstuk 3 behandelt de vraag of de prestaties op verschillende neuropsychologische tests van een groep kinderen met cryptogeen lokalisatiegebonden epilepsie verschillen van leeftijdsgerelateerde normatieve scores. Daarnaast wordt er in deze studie gekeken of er een karakteristiek neuropsychologisch profiel bestaat voor CLRE en of dit profiel beïnvloed wordt door epilepsiefactoren.

De resultaten suggereren dat er inderdaad sprake blijkt te zijn van een karakteristiek cognitief profiel voor kinderen met CLRE; deze kinderen vertonen cognitieve problemen op een breed vlak, met name op alertheid, mentale snelheid en geheugen. Aanvalstype, aanvalsfrequentie, duur van de epilepsie en drug load beïnvloeden dit profiel niet. Debuutsleeftijd is wel een belangrijke factor; hoe vroeger het debuut, hoe slechter de cognitieve prestaties. Ondanks de invloed van debuutsleeftijd, kan het gevonden profiel gezien worden als een stabiel neuropsychologisch profiel, onafhankelijk van tijdelijke factoren.

In hoofdstuk 4 wordt de invloed van duur van de epilepsie op het IQ bestudeerd. Daarnaast wordt de impact van CLRE op IQ vergeleken met de impact van symptomatisch lokalisatiegebonden epilepsie (SLRE) en idiopathisch gegeneraliseerde epilepsie (IGE) op het IQ. Er werden geen significante verschillen gevonden tussen de drie epilepsiegroepen wat betreft het totale $I Q$, het verbale en het performale $I Q$. Deze bevinding bleek met name het gevolg van de factor tijd tussen debuutsleeftijd en onderzoek alsmede de invloed van aanvalsfrequentie tijdens de fase van onderzoek. Deze factoren zijn bediscussieerd in dit hoofdstuk. Bij de subtesten werden alleen verschillen gevonden voor 'overeenkomsten' en 'woordenschat'. Op beide subtesten scoorden kinderen met CLRE en IGE significant beter dan kinderen met SLRE. 
Voor CLRE werd daarnaast gevonden dat IQ stabiel is over de tijd; IQ scores werden niet beter en niet slechter naarmate sprake was van een langere duur van de epilepsie. Ook debuutsleeftijd, aanvalstype, aanvalsfrequentie en het gebruik van antiepileptica hadden geen invloed op de intelligentie van kinderen met CLRE. Daarnaast werd er over de tijd geen differentiatie van het IQ gevonden tussen CLRE, SLRE en IGE.

In hoofdstuk 5 wordt gedrag van kinderen met CLRE beschreven. Deze studie probeert de vraag te beantwoorden welke gedragsproblemen kinderen met CLRE vertonen en of er epilepsiefactoren zijn die gerelateerd zijn aan deze problemen.

Ouders rapporteren problemen in de klinische range op de subschalen 'internaliserend gedrag', 'totaal gedrag' en 'aandachtsproblemen'. Er werd geen relatie gevonden tussen de CBCL-subschalen en aanvalsfrequentie, debuutsleeftijd, duur van de epilepsie en het aantal anti-epileptica. Voor aanvalstype werd wel een relatie gevonden; alhoewel de scores in de normale range vielen, vonden we dat hoe ernstiger het aanvalstype, hoe meer delinquente, agressieve en externaliserende gedragsproblemen gerapporteerd werden. We concludeerden dat de gedragsproblemen die we vonden voor CLRE niet erg verschillen van de gedragsproblemen die voor andere typen epilepsie beschreven zijn. De relatie tussen epilepsie en gedragsproblematiek lijkt dus van algemene aard te zijn en onafhankelijk van type epilepsie, aanvalsfrequentie of welke andere specifieke epilepsiefactor dan ook.

Hoofdstuk 6 beschrijft het psychomotorische en motorische functioneren van kinderen met cryptogeen lokalisatiegebonden epilepsie. Daarnaast is er gekeken of er mogelijk een relatie bestaat tussen deze twee functies.

Problemen in handvaardigheid en evenwicht wordt gevonden bij ongeveer $35 \%$ van de kinderen met CLRE. Balvaardigheden zijn problematisch bij circa $55 \%$ van de kinderen. Eenvoudige motorische reactietijd metingen lieten significante vertraging ten opzichte van referentiewaarden zien en ook de prestaties op een gestandaardiseerde test voor motorische ontwikkeling, de movement-ABC waren significant lager dan de referentiewaarden. Verder vonden we dat hoe beter de prestaties van het kind waren op de eenvoudige motorische reactietijd metingen, hoe beter zijn of haar prestaties waren op de movement-ABC.

Hoofdstuk 7 probeert de vraag te beantwoorden hoe bij kinderen met CLRE de epilepsie interfereert met de cognitieve ontwikkeling op de lange termijn. Daartoe is een follow-up studie uitgevoerd waarbij kinderen werden vergeleken op twee tijdstippen, gemiddeld twee jaar en drie maanden uiteen. Ook hebben we gekeken of eventuele veranderingen in cognitieve prestaties het gevolg zijn van veranderingen in epilepsiefactoren.

Bij kinderen met cryptogeen lokalisatiegebonden epilepsie vonden we enige verbetering in cognitief functioneren van $t_{1}$ naar $t_{2}$. Naast deze neuropsychologische verbetering, bleek de aanvalsfrequentie aanzienlijk te verbeteren. 
Verschillende aspecten van intelligentie, psychomotore snelheid/vloeiendheid, psychomotore snelheid/ alertheid, centrale informatieverwerkingssnelheid, geheugen en persoonlijkheid vertoonden normalisatie in de 1 tot 4 jaar follow up. Voor de meeste van deze taken bleek een positieve relatie te bestaan met de veranderingen in duur van de epilepsie; hoe groter de verandering in duur van de epilepsie, hoe groter de cognitieve verbetering. Dit betekent dat de verbeterde aanvalsfrequentie op den duur (langere follow up) kan leiden tot normalisatie van de prestaties op taken die IQ, psychomotore snelheid en alertheid meten.

In hoofdstuk 8 beschrijven we het beloop van gedrag bij kinderen met cryptogeen lokalisatiegebonden epilepsie, opnieuw tijdens een follow-up studie. Er wordt bekeken of er op lange termijn aanwijzingen zijn voor stabilisatie of verbetering.

Gedrag verbeterde substantieel van $t_{1}$ naar $t_{2}$ op bijna alle subschalen van de $C B C L$; op $t_{2}$ lagen alle subschaal-scores in de normale range. Ook de aanvalsfrequentie verbeterde aanzienlijk van $t_{1}$ naar $t_{2}$, terwijl er geen veranderingen in aanvalstype en aantal anti-epileptica zijn gevonden.

Tenslotte worden de bevindingen uit voorgaande hoofdstukken gecombineerd en bediscussieerd in hoofdstuk 9 . Ook bespreken we CLRE in het dagelijks leven; de relevantie van onze resultaten voor de dagelijkse praktijk.

$\mathrm{Er}$ is een substantiële kans dat kinderen met CLRE in remissie komen of ten minste een redelijke aanvalscontrole bereiken. Om dit te bereiken zal wel gezocht moeten worden naar de juiste anti-epileptica en dit kan een behoorlijke tijd duren. Als er geen sprake is van een snelle en/of goede reactie op de medicatie, kunnen, in de periode die nodig is om aanvalscontrole te bereiken, het neuropsychologisch functioneren, het gedrag en de prestaties op school negatief beïnvloed worden. Daarom is het heel belangrijk dat het kind zo snel mogelijk na het debuut van de epilepsie multidisciplinair onderzocht, begeleid en gevolgd word. Als dit niet gebeurt, kunnen problemen met cognitie, gedrag en school een grote (negatieve) invloed hebben op de verdere ontwikkeling van het kind. 


\section{Dankwoord}

Na ruim vier jaar bezig te zijn geweest met mijn promotie-onderzoek, ben ik dan nu aanbeland bij het laatste hoofdstuk dat ik moet schrijven. Heel graag wil ik iedereen bedanken die direct of indirect betrokken is geweest bij het tot stand komen van dit proefschrift!

Allereerst een woord van dank voor mijn promotoren en mijn co-promotor.

Prof. dr. AP Aldenkamp, beste Bert. Dankjewel voor de zeer leerzame jaren. Jij gaf me de kans me als onderzoeker te ontwikkelen. Niet alleen op wetenschappelijk gebied heb ik veel van je geleerd. De afgelopen jaren heb ik, mede dankzij jou, een persoonlijke groei doorgemaakt.

Met je steeds vaker voorkomende complimenten over mijn artikelen, gaf je me het vertrouwen dat ik dit kon. Als ik nieuwe resultaten niet wist te verklaren, kwam jij geregeld met interessante verklaringen waarvan ik dan vervolgens dacht 'ja, dat klinkt inderdaad erg logisch, waarom kon ik dat zelf niet bedenken'. Je zou als promotor zijnde vooral de tijdsplanning in de gaten houden, maar uiteindelijk was je juist bij de directe begeleiding enorm betrokken en werden het een aantal prettige jaren van intensieve samenwerking.

Prof. Dr. WO Renier, beste Willie. Dank voor je betrokkenheid bij mijn promotie. Met name in de laatste fase van mijn onderzoek heb ik veel gehad aan de adviezen die je me gaf over mijn artikelen. Je interesse in dit project gaf me steeds opnieuw de inspiratie om door te gaan.

Een speciaal woord van waardering wil ik uitspreken voor mijn co-promotor, Mariette Debeij-van Hall. Je twijfelde wel eens of je als neuroloog voldoende kennis had om mij bij mijn psychologische onderzoek te helpen, maar desondanks stond je altijd voor me klaar. Je neurologische kennis gaf juist een leuke en interessante wending aan onze discussies over hoe we nieuwe resultaten nu weer konden verklaren. Ook op momenten dat ik even geen uitweg meer zag, wist jij me te inspireren en kon ik weer verder. Mariette, dankjewel voor je warme betrokkenheid, voor onze waardevolle samenwerking.

En natuurlijk mag Rianne Reijs niet ontbreken in dit dankwoord. Ruim vier jaar geleden ontmoette ik je voor het eerst. Samen zouden we dit klusje wel eens gaan kla- 
ren. We waren de eerste fulltime AIO's van Kempenhaeghe en dus altijd een beetje aan het pionieren. We hadden altijd elkaar om op terug te vallen als een van tweeën het even niet meer helemaal zag zitten. We hebben veel hard werkende, interessante en gezellige momenten gekend. En uiteindelijk een mooi duo-onderzoek neergezet. Hier staan we dan. Tijd voor het verdedigen van ons werk. Rianne bedankt voor de leerzame samenwerking.

Voor het 'adopteren' van een af en toe eenzame AlO wil ik alle (ex-)collega's van de Gedragswetenschappelijke Dienst van Kempenhaeghe bedanken: Hettie, Annemarie, Ricky, Annie, Ine, Monique, Esmee, Nynke, Cynthia, Sandra, Anne, Suzanne, Simone, Rien, Jos, Marc, Antoinette, Saskia, Els en Debby. Drie mensen van de GWD wil ik even in het bijzonder noemen. Caroline van der Linden; jij hebt in de afgelopen vier jaar heel veel praktische dingen voor me geregeld die nodig waren om mijn werk te kunnen doen, dankjewel daarvoor. Antonet Heurter; je hebt een tijd lang een dag extra gewerkt om 'onze' kinderen te kunnen hertesten, dankjewel. Ook Leonie Diepman, dankjewel voor het testen van een deel van 'onze' kinderen. En natuurlijk voor het mij op sleeptouw nemen in mijn begintijd op Kempenhaeghe.

Ook wil ik mijn collega's promovendi bedanken. Tamara Nijsen, Lotty Huijboom, Andrei Sazonov, Vivian Smeets, Joost Nicolai, Roos Rodenburg en Petra van Houdt, bedankt voor de gezellige momenten. Maar ook het samen bespreken van allerlei vragen rondom onderzoek doen en promoveren heb ik als zeer waardevol ervaren.

Verder wil ik graag enkele (ex-)collega's uit het leerstoornissenteam bedanken voor hun betrokkenheid. Biene Weber en Lotte Nieuwenhuis zijn met name in de beginfase betrokken geweest. Biene bedankt voor het benaderen van jouw patiënten voor deelname aan ons follow up onderzoek en voor het becommentariëren van onze eerste artikelen. Lotte dankjewel voor het samen doorspreken van heel veel dossiers om medische gegevens te verzamelen. Frans Hakvoort, dankjewel voor het meedenken over hoe ik schoolgegevens mee kon nemen in mijn verschillende studies en voor het leveren van commentaar op enkele van mijn artikelen.

Johan Arends, vooral tijdens het schrijven van de review is jouw bijdrage voor mij zeer waardevol geweest. Ankie van Ojen, dankjewel, niet alleen voor het terugvinden van allerlei dossiers en dus een heleboel gegevens, maar ook voor de gezellige gesprekjes. Verder wil ik de fysiotherapeuten van Kempenhaeghe bedanken. Samen met hen is mijn hoofdstuk 6 tot stand gekomen.

Een speciaal woord van dank wil ik richten aan de kinderen en hun ouders die hebben deelgenomen aan onze follow up studie. Zonder hen zou een groot gedeelte van mijn proefschrift niet hebben bestaan.

De leden van de leescommissie wil ik hartelijk danken voor de tijd en energie die zij hebben gestoken in het beoordelen van mijn proefschrift. 
Kunstgalerie Kempro wil ik graag bedanken voor het prachtige schilderij dat mijn kaft siert.

En natuurlijk wil ik mijn paranimfen, Sandra Boelen en Tamara Nijsen, bedanken. Sandra, dankjewel voor alle interessante gesprekken die we samen gevoerd hebben. Veel ervan gingen over psychologie, dingen die een van ons in het werk tegen kwam. Maar eerlijk is eerlijk, we hadden ook regelmatig gesprekken die niks met werk te maken hadden. Vooral de vrijdagmiddag gesprekjes, na de leerstoornissenvergadering, waren altijd erg gezellig. Ik denk dat je al die tijd zo betrokken bent geweest, dat je me goed kunt steunen tijdens mijn verdediging. Tamara, een groot gedeelte van onze AlO-tijd hebben we samen doorgebracht. Als een van ons een vraagstuk had waar we niet uitkwamen, probeerden we elkaar altijd te helpen. Ondanks het feit dat onze onderwerpen en achtergronden zover uit elkaar liggen, lukte dat toch regelmatig. I $\mathrm{k}$ wil je bedanken voor al deze leerzame momenten, maar ook voor alle gezellige momenten die we samen hebben gehad op de Cleijne Aa en later op Den Boondert.

Een woord van dank wil ik richten aan mijn familie. Zij hadden altijd het volste vertrouwen dat ik deze promotie met goed resultaat zou afronden. Dank jullie wel voor de momenten die zorgden voor ontspanning naast mijn promotie, voor de andere leuke dingen in het leven.

Lieve Casper en David, door jullie komst is mijn promotietijd iets verlengd, maar dat was het meer dan waard. Jullie zorgden en zorgen nog steeds voor die heerlijke afleiding die je soms nodig hebt bij het schrijven van een proefschrift.

Lieve Marijn, dankjewel voor je eeuwige geduld. Als ik weer eens twijfelde of ik dit allemaal wel kon, sprak jij keer op keer je vertrouwen in mij uit. Je was er altijd voor me. Dankjewel voor je steun en je liefde en natuurlijk voor de twee prachtige zonen die je me ook nog hebt gegeven tijdens mijn promotietijd! 


\section{Curriculum Vitae}

Saskia van Mil werd geboren op 6 februari 1980 te Venray. Zij groeide op in het Brabantse plaatsje Nuenen. Na het doorlopen van de basisschool, ging zij in 1992 naar het Strabrecht College te Geldrop. Hier behaalde ze haar Atheneumdiploma in 1998. Datzelfde jaar startte ze met haar opleiding psychologie aan de Universiteit van Maastricht. $\mathrm{Na}$ het behalen van haar propedeuse in 1999, koos zij voor de richting biologische psychologie met als afstudeerrichting ontwikkelingspsychologie. Tijdens haar psychologiestudie was zij statistiektutor voor tweedejaars studenten en tutor bij een presentatiecursus voor eerstejaars studenten. Een onderzoek naar het Rett syndroom met behulp van EEG/ERP vormde haar afstudeerstage. Haar psychologiediploma behaalde ze in 2003.

In februari 2004 begon ze in het Epilepsiecentrum Kempenhaeghe met haar promotieonderzoek "Children with cryptogenic localization related epilepsy; Neuropsychological outcome".

Naast haar werkzaamheden als promovendus was zij meerdere keren tutor voor eerstejaars geneeskundestudenten. Ook nam ze wekelijks deel aan een multidisciplinair overleg waarin onderzoeksresultaten van kinderen met epilepsie en leer- en/of gedragsproblemen werden besproken om aan de hand daarvan een behandelingstraject vast te stellen.

Saskia woont in Eindhoven. Ze is getrouwd met Marijn en ze is de trotse moeder van Casper (2006) en David (2008). 


\section{List of publications}

van Mil SG, Reijs RP, van Hall MH, Aldenkamp AP.

Neuropsychological profile of children with cryptogenic localization related epilepsy.

Child Neuropsychol. 2008 Jul;14(4):291-302.

van Mil SG, Reijs RP, van Hall MH, Aldenkamp AP.

The effect of duration of epilepsy on IQ in children with CLRE; a comparison to SLRE and IGE.

Seizure. 2008 Jun;17(4):308-13. Epub 2007 Nov 19.

Nicolai J, van der Linden I, Arends JB, van Mil SG, Weber JW, Vles JS, Aldenkamp AP.

EEG characteristics related to educational impairments in children with benign childhood epilepsy with centrotemporal spikes.

Epilepsia. 2007 Nov;48(11):2093-100. Epub 2007 Jul 21.

Reijs RP, van Mil SG, van Hall MH, Arends JB, Weber JW, Renier WO, Aldenkamp AP.

The validity of a separate classification of cryptogenic localization related epilepsy amongst childhood epilepsies.

Seizure. 2007 Jul;16(5):438-44. Epub 2007 Apr 25.

Reijs RP, van Mil SG, Arends JB, van Hall MH, Weber JW, Renier WO, Aldenkamp AP.

Cryptogenic localization related epilepsy in children from a tertiary outpatient clinic: is neurological and neuropsychological outcome predictable?

Clin Neurol Neurosurg. 2007 Jun;109(5):422-30. Epub 2007 Apr 23.

Aldenkamp AP, Arzimanoglou A, Reijs R, Van Mil S.

Optimizing therapy of seizures in children and adolescents with ADHD.

Neurology. 2006 Dec 26;67(12 Suppl 4):S49-51. Review. 